\title{
Nanoporous polymeric materials: A new class of materials with enhanced properties
}

\author{
B. Notario ${ }^{a}$, J. Pinto ${ }^{b}$, M.A. Rodriguez-Perez ${ }^{\mathrm{a}, *}$ \\ ${ }^{a}$ Cellular Materials Laboratory (CellMat), Condensed Matter Physics Department, University of Valladolid, 47011 Valladolid, Spain \\ ${ }^{\mathrm{b}}$ Nanophysics - Smart Materials Group, Istituto Italiano di Tecnologia (IIT), Via Morego 30, 16163 Genova, Italy
}

\section{A R T I C L E I N F O}

\section{Article history:}

Received 15 August 2015

Received in revised form 5 February 2016

Accepted 8 February 2016

Available online 19 February 2016

\section{Keywords:}

Nanoporous polymeric materials

Properties

Nanocellular foams

Cellular polymers

Mechanical properties

Thermal properties

Dielectric properties

Optical properties

\begin{abstract}
A B S T R A C T
Nanoporous polymeric materials are porous materials with pore sizes in the nanometer range (i.e., below $200 \mathrm{~nm}$ ), processed as bulk or film materials, and from a wide set of polymers. Over the last several years, research and development on these novel materials have progressed significantly, because it is believed that the reduction of the pore size to the nanometer range could strongly influence some of the properties of porous polymers, providing unexpected and improved properties compared to conventional porous and microporous polymers and non-porous solids.

In this review, the key properties of these nanoporous polymeric materials (mechanical, thermal, dielectric, optical, filtration, sensing, etc.) are analyzed. The experimental and theoretical results obtained up to date related to the structure-property relations are presented. In several sections, in order to present a more compressive approach, the trends obtained for nanoporous polymers are compared to those for metallic and ceramic nanoporous systems. Moreover, some specific characteristics of these materials, such as the consequences of the confinement of both gas and solid phases, are described. Likewise, the main production methods are briefly described. Finally, some of the potential applications of these materials are also discussed in this paper.
\end{abstract}

๑) 2016 Elsevier Ltd. All rights reserved.

\footnotetext{
* Corresponding author.

E-mail address: marrod@fmc.uva.es (M.A. Rodriguez-Perez).
} 


\section{Contents}

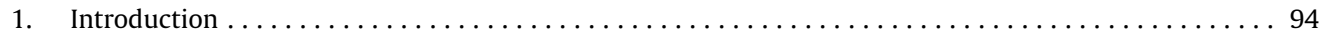

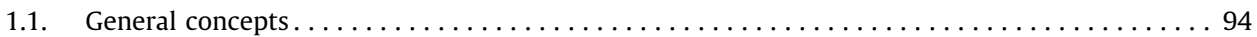

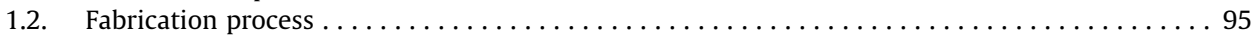

1.3. Expected cellular structure $\ldots \ldots \ldots \ldots \ldots \ldots \ldots \ldots \ldots \ldots \ldots \ldots \ldots \ldots \ldots \ldots \ldots \ldots \ldots \ldots$

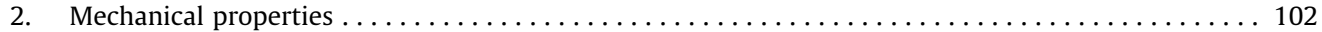

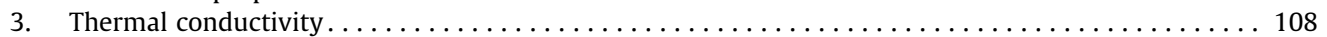

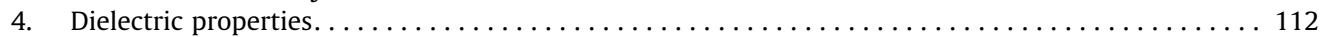

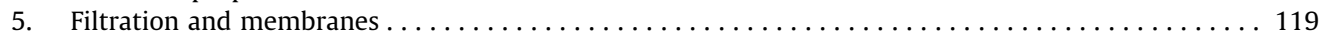

6. Other properties (sensors and optical and multifunctional materials) $\ldots \ldots \ldots \ldots \ldots \ldots$

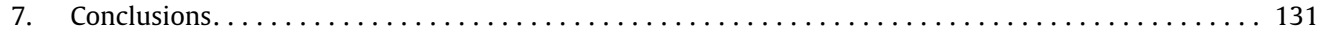

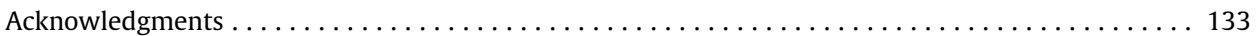

References ......................................... 133

\section{Introduction}

\subsection{General concepts}

Porous polymers, defined as two-phase systems composed of a continuous solid polymeric phase and an either continuous or discontinuous gaseous phase [1-4], are widely used and have a very promising future in important technological sectors such as the automotive and aeronautical industries, renewable energies, construction, cushioning and packaging, and biotechnology. The global market of porous polymeric materials is significant; in fact, around $10 \%$ of annual consumption of plastics is intended for the manufacture of different types of polymeric foams (mainly polyurethane, polyolefin, polystyrene, and polyvinyl chloride (PVC)) [5]. In the year 2013, 19.1 million tons were produced with an economic impact of $\$ 86.9$ billion. In the period of 2013-2019, an annual growth rate of $4.8 \%$ is expected, and therefore the estimated production for the year 2019 is 23.5 million tons.

The increasing interest in these materials relies on reductions in weight, production costs, and raw material needed, as well as on the excellent properties (tailor-made) that can be achieved with them. Moreover, these materials can find application in different fields depending on their structural morphology. For instance, porous materials with highly interconnected open-cell or open-pore morphologies (i.e., the gas and solid phases show continuity) are suitable for filtration, catalysis, cushioning, acoustic absorption, etc., while morphologies with isolated pores in which the gas is enclosed (closed-cell or closed-pore morphologies) have better characteristics for structural applications and for thermal insulation.

Materials with a porous structure are widespread in nature in plant and animal tissues: examples include wood, cork, trabecular bone, or plant parenchyma. After their discovery, human civilization advanced one step further with the development of synthetic porous materials. However, the first polymeric porous materials (typically called "polymeric foams", where foams have pore sizes larger than $200 \mu \mathrm{m}$ ) presented a major drawback: the mechanical properties of the foam were much inferior to those of the former solid even for small density reductions. Microporous polymers, characterized by pore sizes on the order of $1 \mu \mathrm{m}$, were developed at the Massachusetts Institute of Technology (MIT) in the early 1980s [6-8] in order to address this disadvantage. Since their discovery, microporous polymers with high relative densities (low porosities) and their corresponding technologies have been under continuous development. These materials show significant improvements: for instance, they exhibit higher Charpy impact strength, toughness, fatigue life, and thermal stability and lower thermal conductivity than unfoamed plastics and much better mechanical properties than conventional foams [9-12]. These excellent properties allow these materials to cover a significant number of applications, because it is possible to reduce the density of a given polymer with little decrease in their mechanical properties while simultaneously improving other features. 
Similar or even greater improvements than those obtained when MIT invented microporous foams are expected to be achieved for the next generation of nanoporous polymers.

In particular, these novel materials with pore sizes below $200 \mathrm{~nm}$ could have better mechanical properties than microporous foams [13] and thermal conductivities well below those of the best thermal insulators currently on the market [14]. Furthermore, it is expected that the confinement of the constituent phases of these materials (polymer and gas phases) at the nanoscale will enhance several properties involved in transport phenomena, such as radiation-matter interaction, gas storage, sensing properties, and more. This opens the door to a significant number of applications such as super thermal insulation, structural applications, dielectric and optical applications, filtering, sensing, and catalysis.

However, it has not been until recent years when technological development has allowed materials with these features to be manufactured in adequate quantities or with appropriate dimensions to thoroughly study their properties or to become actual candidates for industrial applications. Thus, only recently has it been possible to start verifying the expected properties of these materials experimentally.

In this review, the first reliable experimental results obtained in nanoporous polymeric materials are collected and compared either with the developed theoretical models or with the properties of other nanoporous materials (metallic and ceramic) that share some features with them, mainly the dimensions of their elements in the nanoscale. In this way, the validity of the predictions and the expected properties, such as the mechanical, thermal, dielectric, optical, filtration, and sensing properties, are discussed in detail. Furthermore, non-predicted behaviors or new effects that have been found experimentally with these materials because of the confinement of the constituent phases are also analyzed. Likewise, the key methods leading to these nanoporous polymers (based on the use of solvents, thermal degradation, the gas dissolution foaming technique, etc.) are described briefly in order to provide a more comprehensive understanding of these materials. In addition, the potential applications they could cover in the future because of these enhanced properties are briefly mentioned.

\subsection{Fabrication process}

The fabrication of nanoporous polymeric materials requires the use of specific procedures that overcome the difficulties associated with the production of separated phases at the nanoscale. Several approaches have been developed over the past years in order to achieve polymeric structures with pores on the nanoscale [15]: molecular imprinting, microemulsion templating, phase separation techniques, selective removal of one of the blocks in nanostructured block neat copolymers, foaming, etc. A scheme of the different fabrication processes that exist nowadays is shown in Fig. 1, together with some transmission electron microscopy (TEM) and scanning electron microscopy (SEM) images of nanoporous polymeric materials obtained with some of these techniques.

Regarding phase separation techniques, phase separation can be produced during polymerization and cross-linking in different ways: (1) by the addition of a non-solvent to a polymer/solvent mixture (immersion techniques) [22,23], (2) by chemical induction (i.e., the polymerization is performed in a monomer/non-solvent mixture, the polymerization itself depletes the monomer, and insolubility is induced) [24], and (3) by thermal induction phase separation (TIPS) [25,26]. For the latter, three different mechanisms can be distinguished: spinodal decomposition (liquid-liquid phase separation), physical gelation, crystallization (solid-liquid phase separation), or combinations of these.

For instance, thin films (with a thickness around $500 \mathrm{~nm}$ ) of polystyrene and poly(2-vinylpyridine) with co-continuous morphologies were manufactured by Li et al. [16] based on phase separation immersion techniques. These films presented pore sizes of tens of nanometers and served as templates for thin nanoporous membranes. Another example of the immersion technique can be found in the work of Walheim et al. [27]. They produced nanoporous PMMA films with a thickness lower than $150 \mathrm{~nm}$ by exposing the initial film of PS and PMMA to a selective solvent (cyclohexane) that dissolved the PS. The obtained films presented pore sizes lower than $100 \mathrm{~nm}$ and a surface with high optical transmission. 


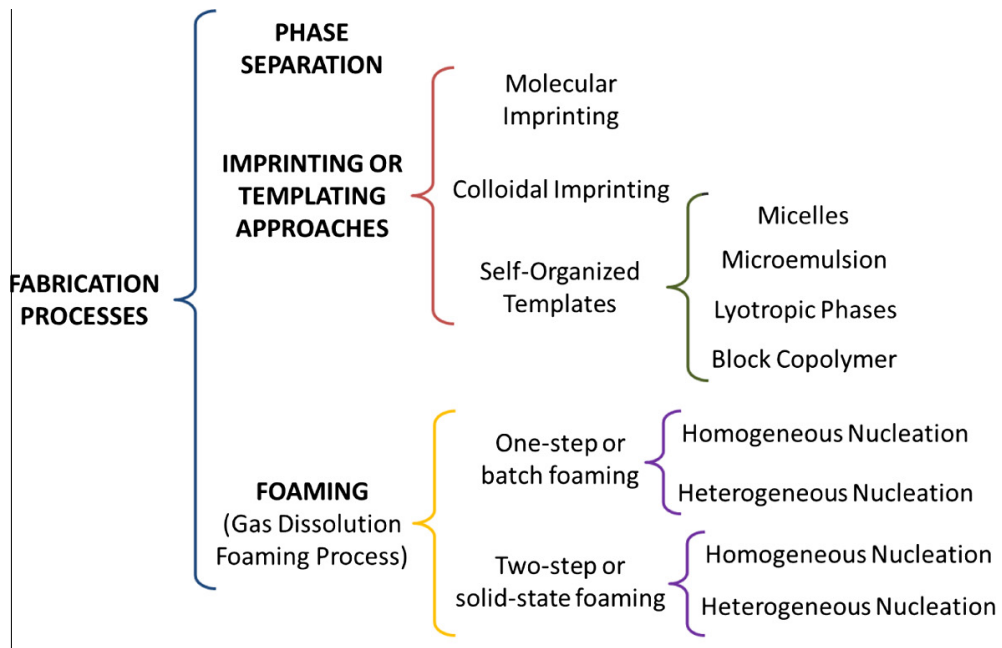

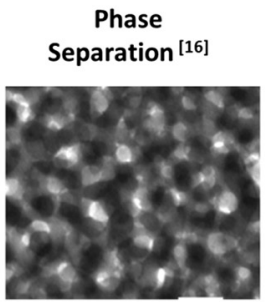

Block Copolymer [19]

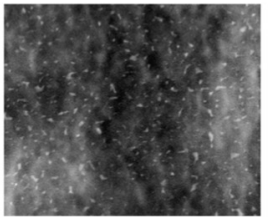

Colloidal Imprinting ${ }^{[17]}$

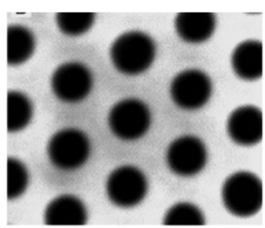

Batch Foaming [20]

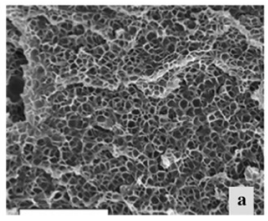

Microemulsion ${ }^{[18]}$

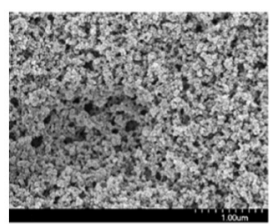

Solid-State Foaming ${ }^{[21]}$

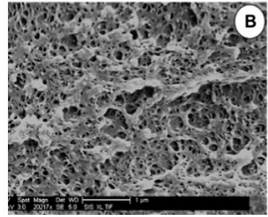

Fig. 1. Different fabrication processes for the production of nanoporous polymeric materials along with some TEM and SEM images of the nanoporous polymers obtained with the different techniques. TEM and SEM images have been included with permission from Refs. [16-21].

In the case of imprinting or templating approaches [28,29], the templates induce a special structure by specific interactions with the growing polymer matrix (i.e., electrostatic interactions, hydrogen bonding, or pattern recognition). The highest target of a template system is the direct replication of a self-organized structure into a permanent (polymeric) material. Nevertheless, this process is complicated because of changes of the mixing thermodynamics throughout polymerization.

One type of templating approach is so-called molecular imprinting. This technique is used to create polymer matrices with pores structured on a molecular scale and is based on the system used by enzymes for substrate recognition. The synthesis is carried out by copolymerization of functional and cross-linking monomers in the presence of a molecular template (imprint molecule) and additional solvents. After polymerization, the template molecules are eliminated from the matrix under certain conditions, leaving behind a cavity complementary in size and shape to the imprinting molecules. 
Another templating technique is colloidal imprinting. In this case, a colloidal crystal is used as a template together with precursors, which enables replication of the crystal morphology followed by swelling and polymerization of the precursors. After polymerization, the template is removed by extraction, dissolution, or calcination, resulting in a porous, ordered polymer.

Examples of both molecular and colloidal imprinting can be found in the literature [17,30-33]. For instance, molecular imprinting was used by Cheong et al. [32] to create a method for the synthesis of a testosterone-specific polymer. The porous polymer obtained was found to interact specifically with testosterone with functional and stereochemical memory similar to artificial antibodies or enzymes.

The colloidal imprinting method was used by Park and coworkers [17] to produce porous polyurethane (PU) membranes (with a thickness of about $10 \mu \mathrm{m}$ ) by using polystyrene (PS) beads as templates. The films obtained presented pore sizes from 0.2 to $3 \mu \mathrm{m}$ and a porosity around $74 \%$.

Perhaps two of the most common self-organized templating techniques are the microemulsion and block copolymer techniques.

Microemulsions are macroscopically homogeneous, optically isotropic, two-phase mixtures of immiscible liquids, which use surfactants to provide a thermodynamically stable microstructure. The exact nature of this microstructure depends on the organization of the surfactant film separating the water and oil domains, which typically have dimensions of $10-500 \mathrm{~nm}$. du Fresne von Hohenesche et al. studied the polycondensation behavior of melamine formaldehyde (MF) resins under acidic polymerization conditions within a bicontinuous microemulsion composed of an oil phase, a water phase, and an iso-C13-(EO)7 type nonionic surfactant [18]. They were able to achieve gels with porosities between 80 and $85 \mathrm{vol} \%$ and pore sizes between 65 and $400 \mathrm{~nm}$.

However, the block copolymers used for this purpose comprise a stable block and a sacrificial block, such that the morphology provides a matrix of the stable material with the labile material as the dispersed phase. Upon a thermal treatment or chemical attack with solvents the unstable block is removed, leaving pores where the size and shape are dictated by the initial copolymer morphology $[19,24,35]$.

Multiblock and triblock copolymers, composed of rigid, semi-rigid, and flexible polyimide matrices with either poly(propylene oxide) or poly(methyl methacrylate) as the thermally labile coblocks, were prepared by Hedrick and coworkers [36]. They produced nanoporous polymeric films of $10 \mu \mathrm{m}$ thickness based on flexible polyimide with pore sizes on the order of tens of nanometers.

The aforementioned techniques are generally restricted to the fabrication of thin films and require the use of organic solvents that have to be subsequently removed.

One promising technique used to overcome these drawbacks is the gas dissolution foaming process and in particular high-pressure or supercritical $\mathrm{CO}_{2}$ gas dissolution foaming, where $\mathrm{CO}_{2}$ is used as a physical blowing agent [34,37-39]. This gas is one of the best options for this type of process because of its excellent diffusion characteristics in the supercritical state and the relatively mild conditions to reach this state $\left(31^{\circ} \mathrm{C}\right.$ and $\left.7.3 \mathrm{MPa}\right)$. Furthermore, carbon dioxide is a green solvent that can be removed without residue or the production of any pollutant compound [40,41].

In its most general form, the equipment used in the gas dissolution foaming technique consists of a high pressure vessel equipped with an accurate pressure pump controller, which is controlled automatically to maintain the temperature and pressure at the desired values. The usual gas dissolution foaming process (called the two-step or solid-state foaming process [8]) has three stages [42]: gas saturation of the polymer sample (under fixed gas pressure and temperature), gas desorption during and after the pressure release (to room pressure and temperature), and foaming of the sample (at a temperature over or around the glass transition temperature $\left(T_{g}\right)$ of the plasticized amorphous polymer or around the melt temperature $\left(T_{m}\right)$ if the polymer is semi crystalline). Nevertheless, if the polymer specimen is in the rubbery state upon saturation with $\mathrm{CO}_{2}$, foam expansion will occur during the pressure release, and the desorption stage will disappear. In this case, the procedure is called one-step or batch foaming $[38,43]$.

Development of nanoporous polymers by gas dissolution foaming requires very high pore nucleation densities $\left(N_{0}\right.$, number of nuclei/cells per cubic centimeter of the unfoamed material) and reduced coalescence of the growing pores. 
Coalescence can be avoided, or maintained without significant influence, by the appropriate selection of a polymer matrix and a foaming temperature near the effective glass transition temperature of amorphous polymers or the melt temperature of semi crystalline polymers.

In order to increase cell nucleation to the desired levels (typically higher than $10^{14}-10^{15}$ nuclei/ $\mathrm{cm}^{3}$ ), several approaches have been developed depending on the nucleation mechanisms involved. With homogeneous materials (i.e., systems with a homogeneous nucleation), there are two approaches to promote nucleation: increasing the saturation pressure or increasing the pressure drop rate [21,38,44-48]. For instance, Pinto et al. [47] were able to produce nanoporous poly(methyl methacrylate) (PMMA) materials with relative densities of around 0.5 and pore sizes between 90 and $700 \mathrm{~nm}$ by increasing the saturation pressure. The same approach was used by Miller et al. [21] who produced nanoporous polyetherimide (PEI) foams with pore sizes between 30 and $120 \mathrm{~nm}$ and relative densities from 0.7 to 0.48 . However, Janani and Famili [48] designed a specific highpressure system capable of producing an instantaneous pressure release (around $300 \mathrm{MPa} / \mathrm{s}$ ) and quenched the sample just after the pressure release in order to preserve the pore structure induced by the pressure release. Using this system, they manufactured nanoporous PS with pore sizes between $500 \mathrm{~nm}$ and $1 \mu \mathrm{m}$ and relative densities of about 0.5 .

Heterogeneous materials (i.e., systems in which heterogeneous nucleation occurs) offer another two main approaches to increase the nucleation rate: the addition of particles (mainly nanoparticles) to the polymer matrix [20,49-52] or the use of block copolymers [47,53-56]. Urbanczyk and coworkers [52] added nanoclays (montmorillonite (MMT)) to poly(styrene-co-acrylonitrile) (SAN) to obtain porous materials with pore sizes between the nanometric and micrometric scales at saturation pressures up to $30 \mathrm{MPa}$. They found that the addition of MMT allowed a decrease in the average pore size from values near $1 \mu \mathrm{m}$ to below $500 \mathrm{~nm}$, but at the same time the relative density of the porous system increased from 0.23 to 0.65 . Costeux and coworkers [20] added either silica nanoparticles or POSS to acrylic and styrenic polymers, obtaining nanoporous polymers with an average pore size of $100 \mathrm{~nm}$, a relative density of 0.15 , and pore densities exceeding $10^{16}$ pores $/ \mathrm{cm}^{3}$. However, the block copolymer approach was employed by Pinto et al. [47] to produce nanoporous polymers with pores in the range of $90-200 \mathrm{~nm}$ and relative densities between 0.4 and 0.6 using blends of PMMA and a triblock copolymer (poly(methyl methacrylate)-block poly(butyl acrylate)-block poly(methyl methacrylate), MAM). Similarly, Yokoyama et al. [54] produced nanoporous foams with very high pore densities (i.e., $10^{16}$ pores $/ \mathrm{cm}^{3}$ ), pore sizes between 10 and $30 \mathrm{~nm}$, and a relative density of 0.5 from monoliths of polystyrene-block-p oly(perfluorooctylethyl methacrylate) (PS-b-PFMA).

\subsection{Expected cellular structure}

A detailed discussion about the expected characteristics of the porous structure of nanoporous polymers is presented in this section in order to provide a better understanding of the influence of nanoporous morphologies on several properties that will be discussed later. Thus, the evolution of the pore size, pore density ( $N_{p}$, pores $/ \mathrm{cm}^{3}$ of porous material), pore wall thickness, and tortuosity of nanoporous polymers is studied. Likewise, the emerging side effects due to the reduction of the pore size to the nanometer scale are also analyzed.

The two fundamental characteristics of nanoporous materials are the average pore size and the relative density. These two parameters are correlated by the pore density; it is possible to represent the three magnitudes on a relative density-pore size map (Fig. 2). In this plot, data obtained from some of the most representative works obtained up to date have been included, and lines of constant pore density have been represented according to Eq. (1) [8]:

$$
N_{p}=\frac{6\left(1-\rho_{\text {rel }}\right)}{\pi \Phi_{3 D}^{3}}
$$

where $\Phi_{3 D}$ is the average pore size in 3D, and $\rho_{\text {rel }}\left(\rho_{\text {rel }}=\rho_{f} / \rho_{s}\right)$ represents the relative density, where $\rho_{f}$ is the density of the nanoporous material and $\rho_{s}$ is the density of the solid phase.

Fig. 2 illustrates the wide range of densities and pore sizes covered by different nanoporous polymeric systems. Nowadays, the main limitation is the difficulty of reaching porous materials with 

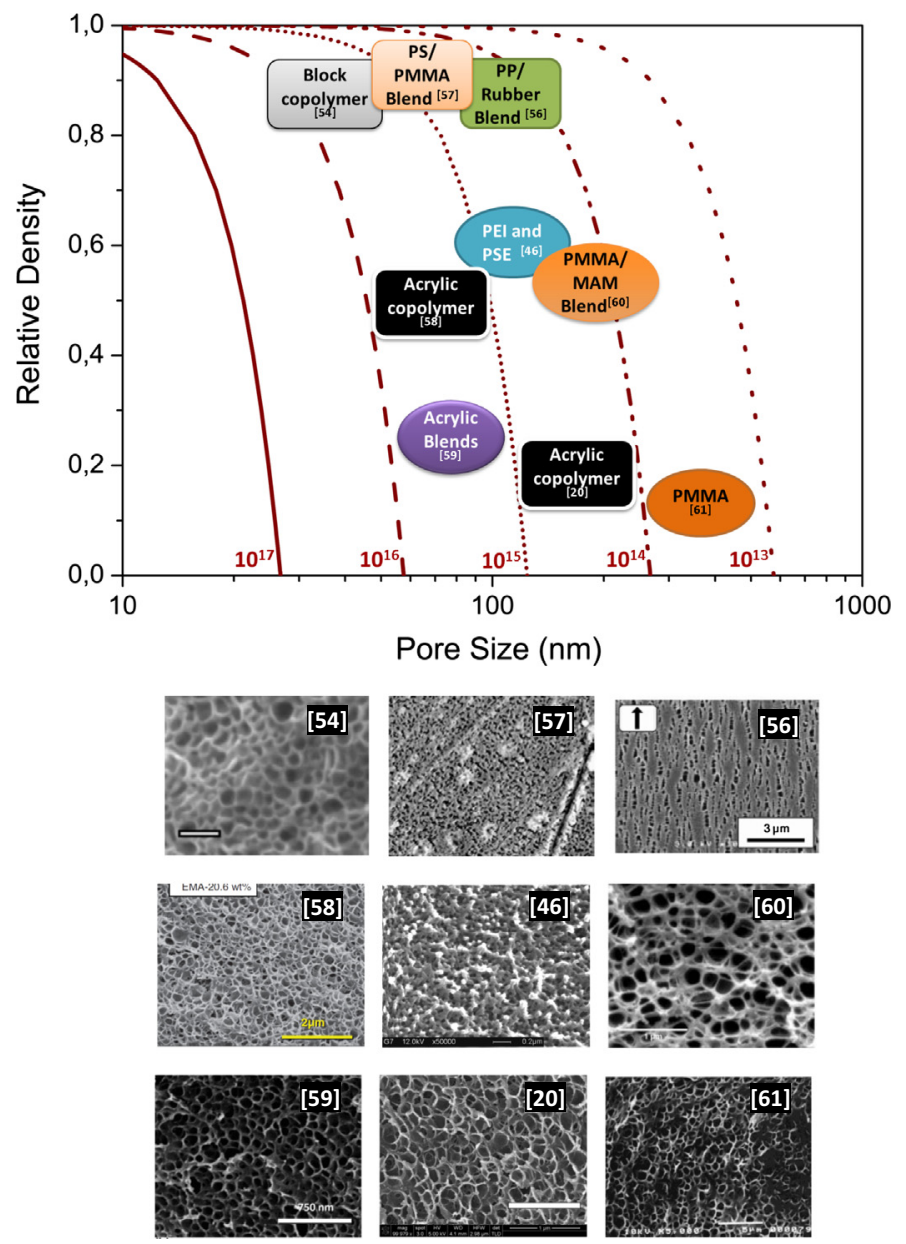

Fig. 2. Main characteristics (relative density, average pore size, and pore nucleation density) of nanoporous polymers achieved with various polymer systems. SEM images have been included with permission from Yokoyama et al. [54], Otsuka et al. [57], Nemoto et al. [56], Costeux et al. [20,58,59], Krause et al. [46], Pinto et al. [60], and Handa and Zhang [61].

medium to low densities and pore sizes below $50 \mathrm{~nm}$. To achieve these requirements, higher pore densities (around $10^{17}$ pores $/ \mathrm{cm}^{3}$ ) are needed. Depending on the fabrication process, these pore densities can be achieved in different ways. For instance, in the case of imprinting or templating approaches, the pore density is determined by the pattern density of the porous structure, whereas, in the case of foaming, these pore densities can be achieved with sufficiently high pore nucleation densities $\left(N_{0}\right.$, number of pore nuclei per cubic centimeter of the solid precursor), which can be calculated using equation [8]:

$$
N_{0}=\frac{N_{p}}{\rho_{\text {rel }}}
$$

In addition, depending on the requirements of the final application, the choice of the production route is important, because no individual technique is capable of covering the entire spectrum of pore sizes and densities [62]. 

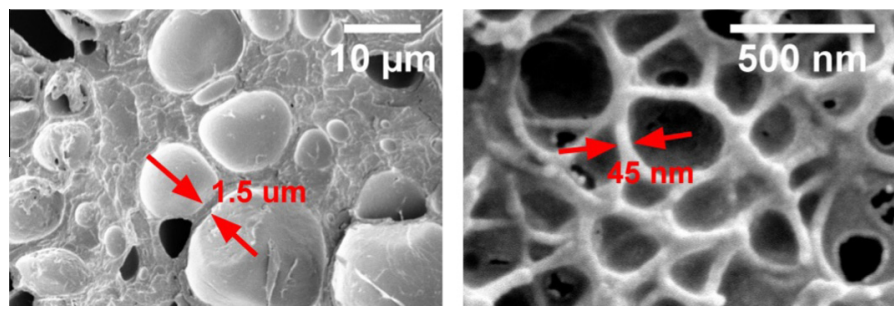

Fig. 3. Pore wall thickness of a microporous PMMA $\left(\rho_{\text {rel }}=0.5\right.$; pore size $\left.=11 \mu \mathrm{m}\right)($ left $)$ and a nanoporous PMMA $\left(\rho_{\text {rel }}=0.5\right.$; pore size $=300 \mathrm{~nm})$ (right).

The reduction of the pore size to the nanometer range involves the confinement of the gaseous phase into nanometric voids. As a consequence, a reduction of the thermal conductivity of the gaseous phase is expected, because it is assumed that these nanoporous materials will present the well-known Knudsen effect $[63,64]$. This effect implies that, when pore size is comparable or smaller than the mean free path of the gas, the molecules of the latter collide more often with the molecules forming the surrounding solid part than among them. Thus, the energy transfer through the gas molecules is reduced.

Furthermore, other phenomena may appear because of the confinement of the gaseous phase to the nanoscale, as suggested by Pinto et al. [65]. They showed that nanopores can act as capacitors that can contribute to electrical conduction by dielectric breakdown or by other processes related to the Knudsen diffusion regime yet unidentified.

The reduction of the pore size from the micrometer to the nanometer range and the increase in pore density also lead to a reduction in the thickness of the pore walls. An example of this reduction is shown graphically in Fig. 3, in which the pore wall thickness of a porous PMMA is reduced from $1.5 \mu \mathrm{m}$ to $45 \mathrm{~nm}$ when the pore size switches from the microscale (Fig. 3 left) to the nanoscale (Fig. 3 right).

An estimation of the expected pore wall thickness of both open- and closed-pore porous materials can be performed by considering the Gibson and Ashby equations [1]. A tetrakaidecahedral pore is assumed because of its similarity to a spherical one. Given this assumption, the expression of the pore wall thickness for an open-pore system is given by the relation:

$$
t^{2}=\frac{l^{2} \rho_{\text {rel }}}{1.06}
$$
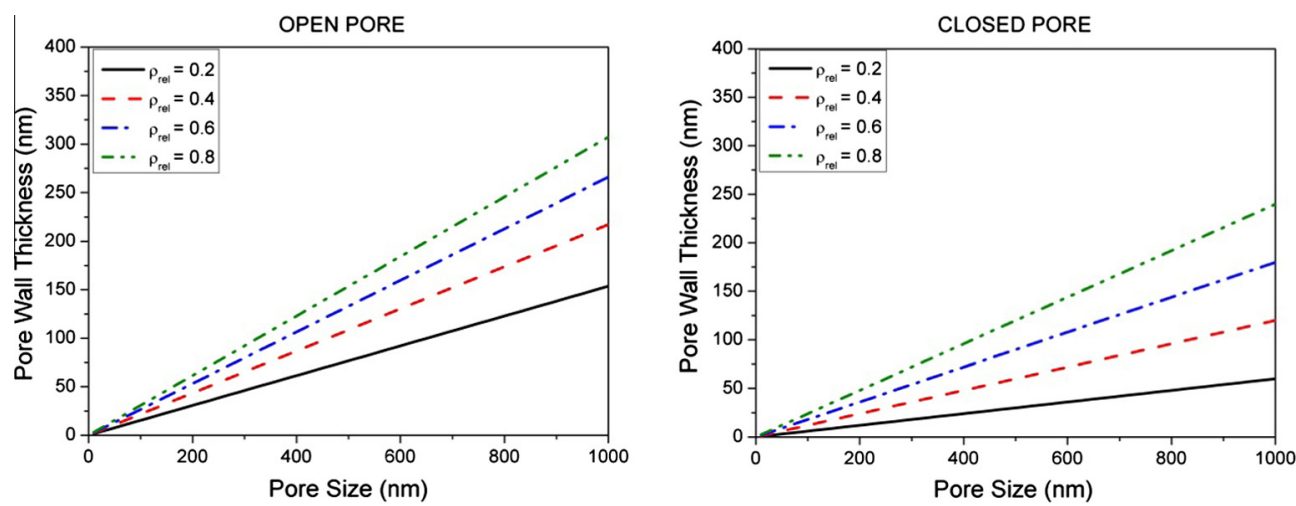

Fig. 4. Pore wall thickness as a function of the average pore size for both an open-pore polymeric system and a closed-pore polymeric material. 
where $t$ represents the pore wall thickness and $l$ the edge length. For the case of a closed-pore system, the relation is given by:

$$
t=\frac{l \rho_{\text {rel }}}{1.18}
$$

It is well known that the edge length can be related to the average pore size through the following equation [1]:

$$
\Phi=B l
$$

where $B$ is a constant that relates the average pore size $\Phi$ of the polyhedron given its edge length $l$. In the case of a tetrakaidecahedral pore, $B$ takes a value of 2.828 .

Pore wall thickness values obtained for both open- and closed-pore polymeric systems are represented in Fig. 4 as a function of the pore size for different relative densities. The pore wall thickness decreases linearly with pore size, reaching values in the case of open-pore materials of below $25 \mathrm{~nm}$ when the pore size is around $100 \mathrm{~nm}$. This effect is even more pronounced for closed-cell materials.

This reduction in the pore wall thickness confines the polymer chains within the pore walls, leading to a reduction in the mobility of the polymeric macromolecules. This effect, known as the confinement effect, was first detected by Reglero Ruiz et al. [66] in PMMA-based nanoporous materials (average pore size around $200 \mathrm{~nm}$ ) by means of differential scanning calorimetry (DSC). They observed an increase of $11^{\circ} \mathrm{C}$ of the glass transition temperature of nanoporous PMMA-based foams with respect to the bulk polymer.

This result was also detected later in nanoporous PEI (average pore size between 30 and $120 \mathrm{~nm}$ ) by Miller and coworkers [13]. They also studied the thermal behavior of porous PEI by DSC, obtaining an increase in the glass transition temperature in the nanoporous system of $5{ }^{\circ} \mathrm{C}$ compared to the solid material. In addition, Notario et al. [67] showed this effect in nanoporous PMMA (average pore size between 200 and $300 \mathrm{~nm}$ ) both by DSC and by dynamic mechanical analysis (DMA). In this study, the nanoporous system presented a glass transition temperature $7^{\circ} \mathrm{C}$ higher than that of both the microporous material and the solid matrix. This phenomenon was confirmed by Pinto and coworkers [65] in PMMA-based foams by means of Raman spectroscopy. They observed that the differences found between relative intensities are associated with the hindering of the vibrational modes, proving the existence of a confinement effect of the polymeric macromolecules.

As a consequence of the confinement of polymeric macromolecules in very thin pore walls, unexpected modifications of different properties or new effects could appear.

Finally, the reduction in the size of the constituent phases (both solid and gas phases) to the nanometer range could also modify the architecture of the porous system, leading to an increase in the tortuosity of the solid and gas phases (see Fig. 5). Tortuosity, defined as the ratio between the dis-

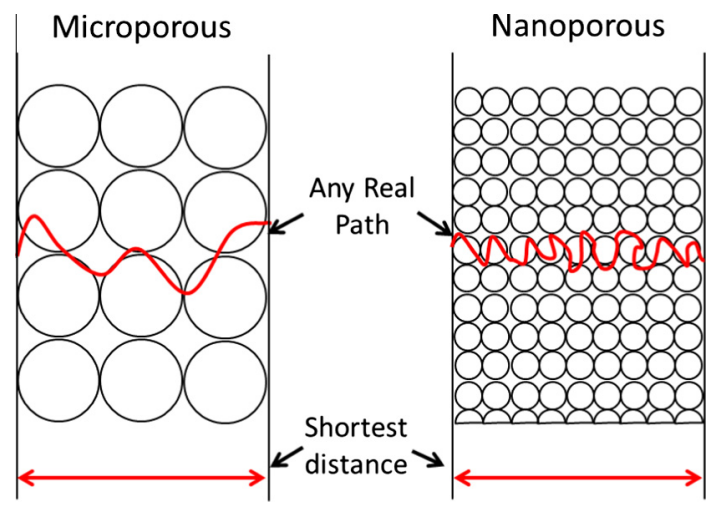

Fig. 5. Scheme of the tortuous path through the solid phase inside a microporous material (left) and a nanoporous one (right). 
tance of any real path and the shortest distance between two points, is a parameter of extremely high importance for material transport properties through the solid phase (thermal and electrical conductivities) in open- and closed-pore morphologies as well as for the flow or transport of substances through the gaseous phase in open-pore morphologies (e.g., filtration processes).

Although there are no theoretical models that argue for this expected increase in tortuosity, it can be inferred from the theory of fractals. As already said by the mathematician Mandelbrot [68], the measured length of a stretch of coastline depends on the scale of the measurement. Empirical evidence suggests that the smaller the increment of the measurement, the longer the measured length becomes. This effect was experimentally observed by Ma et al. [69], who showed how the increase in tortuosity of the current path affected the induced eddy currents in microporous $\mathrm{Cu}$ and $\mathrm{Fe}$.

Some evidence of this phenomenon has also been observed in nanoporous PMMA-based foams [14]. However, Notario et al. [14] suggested that the enhancement in the thermal insulation found with nanoporous PMMA could be attributed both to the confinement of the gaseous phase and to a reduction in the thermal conductivity of the polymer matrix, which is related to an increase in the tortuosity of the solid phase of the porous morphology. This behavior was confirmed by Pinto and coworkers [65] by measuring the DC electrical resistivity of nanoporous PMMA. Their results revealed clear evidence of the increased tortuosity in the transition from the microscale to the nanoscale.

Therefore, a reduction in the pore size to the nanometer scale leads to the confinement of both the solid phase and the gaseous phase as well as to modifications of the porous architecture. As a consequence, unexpected modifications of different properties or new phenomena could appear, which could explain some of the results found for different properties that will be discussed in the following sections. For each property analyzed, the main theoretical models developed to describe that property are explained first, and then the main experimental results published up to now are discussed.

\section{Mechanical properties}

The major drawback of conventional polymer foams is their low mechanical performance. Microporous materials, characterized by pore sizes of around one micron, were developed at MIT in the 1980 s to address this problem. Since their discovery, much effort has been made to study the mechanical behavior of these systems. Results have shown that microporous materials exhibit improved tensile and impact properties over conventional foams in systems such as polycarbonate (PC) [70], polyethersulfone (PESF) and polyphenylsulfone (PPSF) [71], polyethylene terephthalate (PET) [9], and polyvinyl chloride (PVC) [72]. For instance, the tensile strength of microporous PET increases with a decrease in pore size [9]. Likewise, Young's modulus in compression and the elastic collapse strength of microcellular PESF and PPSF were higher than the theoretically predicted value at high relative densities [71]. These behaviors are better than expected, because the mechanical properties of polymeric foams usually depend on the square of the relative density. This dependence between density and the physical properties of a porous material is well established and is given by the Gibson and Ashby equation [1]:

$$
P_{f}=C \cdot P_{s} \cdot\left(\frac{\rho_{f}}{\rho_{s}}\right)^{n}
$$

According to this equation, the property of a porous material $\left(P_{f}\right)$ is equal to the property of the same material that is $100 \%$ solid $\left(P_{s}\right)$ multiplied by the relative density $\left(\rho_{f} / \rho_{s}\right)$ to the power of $n$. $C$ and $n$ are two parameters that can be determined experimentally. $C$ usually takes values around 1 for most physical properties and porous materials, whereas $n$ normally takes values between 1 and 2 (in the case of mechanical properties, $n$ usually takes a value around 2) and depends on the porous structure. By using this equation, it is possible to analyze the improvement in different physical properties of porous materials due to the reduction in pore size; in fact, for some of the microcellular systems previously mentioned and for some properties, the value of $n$ was clearly lower than 2 . In the following discussion, we will use this equation and the values of $n$ that can be obtained when this equation is used to fit experimental data to compare the results obtained by different authors. 

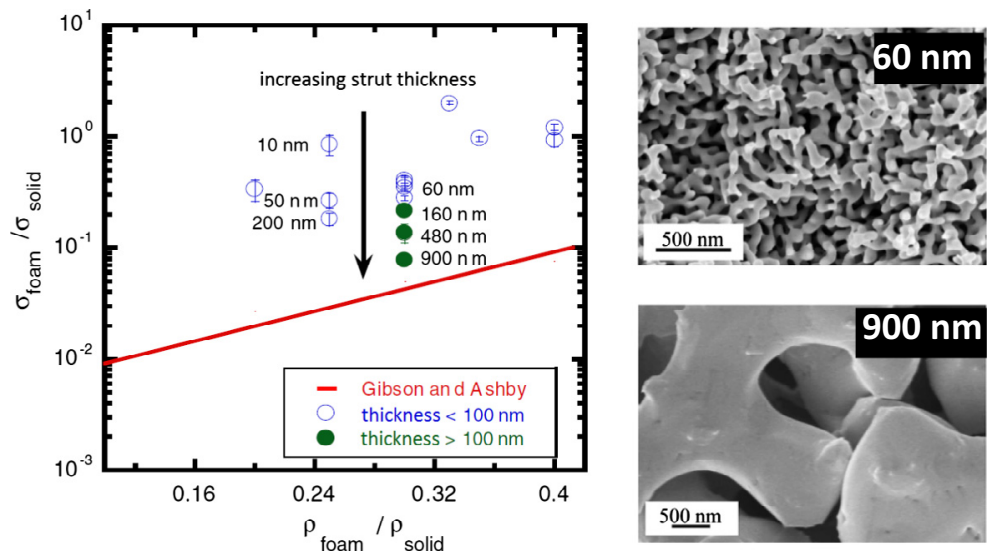

Fig. 6. Left: Yield strength values of nanoporous gold foams normalized by the yield strength of solid gold. The solid line represents the Gibson and Ashby prediction for nanoporous gold. Right: SEM micrographs of the nanoporous gold under study (top: strut thickness $=60 \mathrm{~nm}$; bottom: strut thickness $=900 \mathrm{~nm}$ ). All images have been adapted from Hodge et al. [73].

Since microporous polymers present better mechanical properties than conventional ones, it is expected that a further reduction in the pore size (nanoporous polymeric materials) will enhance the mechanical properties of porous polymers.

Several theoretical studies have modeled some of the expected improvements in these nanoporous materials [73-77], most of them focused on metallic and ceramic systems in which experimental data were available. These theoretical models led to either a scaling law to adjust the Gibson and Ashby equations to systems with pores in the nanometer regime or a new model that reproduces the behavior of these novel systems. All these models are focused on situations with low strain rates.

For instance, Hodge et al. [73] developed a scaling equation that predicts the yield strength of lowdensity $\left(\rho_{\text {rel }}<0.3\right)$, open-cell nanoporous gold (Eq. (7)):

$$
\sigma_{f}=C\left(\sigma_{s}+k \cdot L^{-1 / 2}\right) \cdot\left(\frac{\rho_{f}}{\rho_{s}}\right)^{n}
$$

where $C$ is a fitting coefficient, $\sigma_{s}$ is the bulk material yield strength, $k$ is the Hall-Petch-type coefficient [78] for the theoretical yield strength of the porous metal in the regime of $10 \mathrm{~nm}$ to $1 \mu \mathrm{m}$, and $L$ is the average thickness of the struts.

According to this equation, the lower the average thickness of the struts is, the greater the yield strength (see Fig. 6). Thus, at the nanoscale, the yield strength is governed by the strut thickness in addition to the relative density. A good agreement between the theoretical model and the experimental data for the nanoporous gold system were obtained when $n$ had a value of 1.5 .

The same result was observed by Fan and Fang [74], who obtained the same scaling law as Eq. (7) and suggested another one for nanoporous gold foams with relative densities greater than 0.3 . In this case, the proposed equation was

$$
\sigma_{f}=C\left(\sigma_{s}+k \cdot L^{-1 / 2}\right) \cdot\left(\frac{\rho_{f}}{\rho_{s}}\right)^{n} \cdot\left(1+\left(\frac{\rho_{f}}{\rho_{s}}\right)^{1 / 2}\right)
$$

They took experimental data on gold from the literature and showed that the experimental results were consistent with the developed model when $n$ had a value of 1.5.

The effect of the strut thickness on the yield strength of nanoporous foams seems to be evident; nevertheless, the underlying mechanisms are still not well understood. Currently, there are several explanations for this effect in nanoporous metals [73,74]: (a) the dislocations are depleted from the small sample volumes, and deformation is limited by dislocation source activation; (b) the dislocations interact and pile up, and high dislocation densities are required to explain the high stresses; 


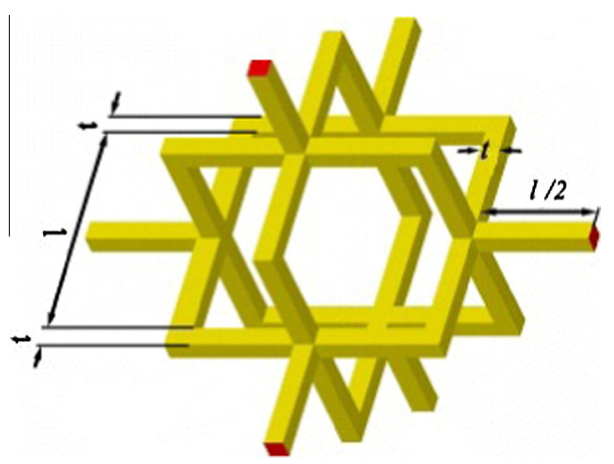

Fig. 7. Unit-cell model for open-cell nanoporous materials.

(c) there is an important reduction in the number of defects; and (d) surface stresses in nano struts can significantly affect their elastic properties. This last aspect has been studied in more detail in several studies. However, more studies are needed in order to understand these effects and to extrapolate them to polymeric systems.

The influence of surface effects on the elastic modulus and on the yield strength of open-pore nanoporous materials was analyzed by Xia and coworkers [75] by using the theory of surface elasticity. They assumed a small aspect ratio between the length $(l)$ and thickness of the struts $(t)$ (see Fig. 7).

With this consideration, they observed that, when the average thickness $(t)$ of the struts in a porous material was reduced to values below $2 \mathrm{~nm}$, surface stresses and surface elasticity influenced both the elastic modulus and the yield strength of nanoporous materials, slightly increasing their values. This result was confirmed in the particular case of nanoporous gold (see Fig. 8). For this reason, they proposed that these two parameters be considered to understand the mechanical behavior of nanoporous systems.

Similarly, Zhang et al. studied the effect of surface energy on the yield strength of nanoporous materials as a function of pore size [76]. They found that the surface energy has an important effect on the overall yield strength of nanoporous materials because of the increased surface area to bulk volume ratio. They observed that the effect of the surface energy on the yield strength is significant for pore sizes lower than $10 \mathrm{~nm}$, but this influence is not so clear when the pore size is greater than this value. This result was confirmed in the particular case of nanoporous aluminum.

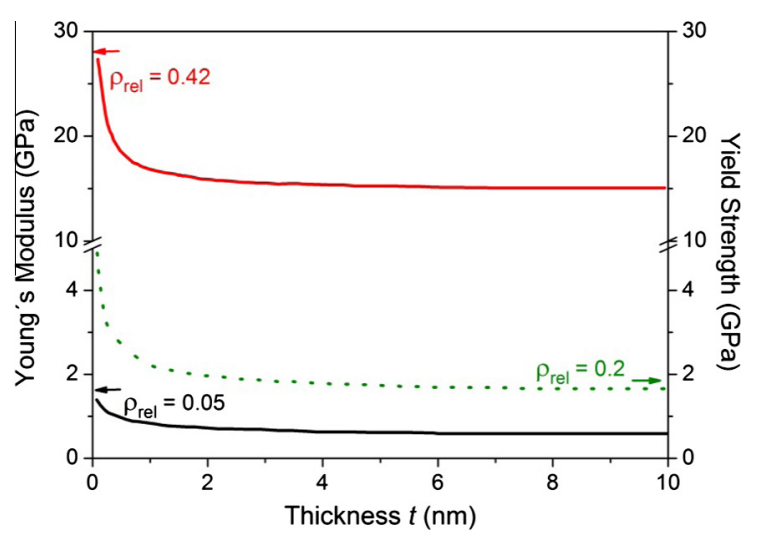

Fig. 8. Young's modulus and yield strength of nanoporous gold (considering surface effects) predicted by Xia et al. [75] according to the Timoshenko model. 
Finally, Duan et al. [77] developed a theoretical model to demonstrate that nanochannel-array materials with cylindrical nanopores can be made stiffer than their non-porous parent materials by manipulating the pore surface elasticity. They showed that these materials will have high bending stiffness and strength and suggested two possible ways (valid for both open- and closed-pore materials) to achieve this: (1) by chemical modification of the pore surface and (2) by choosing a parent material with a smaller Poisson ratio. These results were verified for the case of an aluminum matrix.

To date, theoretical modeling seems to agree on the improvement of certain properties (such as the yield strength or the bending stiffness) with the reduction in the pore size to the nanometer range; nevertheless, there is a lack of theoretical studies specifically developed for nanoporous polymers. Although the mechanical characterization of nanoporous polymeric materials is a recent issue, many other experimental studies have been performed in different nanoporous systems, mainly nanoporous metals and ceramics, which will be discussed below briefly for the purpose of comparison.

It has been shown that nanoporous gold becomes as resistant as solid gold, exhibiting yield strength values similar to that of the bulk $(n \approx 1)$ despite being a highly porous materials (porosities higher than 70\%) [79-81]. Furthermore, Weissmuller et al. [81] demonstrated that the yield strength is higher when the strut thickness is smaller. These results are consistent with those expected theoretically $[73,74]$. However, the elastic modulus of nanoporous gold and that of nanoporous alumina (PAA) presents a similar value $\left(n \approx 1.2, \rho_{\text {rel }}=0.3\right)$ [82] or a lower value $\left(n>2.5, \rho_{\text {rel }}=0.7\right)[83,84]$ than that of the former solid, respectively.

Nanoporous gold seems to have a fracture behavior dictated by the strut thickness [80], although Xia et al. [82] found that the ultimate tensile stress of nanoporous gold films is very sensitive to the presence of defects in the sample. In the case of low-density nanoporous alumina, the fracture toughness was comparable to that of the solid [84].

Finally, the hardness of low-density nanoporous alumina was studied by Xia et al. [84], who showed that nanoporous alumina exhibited a hardness three times lower than that observed in bulk alumina.

In general, improvements in nanoporous systems (at least in some metals and ceramics) are well established both theoretically and experimentally. The behavior of nanoporous polymers cannot be inferred from the behavior of metals or other materials, and therefore several attempts have been made to verify the expected improvements in the mechanical properties of nanoporous polymeric materials.

Nevertheless, one of the limitations of the mechanical testing of nanoporous polymeric materials is the production of sufficiently large samples that can be subjected to standard test protocols. For this reason, it has not been until recently that technological development has allowed the manufacture of samples in adequate quantities or with appropriate dimensions to thoroughly study these properties.

In order to better compare and understand the results obtained to date, the mechanical properties will be divided into those studied at low strain rates and those obtained at high strain rates.

For low strain rates, Miller and Kumar [13] observed an increase of the strain and stress at break (in tension) of polyetherimide (PEI) nanoporous foams (average pore size between 30 and $120 \mathrm{~nm}$ ) with respect to those of microporous foams (average pore size between 2 and $4 \mu \mathrm{m}$ ) for several densities ( $\rho_{\text {rel }}=0.9,0.85$ or 0.75 ). As a direct consequence of the increased strain at break, the toughness of nanoporous PEI was significantly improved compared to that of the microporous foam (by a factor of 2-3). In this case, they affirmed that the confinement effect cannot explain the increased toughness, or molecular mobility of the nanoporous tensile samples, because in fact the data suggest the opposite.

Sharudin and Ohshima [85] also found a slight increase in the stress at break and toughness in polypropylene/styrene- $b$-ethylene-butene- $b$-styrene (PP/SEBS) nanoporous polymers with densities (average pore size around $250 \mathrm{~nm}$ ) similar to those of unfoamed materials; however, the strain at break was similar to that of the solid sample.

On the contrary, Notario et al. [67] produced microporous and nanoporous polymethylmethacrylate (PMMA) foams of similar densities $\left(\rho_{\text {rel }}=0.5\right.$ ) and found a reduction in the stress and strain at break (in tension) of nanoporous foams (pore size between 200 and $300 \mathrm{~nm}$ ) in comparison with those of the microporous foams (pore size between 7 and $11 \mu \mathrm{m}$ ). As a direct result of the reduced strain at break, the toughness of the nanoporous foams was also significantly lower than that of microporous 
PMMA. The confinement of the polymer chains within the pore walls together with the lower stress supported by the pore walls of the nanoporous foams could be the reason for the early breakdown of the nanoporous PMMA.

According to the tensile tests of Miller and Kumar [13], the pore size had no influence on the Young's modulus of nanoporous PEI compared to microporous PEI in the elastic regime; nevertheless, the yield strength was slightly reduced.

The opposite trend was found in nanoporous PMMA by Notario and coworkers [67], who showed an elastic modulus $11 \%$ better than that of microporous foams but a significant reduction of around $60 \%$ of the yield strength. This enhancement in the elastic modulus was confirmed by dynamic mechanical analysis (DMA). An improvement of approximately $37 \%$ of the elastic modulus (measured at room temperature) of nanoporous PMMA compared to that of microporous PMMA was again observed.

However, Sharudin and Ohshima [85] observed an increased yield stress and a similar Young's modulus in nanoporous PP/SEBS blends compared to the solid material.

The yield strength results of nanoporous PEI and PMMA are the opposite of those predicted theoretically by Fan and Fang [74] and by Hodge and coworkers [73]. The reason may lie in the fact that these models have been developed for nanoporous metals and therefore are not applicable to polymers, since the deformation mechanisms in this type of material are very different.

An analysis of the mechanical behavior at high strain rates of both the solid and the microporous and nanoporous polymeric foams was performed in two different systems: PEI and PMMA [13,67]. PEI nanoporous polymers were tested according to the falling dart procedure, while PMMA samples were analyzed according to the Charpy impact tests. Independently of the technique used and the system under study, the results show a significant increase in the impact resistance of nanoporous polymers in comparison to microporous ones (see Fig. 9). The improvement found between microporous and nanoporous PMMA was about $25 \%$ for a relative density of 0.5 , while the solid material exhibited a behavior similar to that of the microporous foams. Nanoporous PEI foams always presented a higher value than microporous and solid PEI. For instance, for a given relative density of 0.90 , nanoporous PEI presented a $600 \%$ increase over that of the microporous material and a $60 \%$ increase compared to solid PEI.

These significant increases in the impact resistance of nanoporous polymeric materials with respect to microporous ones have been attributed to the reduction in the pore size. It is well known that voids in a porous material act as stress concentrators, reducing the triaxial tension in front of the crack tip [86-88]. Recently, several research groups have studied the possible reduction of the stress

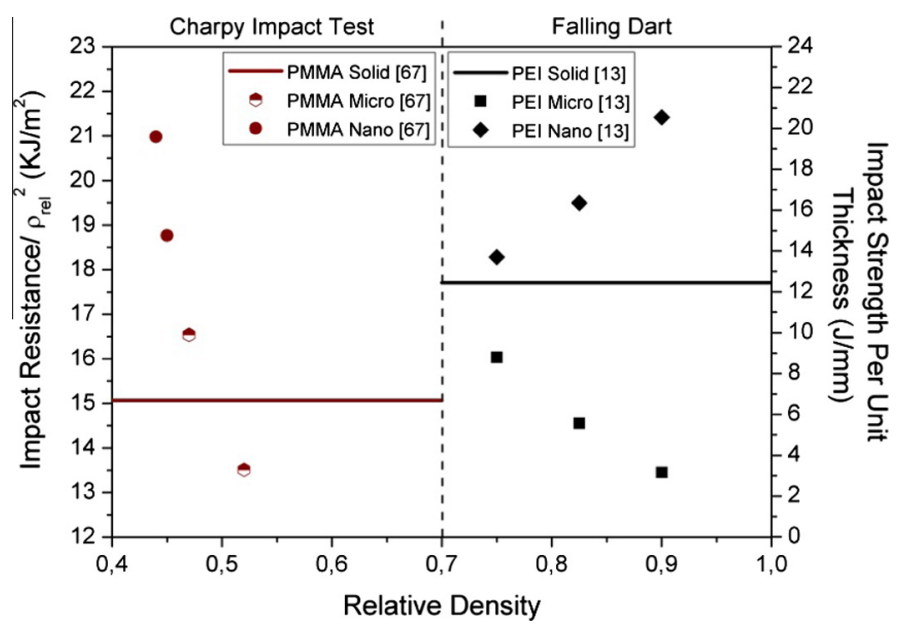

Fig. 9. Mechanical behavior at high strain rates for PMMA [67] and PEI [13] systems. 


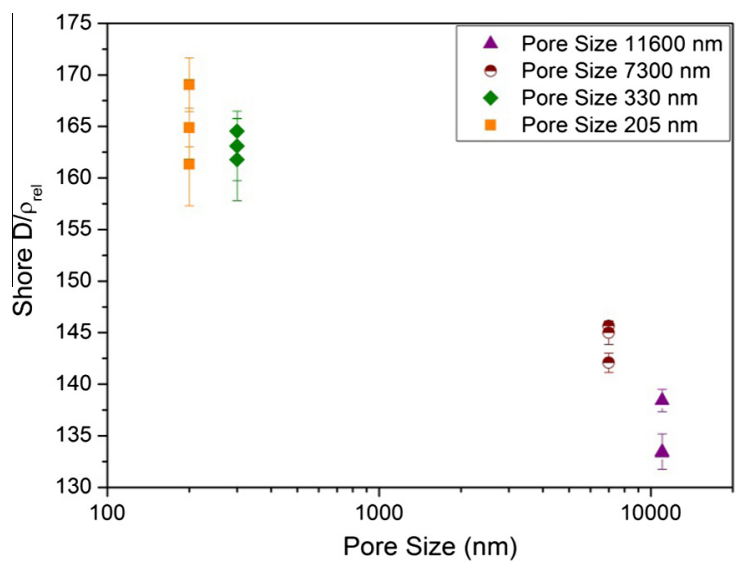

Fig. 10. Shore hardness normalized by the relative density for both microporous and nanoporous PMMA [67].

concentration when the pore size is reduced; however, no conclusive results in the relation between impact resistance and pore size were found, which is probably because of the small pore ranges analyzed [70,86-89]. Nevertheless, in the works of Miller and Kumar [13] and Notario et al. [67], the materials span the micrometer and nanometer range (a much larger range of pore sizes), demonstrating a significant effect.

Finally, the shore hardness of nanoporous and microporous PMMA foams was also studied by Notario et al. [67]. Again, a significant improvement of about $15 \%$ in the shore hardness of nanoporous foams compared to that of microporous foams was obtained (Fig. 10). This significant improvement was attributed to the presence of the nanoporous structure (with a more uniform porous structure and pore sizes in the nanometer range) and perhaps to the modification of the features of the polymer matrix owing to the observed confinement of the macromolecules on the nanometric scale.

In conclusion, it has been demonstrated that nanoporous polymers present several enhanced mechanical properties compared with microporous materials. It has been demonstrated that the mechanical behavior at high strain rates and the shore hardness of nanoporous polymers are significantly enhanced than those of both microporous and solid materials.

However, the results of the mechanical response at low strain rates (in tension) were inconclusive. Nanoporous PEI as well as nanoporous PP/SEBS blends presented an increased stress at break, strain at break, and toughness with respect to microporous materials, while nanoporous PMMA exhibited the opposite behavior. In general, the nanoporous systems had a yield strength similar to that of the microcellular systems, except in the case of PMMA, in which it was dramatically reduced. The modulus of elasticity also presented contradictory behavior: nanoporous PMMA exhibited a higher value than microporous systems, whereas nanoporous PEI showed the opposite behavior. However, all nanoporous polymers had a Young's modulus value lower than the solid.

A possible alteration of the fundamental properties of the base polymer due to the confinement of the polymer chains within the pore walls, or due to the stretching of the polymer chains induced during the manufacturing process [90], could be the cause of the different behaviors obtained. Nevertheless, more studies with different polymeric matrices are needed to understand, confirm or discard the contradictory tensile results that have been obtained up to now.

Thus, according to the works carried out to date, it can be concluded that nanoporous polymeric materials exhibit some mechanical properties superior to microporous materials at the same porosity, but it seems that the density, the nature of the confined material, and the morphology of the porous structure will also determine whether the mechanical properties of nanoporous systems will exceed those of the microporous material or the solid. 
Moreover, the correlation between the experimental results on the yield strength of metals and polymers with the corresponding theoretical models is unclear, and it is necessary to develop more specific models for polymers.

\section{Thermal conductivity}

In recent years, there has been increasing interest in the development of efficient materials for thermal insulation applications. According to the project "Energy Efficiency Trends in Buildings in the $E U$ ", dwelling houses represent around 25\% of the total energy consumption of western countries, where space heating represents more than $50 \%$ of this energy. If high efficiencies in household heating were reached, then it would be possible to achieve both economic savings and reductions in $\mathrm{CO}_{2}$ emissions.

Porous polymeric materials with high porosities could lead to high-efficiency thermal insulators because of the good insulation capacity of the gaseous phase, which has a much lower conductivity than the polymer matrix. The evaluation of the thermal conductivity of porous materials from the conductivity data of the two component phases and the structure of the material is an interesting subject that has been approached by different authors [91-94]. In a porous material, it is assumed that there are four different contributions to the total thermal conductivity $\left(\lambda_{t}\right)$ (Eq. (9)):

$$
\lambda_{t}=\lambda_{g}+\lambda_{s}+\lambda_{c}+\lambda_{r}
$$

where $\lambda_{g}$ represents the conduction through the gas phase, $\lambda_{s}$ is the conduction along the pore walls and struts of the solid material, $\lambda_{c}$ represents the convection within the pores, and $\lambda_{r}$ is the thermal radiation term.

In order to analyze the influence of the reduction in the pore size from the micrometer to the nanometer range on the thermal conductivity, it should be noted that convection plays a minor role in closed-pore materials with pore sizes below $4 \mathrm{~mm}$ in diameter [95] and in open-pore systems with pore sizes less than $2 \mathrm{~mm}$ [96] (and therefore will be negligible in closed and open micro- and nanoporous polymers). Likewise, the influence of the radiation term is well known in conventional and microporous materials, and this term is negligible for porous materials with relative densities over 0.2 [91]. However, the conventional models used to evaluate the radiation mechanism in porous polymers assumes that the wavelength of the infrared radiation is smaller than the pore size, but this presumption is incorrect in nanoporous polymers [97]. To overcome these difficulties, recent theoretical studies carried out in nanoporous materials have shown that the contribution of the radiation mechanism can be neglected even at low densities [98].

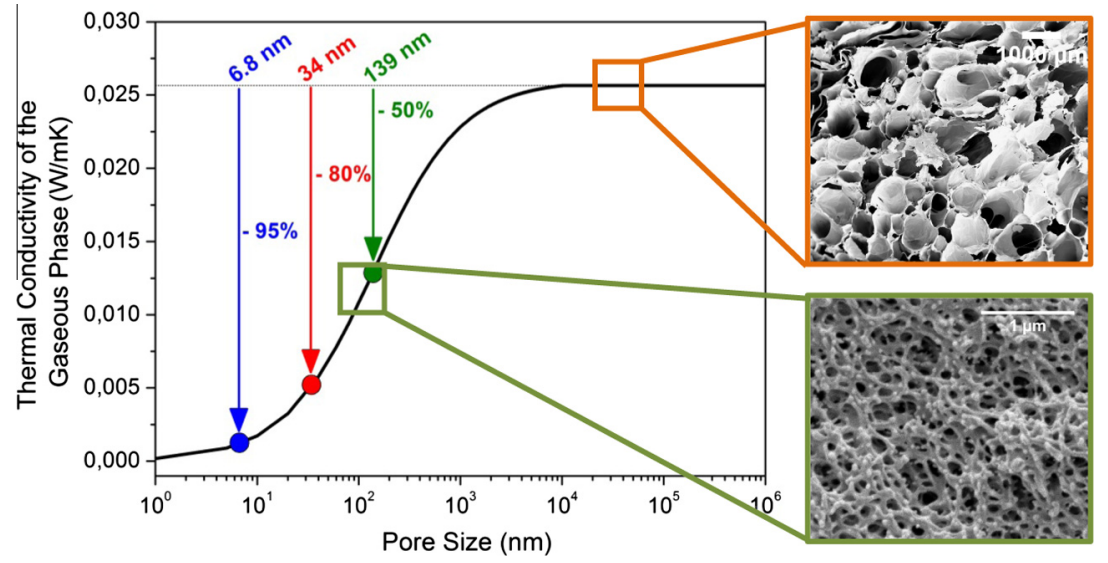

Fig. 11. Predicted relationship between the air thermal conductivity and the pore size due to the Knudsen effect, together with SEM micrographs (top: microporous PE; bottom: nanoporous PMMA/MAM) that have been included with permission from Notario et al. [14]. 
Therefore, it is expected that the change from the microscale to the nanoscale only affects the conduction through the gas and solid phases. Existing theoretical and experimental studies on this subject are discussed in the following paragraphs.

It is assumed that nanoporous polymeric materials will lead to a decrease in the thermal conductivity of the gaseous phase due to the so-called Knudsen effect [63,64]. This effect implies that the molecules of the gas collide more often with the molecules forming the surrounding solid part than with other gas molecules when pore size is comparable or smaller than the mean free path of the gas. Thus, the energy transfer through the gas molecules is decreased.

Then, the effective thermal conductivity of the gas in air-filled porous structures can be described by the Knudsen equation:

$$
\lambda_{g}^{\prime}=\frac{\lambda_{g 0}^{\prime}}{\left(1+\beta\left(l_{g} / \Phi\right)\right)}
$$

where $\lambda_{g 0}^{\prime}$ is the thermal conductivity of free air $(0.026 \mathrm{~W} / \mathrm{m} \mathrm{K}$ at room temperature), $\beta$ is a parameter that takes into account the energy transfer between gas molecules and the limiting solid structure (about 2 for air), $l_{g}$ is the mean free path of the gas molecules $\left(l_{g} \approx 70 \mathrm{~nm}\right.$ at room temperature), and $\Phi$ is the average pore diameter.

According to Eq. (10), a significant reduction in $\lambda_{\mathrm{g}}^{\prime}$ is obtained when pore size decreases below a micron (see Fig. 11). Therefore, for porous materials with pore sizes in the nanometer regime, a reduction in the conduction through the gas phase should be expected. Furthermore, taking advantage of this benefit, it will be possible to reduce the thermal conductivity effectively over the long term.

The expected reduction in the thermal conductivity of the gas phase has been widely studies from a theoretical point of view [98-104]. For instance, Hrubesh and Pekala [99] studied the reduction of the thermal conductivity of open-pore nanoporous organic and inorganic aerogels (pore size between 10 and $90 \mathrm{~nm}$ ) through the analysis of the three main components of thermal conductivity (conduction in the solid and gas phases and radiation). A significant reduction (around 90\%) in the thermal conductivity of the gaseous phase was obtained when the pore size decreased from $90 \mathrm{~nm}$ to $10 \mathrm{~nm}$; the Knudsen effect was identified as the main factor responsible for this reduction. The radiation term was analyzed using the classical diffusion approximation, but experimental values of the extinction coefficient were introduced. Using this model, they obtained a good agreement between experimental and theoretical thermal conductivity results, showing that the radiation term influences the overall thermal conductivity for relative densities lower than 0.1 .

The diverse heat transfer mechanisms in a porous polystyrene with pore sizes both at the micrometer (pore size around $1 \mu \mathrm{m}$ ) and nanometer (two pore sizes used: $250 \mathrm{~nm}$ and $100 \mathrm{~nm}$ ) scale were analyzed theoretically by Forest and coworkers [100]. They observed that, the lower the pore size, the lower the thermal conductivity because of the Knudsen effect.

A theoretical study (based on the Knudsen equations) of the coupled heat transfer by conduction and radiation in one-dimensional multi-phase media was developed by Ferkl et al. [98]. This model was used to understand the interplay of conduction and radiation on the micro- and nanoscales. A PS foam, with pore sizes ranging from $10 \mathrm{~nm}$ to $1 \mathrm{~cm}$, open-pore morphology, and relative densities around 0.1 , was used as an example. They observed that the lowest thermal conductivity was achieved by reducing the pore size to the nanometer range (because of the Knudsen effect) and that the contribution of the radiation term in low-density nanoporous materials can be neglected, which is contrary to the results of Hrubesh and Pekala [99].

Together with the Knudsen effect, which implies a confinement of the gaseous phase inside the pores, other mechanisms related to the conduction through the polymer matrix also arise and can justify the reduction in the thermal conductivity in the nanometer regime. In this case, the confinement of the matrix hinders the energy transfer through it because of a modified phonon scattering mechanism. In addition, the increase in the tortuosity described in Section 1.3 also contributes to the reduction in heat transfer because of the conduction to the solid phase (a longer distance to transmit the energy will also result in increased phonon scattering). Several works have studied this reduction in the solid-phase thermal conductivity from a theoretical point of view. 
For instance, Sundarram and Li [101] used finite element analysis (FEA) and molecular dynamics (MD) to study the thermal behavior of open-pore polymers (in particular, PMMA and PEI). A reduction in the thermal conductivity when the pore size was decreased from $1 \mathrm{~mm}$ to $1 \mathrm{~nm}$ was predicted and was mainly attributed to the phonon scattering effect in the solid polymer matrix. Furthermore, two unusual results were also reported in this paper: first, they stated that the Knudsen effect has little relevance. Second, a decrease in the gaseous phase contribution when the pore size is reduced from $500 \mu \mathrm{m}$ to $10 \mu \mathrm{m}$ was also predicted for a constant density. These predictions do not match the well-known Knudsen equations and are also contrary to some experimental results found in porous polyethylene (PE) [14]. Therefore, it can be expected that the contribution of the phonon scattering mechanism is lower than the one assumed in this study.

The decrease in the phonon mean-free path, which arises from increased phonon scattering at the pore surfaces, was used by Lee et al. [102] to justify the reduction of two orders of magnitude in the thermal conductivity of open nanoporous $\mathrm{Si}$ (average pore size between 0.5 and $3 \mathrm{~nm}$ ) with respect to the bulk. In this case, the Knudsen effect was not considered, because they only modeled the thermal conductivity along the solid phase. Furthermore, their MD approach (developed for an arrangement of nanometer-sized cylindrical pores) clearly showed that the thermal conductivity of nanoporous $\mathrm{Si}$ decreases as a function of pore size.

Using Monte Carlo simulations, Bera and coworkers [103] observed how the thermal conductivity of open nanoporous $\mathrm{Si}$, nanoporous $\mathrm{Ge}$, and nanoporous $\mathrm{SiGe}$ alloys decreases significantly when the pore size is lower than $100 \mathrm{~nm}$. Again, this behavior was justified by the increased phonon scattering mechanisms without considering the Knudsen effect, because they only modeled the thermal conductivity of the solid matrix.

Finally, Tsui et al. [104] proposed a serial-parallel hybrid model to study the anisotropic behavior of the thermal conductivity of close-pore nanoporous silica films as a function of porosity (ranging from $21 \%$ to $64 \%$ ) for a constant pore size (not specified in the article). Using this model, they were able to consider the inhomogeneities of the nanopore distribution (preferably oriented in the horizontal plane), and their thermal conductivity results were similar to those provided by the Gibson and Ashby model [105]. Furthermore, because of the high thermal conductivity of $\mathrm{SiO}_{2}(1.4 \mathrm{~W} / \mathrm{m} \mathrm{K})$ and the low-midrange porosity (20-60\%), the contribution of the gas phase was very small regardless of the pore size. For this reason, it was impossible to assess whether considering the Knudsen effect will modify the results.

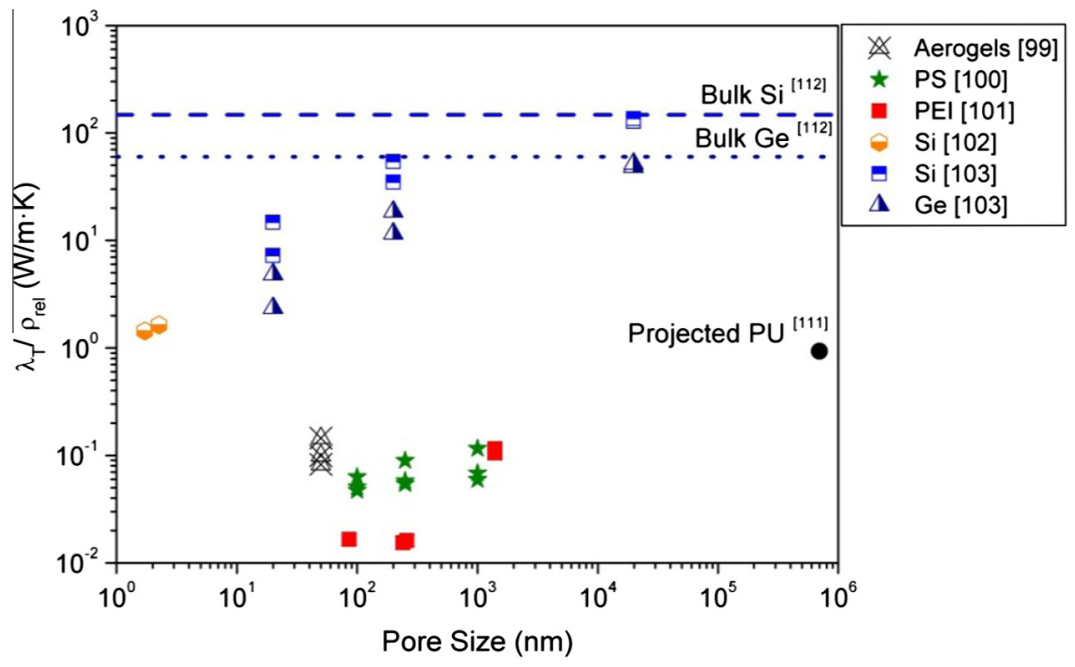

Fig. 12. Relationship between thermal conductivity divided by the relative density and the pore size for different nanoporous systems [99-103], together with the thermal conductivity of projected PU [111] and bulk Si and Ge [112]. 
Therefore, theoretical models developed for both nanoporous polymeric materials and other nanoporous systems agree that a reduction in the pore size implies a decrease in the thermal conductivity (see Fig. 12). In this figure, the thermal conductivity of nanoporous materials was divided by their relative density in order to analyze the influence of the pore size independently of the density. Furthermore, the thermal conductivity of a typical thermal insulator, rigid projected PU, and the thermal conductivity of typical semiconductors, bulk Si and Ge, were included for comparison purposes. Nanoporous thermal insulators are much better than conventional ones (projected PU), and the thermal conductivity of nanoporous semiconductors is lower than that of the solid. The confinement of the gas molecules within pores or a possible alteration of the phonon scattering mechanisms in the matrix are the mechanisms underlying this phenomenon. This expected reduction in the thermal conductivity has been previously experimentally demonstrated in aerogels [63,106-108], porous metals [109], and porous ceramics [110] (these works will be discussed below for comparison). However, the thermal conductivity of polymeric foams is a recent issue because of the technical difficulties found in the production of nanoporous polymers with adequate densities, pore sizes, and external dimensions to allow the characterization of their properties as thermal insulators. For this reason, experimental works on this topic are still scarce. These works are described in the following paragraphs.

A clear influenced of the pore size on the gaseous conductivity of aerogels with an average pore size between 10 and $90 \mathrm{~nm}$ (reductions of up to 39\% of the gas phase [63]) due to the Knudsen effect was observed by Lu et al. [63] and by Lee and coworkers [106]. The thermal conductivity of these openpore materials was measured from vacuum to ambient pressure by means of a transient hot-wire device, which led to extraordinarily low thermal conductivity values $(0.015 \mathrm{~W} / \mathrm{m} \mathrm{K}$ for a relative density of 0.10$)$.
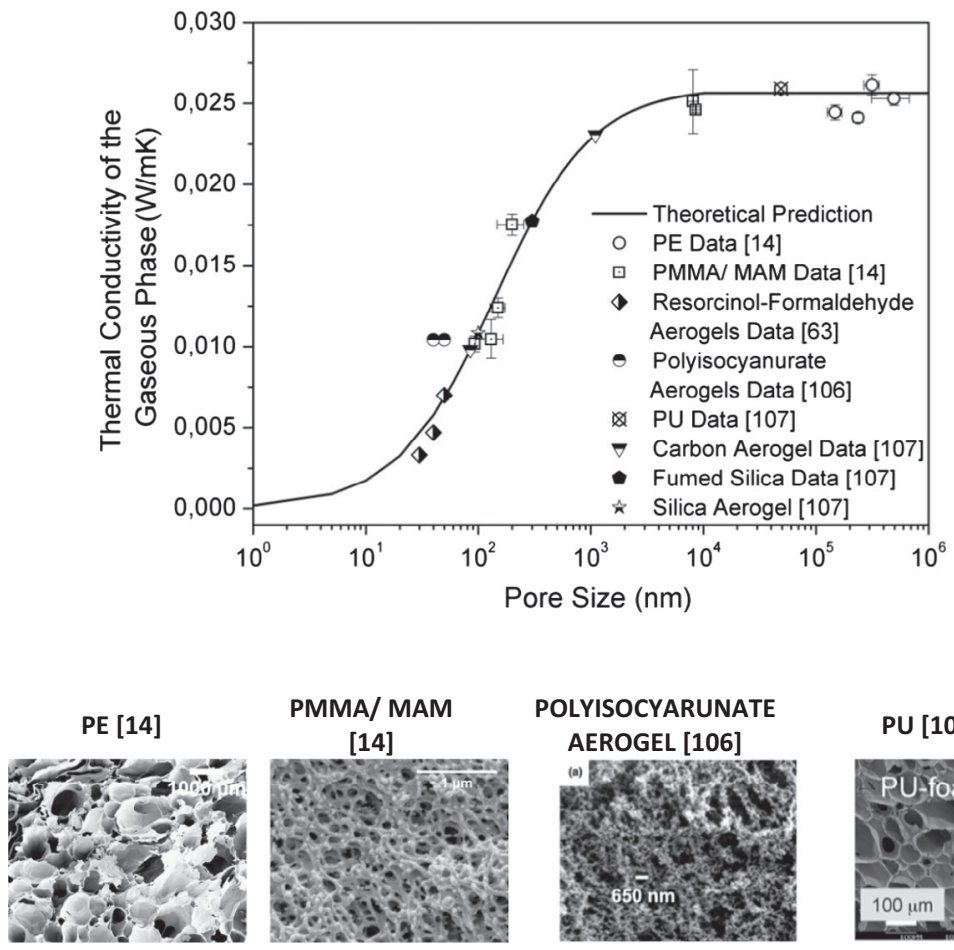

PU [107]

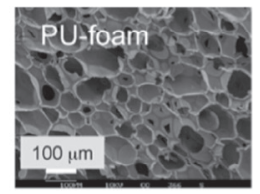

Fig. 13. Top: Effect of pore size on the gas thermal conductivity in open-pore polymeric materials [14], together with the theoretical prediction obtained from the Knudsen equation, and some of the previous results obtained in different nanoporous systems [63,106,107]. Bottom: SEM images of the samples analyzed that have been included with permission from $[14,106,107]$. 
Using the same procedure, Reichenauer et al. [107] measured the thermal conductivity of openpore fumed silica, silica and carbon aerogels, solid glass spheres, and PU foams. Pore sizes of these samples ranged from about $100 \mathrm{~nm}$ to $1 \mathrm{~mm}$. Again, a clear reduction of the thermal conductivity (around 88\% when the pore size is reduced from 1100 to $85 \mathrm{~nm}$ ) due to the Knudsen effect was detected. In this case, the nanoporous systems under study were not polymeric materials.

Thermal conductivity of open-pore nanoporous Bi films (pore sizes from 5 to $10 \mathrm{~nm}$ ) was experimentally determined by Song et al. [109] by a differential 3- $\omega$ method. Nanoporous Bi exhibited an order of magnitude reduction in thermal conductivity compared to that of the solid, probably because of a reduction in the phonon mean free path. The Knudsen effect was not considered in this case, because the thermal conductivity of the gaseous phase was not taken into account.

Finally, the thermal conductivity of open-pore zirconia ceramics with pore sizes below $100 \mathrm{~nm}$ was also characterized by Nait-Ali et al. [110]. They pointed out that the pores should be as small as possible to reduce the thermal conductivity through the gas phase, as Knudsen effect predicts, and thus to achieve a thermally insulating material.

In general, thermal insulation improvements in nanoporous systems (at least in non-polymeric materials; see Fig. 13) are well established both theoretically and experimentally. Much effort have been made in recent years to demonstrate this expected improvement in nanoporous polymers as well. However, although there are patents $[113,114]$ and articles $[20,62,115]$ in which it is proposed to take advantage of this expected reduction in the thermal conductivity, to date there is only one experimental validation of this effect because of the technical difficulties associated with the production of nanoporous polymers.

Notario and coworkers [14] produced a wide set of PE- and PMMA-based polymeric foams with open-pore morphologies, pore sizes ranging from $90 \mathrm{~nm}$ to $100 \mu \mathrm{m}$, and relative densities from 0.12 to 0.6 , and characterized their thermal conductivity (see Fig. 13). They demonstrated that it is possible to reduce the thermal conductivity of polymeric foams because of (a) a reduction of the gaseous conductivity due to the Knudsen effect, and there is good agreement between experimental data and theoretical predictions according to the Knudsen equation; and (b) a reduction of the thermal conductivity through the solid phase because of an increment of the tortuosity of the porous structure and/or a confinement effect in the polymeric matrix, which can be related to a different phonon scattering mechanism.

As a conclusion, theoretical models developed both for nanoporous polymers and for other nanoporous materials (aerogels and metals) predict a reduction of the thermal conductivity when the pore size is below a micron. The confinement of both the gaseous phase (Knudsen effect) and the solid phase (different phonon scattering mechanisms/increased tortuosity) are the phenomena underlying this effect.

Experimental results, both in polymers and other materials (aerogels, metals, and ceramics), verify this expected reduction in the thermal conductivity. The two theoretical arguments mentioned above are used to justify this decrease in the thermal conductivity.

The number of works in nanoporous polymers to date has been limited; however, the Knudsen effect depends only on the morphology of the porous structure and is independent of the solid matrix. Therefore, it can be stated that there is sufficient evidence to confirm its presence in a wide range of nanoporous materials, such as polymers, aerogels, metals, and ceramics. However, the analysis of the radiation term is still scarce, and there exist contradictory results on the weight of this contribution as a function of the density and cell size in nanoporous polymers.

\section{Dielectric properties}

The continuous miniaturization in the microelectronics industry (feature size below $100 \mathrm{~nm}$ ) has led to the production of low-dielectric-constant $(k)$ materials to mitigate interconnect resistancecapacitance (RC) delays, cross-talk noise, and power dissipation. According to the National Technology Roadmap for Semiconductors (NTRS) published in 1997 in California, USA [116], materials with dielectrics constants around 1.5-2.0 were required in the year 2006 (and are currently being pursued), and materials with $k \leqslant 1.5$ were demanded in the year 2012 to overcome these drawbacks. In addition, 


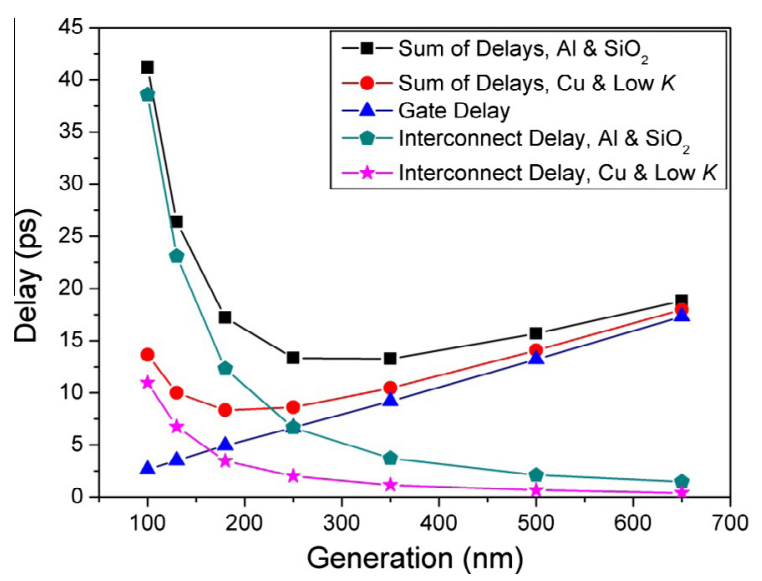

Fig. 14. Calculated gate and interconnect delay versus technology generation for conventional materials such as $\mathrm{Al}$ and $\mathrm{SiO}_{2}$ and for new materials such as Cu or low- $k$ materials. This figure has been adapted from [116].

these materials should have good thermal and chemical stability, low moisture uptake, high mechanical resistance, and high dielectric breakdown fields. These requirements have not been achieved yet in the microelectronics industry.

Implementation of low- $k$ materials for 100-nm technology generation requires the development of new materials and technologies. Fig. 14 shows how the use of low- $k$ materials will decrease the interconnect delays with respect to conventional materials used in microelectronics such as aluminum ( $\mathrm{Al})$ and silicon dioxide $\left(\mathrm{SiO}_{2}\right)$. However, this methodology will only cover the needs for the closest technological generations. Technology generations beyond $100 \mathrm{~nm}$ will demand either new systems or new approaches to interconnects.

This demand for low- $k$ materials has stimulated great efforts to explore the applicability of porous materials, especially porous polymeric systems, to replace silicon dioxide $\left(\mathrm{SiO}_{2}, k>3.5\right)$ as the interlevel dielectric. The low dielectric constant of the polymer $(k<3)$ [117] together with that of air $(k=1)$ make these porous polymeric systems promising candidates as low- $k$ systems.

In this case, nanoporous materials are in demand because of the reduced dimensions of developing devices, where the pores must be smaller than the thickness of the film (preferably an order of magnitude lower [118]). However, it is not expected that these materials will show new effects due to the presence of porosity. Indeed, one of the objectives of this review is to analyze whether there is any real influence of pore size on the dielectric behavior of these nanoporous systems.

The equation that describes the dielectric constant $k_{t}$ of a two-phase system is the so-called Lichterecker mixing rule [119]:

$$
k_{t}^{\alpha}=k_{s}^{\alpha}\left(1-V_{g}\right)+k_{g}^{\alpha} V_{g}
$$

where $k_{s}$ and $k_{g}$ are the dielectric constants of the solid and gaseous phases, respectively, $V_{g}$ is the volume fraction of voids (i.e., the porosity), and $\alpha$ is a parameter that determines the type of rule of mixtures. If $\alpha=-1$, then the serial mixing rule can be used (which represents a lower limit of the dielectric constant):

$$
\frac{1}{k_{t}}=\frac{\left(1-V_{g}\right)}{k_{s}}+\frac{V_{g}}{k_{g}}
$$

When $\alpha=1$, the parallel mixing rule (an upper limit of the dielectric constant) is given as:

$$
k_{t}=k_{s}\left(1-V_{g}\right)+k_{g} V_{g}
$$




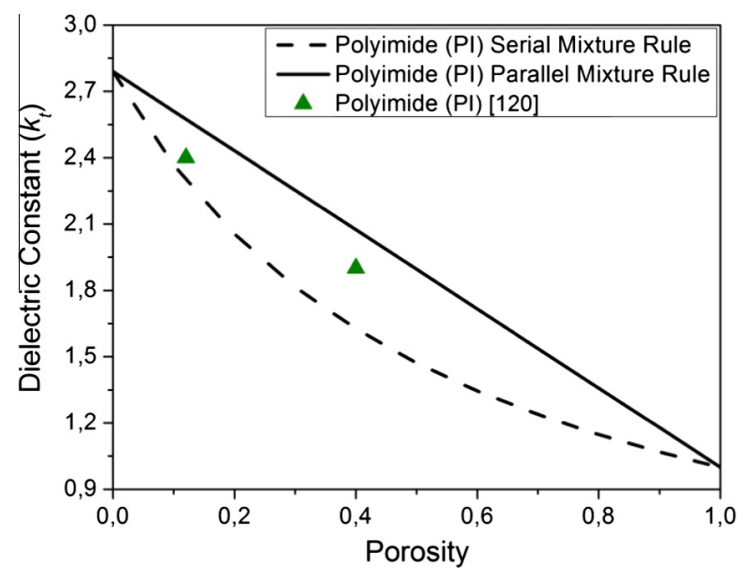

Fig. 15. Variation of the dielectric constant as a function of porosity according to Eqs. (12) and (13) for the particular case of a nanoporous polyimide $\left(k_{s}=2.79\right)$, together with some experimental results [120].

In the case where $\alpha \rightarrow 0$, an intermediate form between the serial and parallel forms (logarithmic mixture rule) is found:

$$
\log k_{t}=\left(1-V_{g}\right) \log k_{s}+V_{g} \log k_{g}
$$

According to these expressions, increased porosity leads to a reduction in the dielectric constant (see Fig. 15, in which experimental results obtained by Krause et al. [120] in polyimide films are included. These experimental values show an intermediate behavior between the upper and lower limits). Nevertheless, this increased porosity also tends to reduce the mechanical resistance of the system. For this reason, control over pore size, shape, and distribution is important to obtain the appropriate mechanical properties to withstand the aforementioned requirements (close-pore morphologies are preferred in terms of their mechanical behavior).

This expected reduction in the dielectric constant of nanoporous systems has been experimentally demonstrated both in polymeric materials and in other systems, such as silica [121-123] or organosilicates [124-129]. The results concerning the latter will be described briefly below for comparison with the results obtained in polymeric materials.

Nanoporous silica films (also known as aerogels or xerogels) have been intensively developed in recent years. These materials exhibit high thermal stability, small pore sizes, and dielectric constants that can be tailored from 1 to 4 [121-123]; nevertheless, a surface treatment and film aging must be applied to minimize their moisture absorption. For instance, Baskaran et al. [122] synthesized closedpore nanoporous silica films (thickness between 0.5 and $1.2 \mathrm{~mm}$ ) with dielectric constants ranging from 1.8 to 2.5 and pore sizes less than $5 \mathrm{~nm}$. In particular, they obtained a material with a dielectric constant of 2.2 (lower than that of the solid, $k_{s} \approx 4$ ) that had a stable dielectric response with time, a porosity around 55\%, a good texture, and acceptable mechanical properties ( $n=2$ for the Young's modulus vs. density curve (Eq. (6))). Furthermore, an aging treatment was applied to reduce the moisture level.

Organosilicates are also promising materials for low- $k$ dielectrics because of their intrinsic hydrophobic behavior and the high thermal stability of the solid matrix [124-129]. Yang and coworkers $[124,125]$ produced poly(methyl silsesquioxane) (MSQ) nanoporous organosilicate films (thicknesses of $0.3-0.8 \mu \mathrm{m}$ ) with pore sizes between 2 and $6 \mathrm{~nm}$, porosities from $30 \%$ to $50 \%$, and $k$ values from 2 to 1.5 (lower values than that of the solid, $k_{s} \approx 2.8$ ). This closed-pore organosilicate exhibited good thermal stability, acceptable mechanical strength $(n=2$ for the Young's modulus, and $n=3$ for the hardness of the system with a porosity of 0.3 ), and a high electrical breakdown field $(>1.5 \mathrm{MV} / \mathrm{cm})$. Similarly, closed pore nanoporous poly(methylsilsesquioxane) films with a final thickness around $1 \mu \mathrm{m}$ were prepared by Nguyen et al. [126]. These organosilicate films presented 

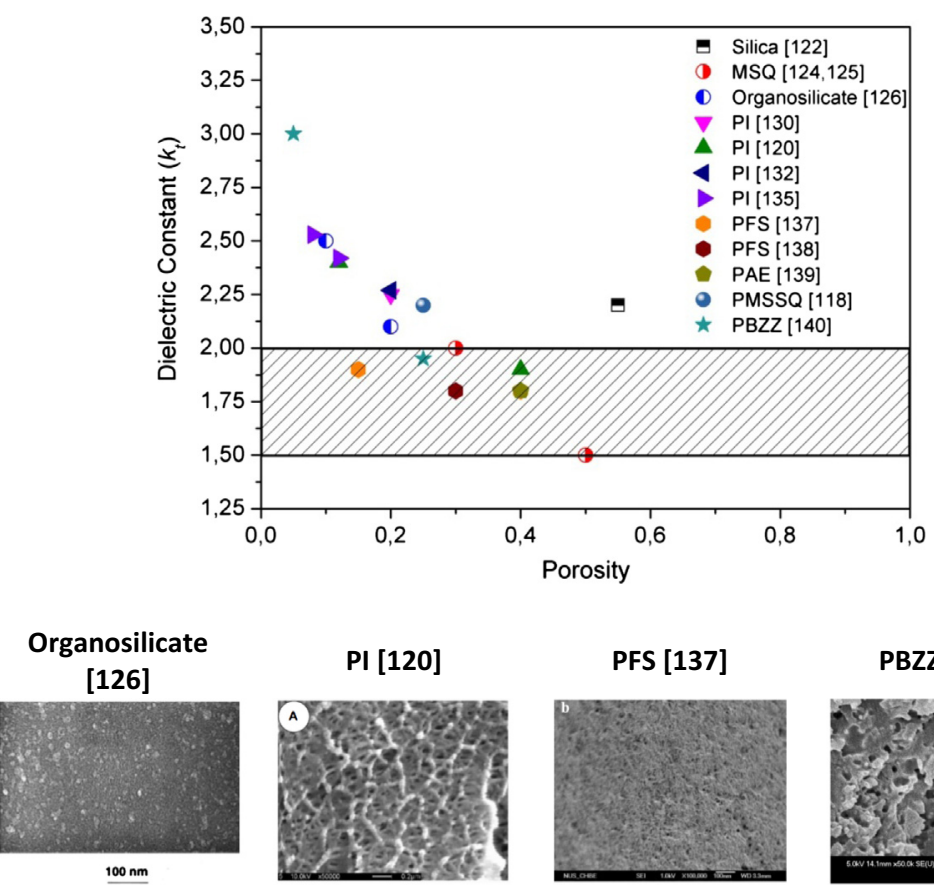

PFS [137]

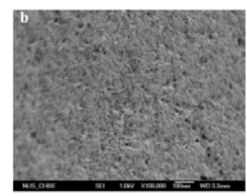

PBZZ [140]

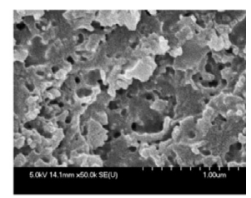

Fig. 16. Top: Dielectric constant values obtained for different nanoporous systems (both polymeric and non-polymeric) as a function of porosity. The shaded area represents the dielectric constant values required by NTRS. Bottom: SEM (PI, PFS, and PBZZ) and TEM (organosilicate) micrographs of some of the nanoporous materials under study included with permission from $[120,126,137,140]$.

an average pore size of $20 \mathrm{~nm}$, porosities ranging from $10 \%$ to $20 \%$, dielectric constants from 2.5 to 2.1 (a reduction around $10 \%$ and $24 \%$, respectively, with respect to the solid), a thermal stability around $250^{\circ} \mathrm{C}$, and a high dielectric breakdown $(2-3 \mathrm{MV} / \mathrm{cm})$.

Experimental results obtained in non-polymeric nanoporous materials clearly showed a reduced dielectric constant in comparison with the former solid, with values close to those required by the NTRS in the year 2006 (especially in the case of organosilicates with porosities higher than 0.2; see Fig. 16). However, further studies are needed to verify whether these materials are potential candidates to be used in microelectronics (see Table 1).

Nanoporous polymers have emerged in recent years as potential low $k$ materials for use in the development of advanced integrated circuits. The low dielectric constant of the polymer matrix $(k<3)$ compared to the inorganic alternatives, together with the lower manufacturing costs and ease of processing, make these materials promising candidates. Nevertheless, their major drawback compared to inorganic materials is their low thermal stability. These materials must withstand the high temperatures associated with the processes used to deposit metal lines and anneal devices. Though a wide variety of polymers have been analyzed for use in microelectronics devices, only some of them meet the stringent requirements.

Polyimides (PI) are a favored material because of their high thermal stability, low stress coefficient of thermal expansion, low dielectric constant, high resistivity, and high dielectric breakdown [120,130-135]. For instance, Lee et al. [130] managed to develop a nanoporous PI films (thickness: $200 \mu \mathrm{m}$ ) with pore sizes from 10 to $40 \mathrm{~nm}$, a porosity around $20 \%$, and a dielectric constant of 2.25 (a reduction of $31 \%$ with respect to the solid). These closed-pore (with some interconnections) PI films exhibited a high thermal stability $\left(>300^{\circ} \mathrm{C}\right)$, and acceptable mechanical behavior $(n=2$ for the Young modulus). 
Table 1

Comparison between the requirements demanded by the NTRS in the year 2006 and the results obtained to date.

\begin{tabular}{|c|c|c|c|c|c|c|c|c|}
\hline System & Porosity & $\begin{array}{l}\text { Pore size } \\
(\mathrm{nm})\end{array}$ & $1.5<k<2.0$ & $\begin{array}{l}\text { Thermal } \\
\text { stability }\end{array}$ & $\begin{array}{l}\text { Chemical } \\
\text { stability }\end{array}$ & Low moisture uptake & $\begin{array}{l}\text { High mechanical } \\
\text { resistance }\end{array}$ & $\begin{array}{l}\text { High dielectric } \\
\text { breakdown }\end{array}$ \\
\hline Silica [122] & 0.55 & $<5$ & 2.2 & Not Studied & Not Studied & Acceptable & $\begin{array}{l}\text { Acceptable } \\
\text { Elastic Modulus: } n=2\end{array}$ & Not Studied \\
\hline Organosilicates $[124,125]$ & $0.3-0.5$ & $2-6$ & $2-1.5$ & Not Studied & Not Studied & $\begin{array}{l}\text { Not studied, though by nature they } \\
\text { are hydrophobic }\end{array}$ & $\begin{array}{l}\text { Acceptable Elastic } \\
\text { Modulus: } n=2 \\
\text { Acceptable-Bad } \\
\text { Hardness: } n=3\end{array}$ & $>1.5 \mathrm{MV} / \mathrm{cm}$ \\
\hline Organosilicates [126] & $0.1-0.2$ & 20 & $2.5-2.1$ & $\begin{array}{l}\approx 250^{\circ} \mathrm{C} \\
\text { Acceptable }\end{array}$ & Not Studied & $\begin{array}{l}\text { Not studied, though by nature they } \\
\text { are hydrophobic }\end{array}$ & Not Studied & $>2 \mathrm{MV} / \mathrm{cm}$ \\
\hline Polyimides [130] & 0.2 & $10-40$ & 2.25 & $>300^{\circ} \mathrm{C}$ & Not Studied & Not Studied & $\begin{array}{l}\text { Acceptable } \\
\text { Elastic Modulus: } n=2\end{array}$ & Not Studied \\
\hline Polyimides [120] & $0.12-0.4$ & $20-50$ & 2.4 & $>250{ }^{\circ} \mathrm{C}$ & Not Studied & Not Studied & $\frac{\text { Good }}{\text { Elastic Modulus: } n=1.4}$ & Not Studied \\
\hline Polyimides [132] & 0.2 & 10 & 2.27 & $>300^{\circ} \mathrm{C}$ & Not Studied & Absorbs & $\frac{\text { Acceptable }}{\text { Elastic Modulus: } n>2}$ & Not Studied \\
\hline Polyimides [135] & $0.08-0.12$ & $35-70$ & $2.53-2.42$ & $\approx 250^{\circ} \mathrm{C}$ & Not Studied & Not Studied & $\begin{array}{l}\text { Very Good } \\
\text { Yield Strength: } \\
n \approx 1\end{array}$ & Not Studied \\
\hline $\begin{array}{l}\text { Polyimides } / \mathrm{SiO}_{2} \\
\quad \text { Nanocomposites [136] }\end{array}$ & $0.1-0.45$ & $20-50$ & $3.5-2.6$ & Not Studied & Not Studied & Not Studied & Not Studied & Not Studied \\
\hline Fluoropolymer [137] & $0.15-0.4$ & $30-50$ & $1.9-1.8$ & $\approx 300^{\circ} \mathrm{C}$ & Not Studied & Not Studied & Not Studied & Not Studied \\
\hline Fluoropolymer [138] & 0.3 & $90-150$ & 1.8 & Not Studied & $\begin{array}{l}\frac{\text { Good }}{\text { (THF \& }} \\
\text { Chloroform) }\end{array}$ & Not Studied & Not Studied & Not Studied \\
\hline Poly(aryl ether) [139] & 0.4 & 3 & 1.8 & $>300{ }^{\circ} \mathrm{C}$ & Not Studied & Hydrophobic & Not Studied & Not Studied \\
\hline $\begin{array}{l}\text { Poly } \\
\text { (methylsilsesquioxane) } \\
{[118]}\end{array}$ & $0.09-0.25$ & $<3$ & 2.2 & Not Studied & Not Studied & Not Studied & $\begin{array}{l}\text { Bad } \\
\text { Elastic Modulus and } \\
\text { Hardness: } n \approx 4\end{array}$ & Not Studied \\
\hline Polybenzoxazine [140] & $0.05-0.25$ & 50 & $3-1.95$ & $\approx 340^{\circ} \mathrm{C}$ & Not Studied & Not Studied & Not Studied & Not Studied \\
\hline
\end{tabular}


Five different nanoporous PI films (thickness around $100 \mu \mathrm{m}$ ) were produced by Krause and coworkers [120]. These nanoporous films exhibited porosities ranging from $12 \%$ to $40 \%, k$ values from 2.4 to 1.9 , respectively (lower values than that of the solid, $k_{s}=2.79$ ), and pores with a closed morphology and an average size from 20 to $50 \mathrm{~nm}$. In this case, the thermal stability of nanoporous PI was higher than $250^{\circ} \mathrm{C}$, and the mechanical response was improved ( $n=1.4$ for the Young's modulus) with respect to the results obtained by Lee et al. [130].

Carter et al. [132] also produced closed-pore nanoporous PI films with an average thickness from 1 to $40 \mu \mathrm{m}$, an average pore size around $10 \mathrm{~nm}$, a porosity around $20 \%$, and a dielectric constant of 2.27 (a lower value than that of the bulk, $k_{s}=2.56$ ). The mechanical behavior of these films was measured, and a value of $n>2$ was obtained for the elastic modulus. These nanoporous PI films absorbed moisture, although less than the solid did, and exhibited a high thermal stability $\left(>300^{\circ} \mathrm{C}\right)$.

Similarly, Mehdipour-Ataei and Aram [135] developed nanoporous PI films (the thickness was not specified in the article) with pores exhibiting a closed morphology, pore sizes between 35 and $70 \mathrm{~nm}$, porosities ranging from $8 \%$ to $12 \%$, and dielectric constant values from 2.53 to 2.42 (the values were lower than that of the solid, $k_{s}=3.06$ ). These films presented very good mechanical properties ( $n \approx 1$ for the yield strength) but lower thermal stability values $\left(\approx 250^{\circ} \mathrm{C}\right)$ than the ones in previous works.

Li and coworkers [136] developed PI/silica nanocomposite nanoporous films with thicknesses between 100 and $200 \mu \mathrm{m}$. This closed-pore system exhibited pore sizes ranging from 20 to $50 \mathrm{~nm}$, porosities from 0.1 to 0.45 , and lower dielectric constants than that of the solid (from 3.5-2.6 for the porous film to 3.8 for the bulk system). In this case, the thermal and mechanical properties were not studied.

Other potential candidate for interlayer dielectric applications are fluoropolymers [137,138]. These materials are characterized by good chemical stability and by the lowest dielectric constants among the bulk polymers (around 2.4). However, their main drawback is their insufficient thermal stability for integration procedures, and furthermore there are concerns about fluoric acid evolution during processing and its reactions with the metals employed. Fu et al. [137] managed to overcome the problem of thermal stability and produce closed-pore nanoporous poly(pentafluorostyrene) (PFS) films with a thermal stability of around $300^{\circ} \mathrm{C}$. These nanoporous films exhibited a thickness of about 1$2 \mu \mathrm{m}$, an average size from 30 to $50 \mathrm{~nm}$, porosities ranging from 15 to $40 \%$, and $k$ values from 1.9 to 1.8 , respectively (a reduction of about $20 \%$ with respect to the bulk).

A good chemical resistance to common organic solvents such as tetrahydrofuran (THF) and chloroform was achieved by Fu and coworkers [138] by producing crosslinked nanoporous fluoropolymer films with a thickness of around $2-4 \mu \mathrm{m}$. This closed pore system had pores between 90 and $150 \mathrm{~nm}$, a porosity around 30\%, and a dielectric constant of 1.8 (a lower value than that of the bulk, $k_{s}=2.2$ ). The dielectric constants obtained with fluoropolymers in this study and in the previous one were lower than those achieved in polyimide and are within the range demanded by the NTRS.

Another variety of nanoporous polymers that have been proposed as low $k$ materials is polyaryl ether (PAE). This class of polymers presents attractive properties such as excellent chemical resistance, high thermal stability, and good mechanical properties. For instance, Xu and coworkers [139] obtained hydrophobic closed-pore nanoporous PAE films (thickness: $490 \mathrm{~nm}$ ) with a porosity of $40 \%$, pore sizes around $3 \mathrm{~nm}$, a dielectric constant equal to 1.8 (a reduction of $32 \%$ with respect to the solid), and a thermal stability higher than $300^{\circ} \mathrm{C}$.

Another area of significant interest is polysilsesquioxanes (PSSQs) and, in particular, materials based on poly(methylsilsesquioxane) (PMSSQ). The synthesis of these materials can open the door to new materials with improved properties, especially materials with low dielectric constants. For instance, nanoporous PMSSQ films with a final thickness in the range of $600 \mathrm{~nm}$ to $1 \mu \mathrm{m}$ were synthesized by Ro et al. [118]. These films presented a porosity from $9 \%$ to $25 \%$, a pore size lower than $3 \mathrm{~nm}$, and a dielectric constant of 2.2 for the material with a porosity of $25 \%$ (a lower value than that of the solid, $k_{s}=2.7$ ). However, the mechanical properties of the nanoporous films must be improved, since the modulus of elasticity and the hardness decreased substantially with porosity ( $n \approx 4$, for both the elastic modulus and the hardness). 
Finally, polybenzoxazines (PBZZ) are also a novel material for use in microelectronics. This polymer is a newly developed high-performance thermoset that presents low moisture uptake and in some cases exhibits a glass transition temperature much higher than cure temperature. Su et al. [140] prepared closed-pore nanoporous PBZZ films (thickness between 0.125 and $0.75 \mathrm{~mm}$ ) with a porosity ranging from 5 to $25 \%$; $k$ from 3 to 1.95 , respectively (lower values than that of the solid, $k_{s} \approx 3.6$ ); pore sizes around $50 \mathrm{~nm}$; and a thermal stability around $340^{\circ} \mathrm{C}$.

Therefore, as expected theoretically, nanoporous polymers reduce the dielectric constant of the former solid by the introduction of a gas phase into the polymer matrix. Some of them (fluoropolymers, polyaryl ethers, polyimides, and polybenzoxazines with porosities higher than 0.2) manage to achieve the dielectric constant values demanded by the NTRS to be implanted in integrated circuits (see Fig. 16). Likewise, as shown in Fig. 17, in principle, the pore size has no influence on the dielectric constant of nanoporous materials, and the porosity is primarily responsible for the reduction in this parameter (see Figs. 15 and 16). However, the existence, or future appearance, of side effects due to the reduction of pore size to the nanoscale cannot be completely neglected, since some evidence of a possible modification of the capacity and conduction mechanisms in nanoporous polymers has been found when the pore size moves from the micrometer to the nanometer range [65].

However, properties such as moisture uptake, chemical stability, and dielectric breakdown must be studied, and other properties such as the mechanical behavior and thermal resistance need to be improved, so that the development of these polymeric systems becomes a reality (see Table 1).

The key to achieving low dielectric constant values involves increasing the porosity, which, given the size of the system (and therefore the size of the pores to be formed), implies extraordinarily high cell densities. This fact, as it was mentioned at the beginning of this review (see the Expected Cellular Structure section), is currently one of the main goals for nanoporous materials.

Furthermore, it has been demonstrated that pore size does not seem to provide an additional advantage to nanoporous systems; this is only a requirement imposed by the dimensions of the devices to be developed. Further studies are needed with materials both at the micrometer and nanometer ranges (and thus with thicker systems) to confirm whether there may be a positive or negative influence of the pore size on the dielectric properties of the porous material.

Thus, new nanoporous low- $k$ dielectric materials (both polymeric and non-polymeric) are actively being pursued. Low dielectric constants have been achieved, especially with materials with a porosity higher than $20 \%$. However, because of the strict requirements demanded, they have not yet been implemented in the field of microelectronics, since the requirements demanded in the year 2006 have not been reached yet.

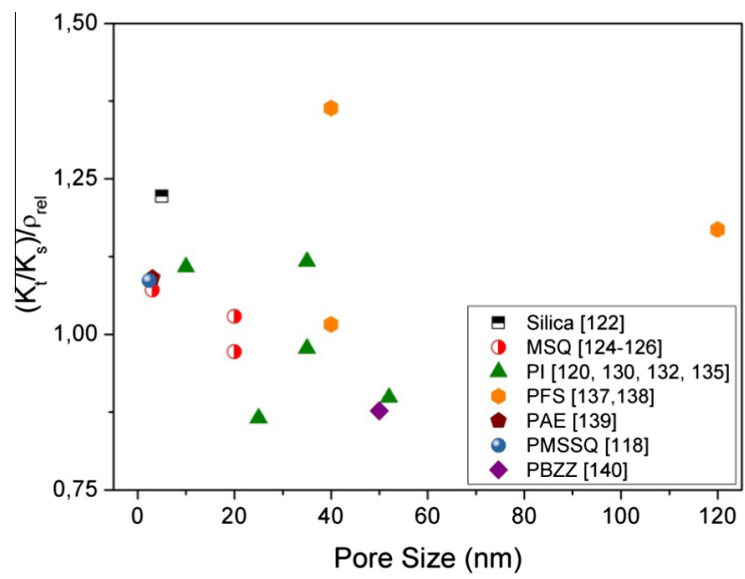

Fig. 17. Dielectric constant values of the foams normalized by the dielectric constant of the solid and divided by the relative density versus pore size for different nanoporous materials [118,120,122,124-126,130,132,135,137-140]. 


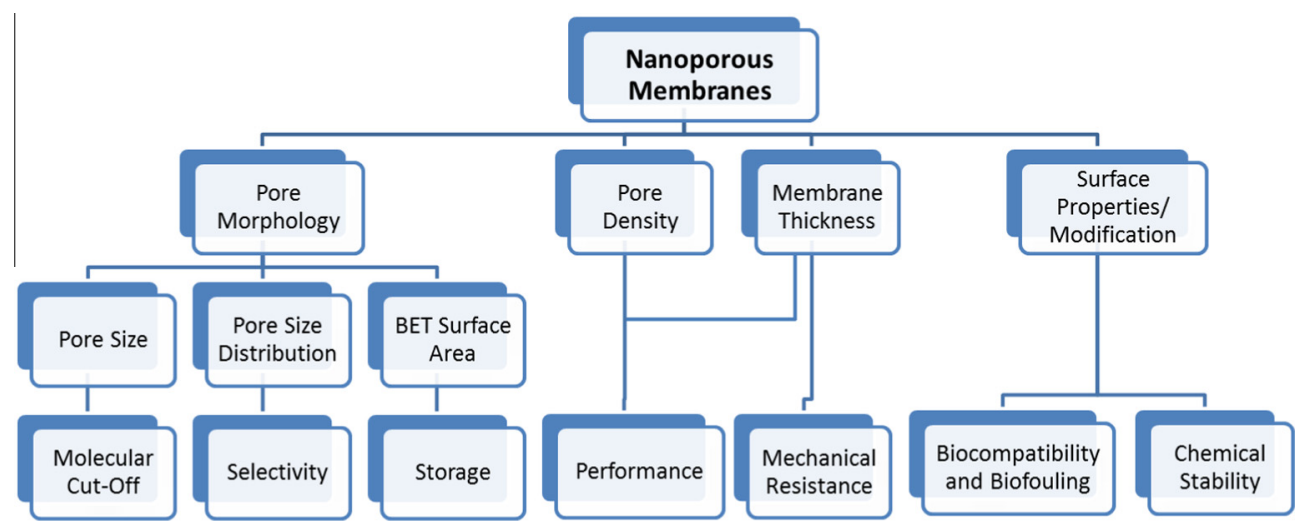

Fig. 18. Scheme of the main membrane features that influence performance.

\section{Filtration and membranes}

In recent years, the use of membranes developed using nanoporous materials and in particular nanoporous polymers has greatly increased in fields such as gas storage, tissue engineering, and water treatment, among others. The unique properties exhibited by nanoporous materials such as a large specific surface to volume ratio, a high inner surface area, or exclusive size sieving and shape selectivity, are some of the reasons that have led the industry and researchers to further develop these materials.

The successful design and application of a nanoporous membrane for a specific application depends on diverse critical membrane properties (see Fig. 18). First, the production of membranes with a specific pore size and a narrow pore size distribution will allow precise control over molecular sieving. Second, membranes with a high Brunauer-Emmett-Teller (BET) surface area will allow the storage of larger amounts of gas. Third, many applications required a low flow resistance to allow a high flux, which leads to high-porosity and low-thickness membranes. Fourth, an appropriate mechanical resistance, as well as good thermal and chemical stability in different environments, is crucial for longterm applications. Finally, for in vivo devices, good biocompatibility and good resistance against biofouling are essential to avoid immunological response and loss of functionality, respectively.

Several theoretical models for gas storage, gas permeation, or liquid flow across porous membranes have been developed over the years to study their behavior. There has been a resurgence in interest in hydrogen storage as a fuel owing to a decreased reliance on oil and to the potential need for a reduction in air pollution. However, before changing from petroleum to hydrogen, it is necessary to develop a suitable hydrogen storage mechanism that accomplishes the US Department of Energy (DOE) targets: gravimetric goals (net useful energy/max system mass) of $6 \mathrm{wt} . \%$ in the year 2010 and $9 \mathrm{wt} . \%$ in the year 2015 and volumetric goals (net useful energy/max system volume) of $1.5 \mathrm{~kW} h / 1$ in 2010 and $2.7 \mathrm{~kW} \mathrm{h/1} \mathrm{in} 2015$ [141]. Thus, several theoretical models have been developed in order to determine the main parameters that are going to govern the behavior of the system.

For instance, Cabria and coworkers [142] developed a quantum-mechanical and thermodynamical theoretical model to determine the optimal pore size for hydrogen storage in carbon nanoporous materials, in which the porosity and membrane thickness are not taken into account. This model, developed for the storage of hydrogen in slitpores, predicts that a material with a pore width equal to or larger than $5.6 \AA$ can reach the DOE goals for the year 2010 for applications at low temperatures $(77 \mathrm{~K})$ and at any pressure. For applications at $300 \mathrm{~K}$ and at least $10 \mathrm{MPa}$, the width of the pore should be about 6 A. This model was corroborated with experimental data presented in the literature for carbon-based materials, which showed a good agreement between the theoretical prediction and the experimental values.

Similarly, Bénard et al. [143] studied the physisorption of hydrogen on activated carbon (AC) nanoporous structures with slitpores (pore width varying from 0.9 to $2 \mathrm{~nm}$ ) by means of the Ono-Kondo 
adsorption isotherm model [144], in which the porosity and membrane thickness are neglected. Theoretical results showed that AC slitpores with a width higher than $1 \mathrm{~nm}$ show a maximum absorption around $7 \mathrm{wt} . \%$ at $77 \mathrm{~K}$ and $4 \mathrm{MPa}$ (a value higher than that required by the DOE in 2010).

In the case of gas diffusion, the Knudsen number (i.e., the ratio between the mean free path and the pore diameter $\left.\left(l_{g} / \Phi\right)\right)$ will determine the mechanism of gas permeation [145]. If the pores are in the range of 5-20 $\AA$, the gases will be separated by molecular sieving (see Fig. 19, surface diffusion). This type of transport is complex and includes both diffusion in the gas phase and diffusion of adsorbed species on the surface of the pores.

If the mean free path of the gas is comparable with the pore diameter (Knudsen number around 1), transport is the result of collisions between the pore walls and the diffusing gas molecules (Knudsen diffusion [146,147], Fig. 19). The gas flow of a membrane in the Knudsen regime is given by

$$
J=\frac{V_{g} \cdot\left(P_{0}-P_{l}\right)}{\tau \cdot l \cdot R T} \cdot 0.33 \Phi \sqrt{\frac{8 R T}{\pi M_{\text {gas }}}}
$$

where $J$ is the gas flux through a membrane with a pore diameter $\Phi$ and a thickness $l$ under a pressure difference $\left(P_{0}-P_{l}\right), V_{g}$ is the porosity, $R$ is the gas constant, $T$ is the temperature, $M_{g a s}$ is the molecular weight of the gas, and $\tau$ is the tortuosity in the gas phase (as defined previously in Section 1.3).

However, when the mean free path of the molecules is much smaller than the pore size (a small Knudsen number), transport is the result of random collisions between them. In this situation, gases permeate the membrane by convective flow (see Fig. 19), as described by Poiseuille's law [147]:

$$
J=\frac{V_{g} \Phi^{2}}{32 \eta} \frac{\left(P_{0}-P_{l}\right)\left(P_{0}+P_{l}\right)}{l \cdot R T}
$$

where $\eta$ is the viscosity of the gas and $\left(P_{0}+P_{l}\right)$ is a term that takes into account the expansion of the gas when it moves under a pressure gradient.

For instance, the low pressure transport of gases such as $\mathrm{H}_{2}, \mathrm{He}, \mathrm{N}_{2}$, and $\mathrm{Ar}$, among others, was modeled by Bhatia [148] in nanoporous membranes through an oscillator theory developed for cylindrical pores (pore diameters from 0.5 to $2.5 \mathrm{~nm}$, corresponding to Knudsen diffusion transport). With

\section{Porous membranes}

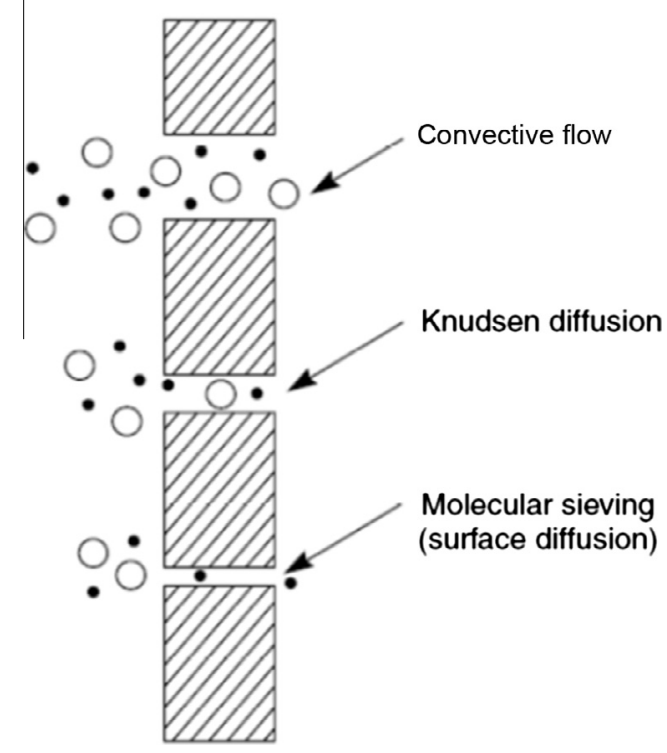

Fig. 19. Different mechanism for permeation of gases through porous membranes adapted from [145]. 

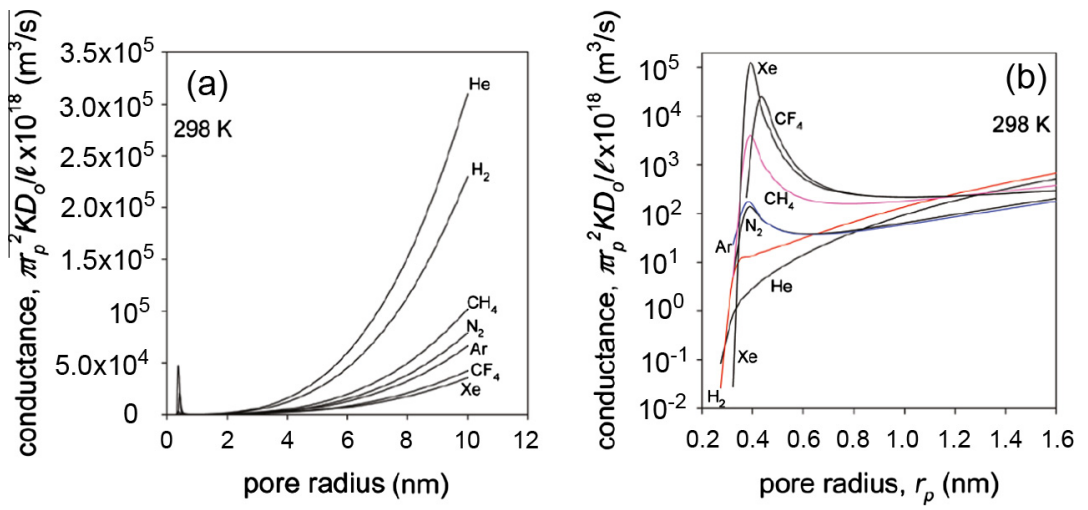

Fig. 20. Variation of pore conductance as a function of pore radius: (a) pore radius varying from 0 to $12 \mathrm{~nm}$ and (b) zoom view over the pore radius range of $0.2-1.6 \mathrm{~nm}$. In the figure, $r_{p}$ represents the pore radius, $K$ is the Boltzmann constant, $D_{0}$ is the diffusion coefficient, and $l$ is the pore length. The figure has been included with permission from Bhatia [148].

this model, it was demonstrated that the Knudsen approximation represents an upper bound in the diffusivity of gases. However, they showed that, as the pore size increases, the conductance (defined in terms of the diffusivity, as shown on the $y$ axis of Fig. 20) of gases increases, since the gas molecules have more space to pass through the membrane (see Fig. 20), which reduces the molecular sieving. In Fig. 20(b), a sharp maximum around $0.4 \mathrm{~nm}$ is observed. This effect is known as the levitation effect and is discussed elsewhere [149,150]. Furthermore, a good correlation was obtained when the model was applied to permeability literature data from a zeolite membrane with a porosity of around $21 \%$ and a pore diameter lower than $1 \mathrm{~nm}$. In addition, the model provides an expression for the tortuosity, showing that it can increase or decrease with the uniformity of the pore size distribution as well as with the temperature, because gases preferentially flow through more conducting pores. Thus, in this application, tortuosity does not depend exclusively on structural parameters.

However, a good correlation between the experimental diffusivities of gases ( $\mathrm{He}, \mathrm{N}_{2}, \mathrm{O}_{2}$, and $\mathrm{Ar}$ ) and the Knudsen diffusion equation was obtained by Phillip et al. [151] in nanoporous PS membranes with a porosity of $26 \%$, cylindrical nanopores with an average diameter of $17 \mathrm{~nm}$, and a membrane thickness of $0.3 \mu \mathrm{m}$. They also showed that the diffusion coefficients calculated from classical kinetic theory overestimates the diffusivity values expected by $7 \%$.

In the case of liquid flow through a nanoporous membrane, different theoretical models have been developed to analyze the liquid transport according to different pore geometries. In general, most of the models describe the membranes as a series of cylindrical capillary pores of diameter $\Phi$. The liquid flow through a pore with this geometry is given by the Hagen-Poiseuille's equation [146] as follows:

$$
J=\frac{V_{g} \Phi^{2}}{32 \mu \cdot \tau \cdot l} \Delta P
$$

where $\Delta P$ is the pressure difference through the pore, $\mu$ is the liquid viscosity, and $l$ is the pore length.

Another important parameter that must be taken into account in liquid transport is the diffusivity. In general, in a porous membrane, the effective diffusion coefficient $D_{\text {eff }}$ is related to the diffusion coefficient in free solution $D_{0}$ as follows [152]:

$$
D_{\text {eff }}=\frac{D_{0} V_{g} \delta}{\tau}
$$

where $\delta$ is a constrictivity factor that accounts for the constricted transport paths caused by the small pores and takes values $\leqslant 1$, whereas $\tau$ is the tortuosity in the gas phase and takes values $>1$.

The diffusion permeability of different solutes (antibiotics, proteins, and several biomolecules) across gyroid nanoporous 1,2-polybutadiene (1,2-PB) membranes was studied by Li et al. [153] using Eq. (18). These membranes, which presented pore sizes around $10 \mathrm{~nm}$, porosities around $40 \%$, and membrane thicknesses of $20 \mu \mathrm{m}$, exhibited different diffusion rates depending on the solute (from 
$10^{-6}$ in the case of glucose to $10^{-9}$ in the case of cytochrome C). Furthermore, the constrictivity factor was calculated from the experimental results obtained for $D_{\text {eff }}$ according to Eq. (18), showing that, apart from size exclusion, there are other factors that strongly affect the diffusion of molecules through nanoporous membranes such as solute-solute and solute-membrane interactions (electrostatic, hydrophobic, charge transfer, or hydrogen bonding interactions).

Adiga and coworkers [154] reviewed the basic mechanisms underlying liquid transport in nanoporous membranes with cylindrical nanopores for biomedical applications. In this case, two different expressions were proposed for the effective diffusion coefficient of rigid molecules:

$$
\begin{aligned}
& \frac{D_{e f f}}{D_{0}}=\frac{\left(1-\frac{\Phi_{s}}{\Phi}\right)^{2}}{\left(1+2.4 \frac{\Phi_{s}}{\Phi}\right)} \\
& \frac{D_{e f f}}{D_{0}}=\left(1-\frac{\Phi_{s}}{\Phi}\right)^{2}\left(1-2.104 \frac{\Phi_{s}}{\Phi}+2.09 \frac{\Phi_{s}{ }^{3}}{\Phi}-0.95 \frac{\Phi_{s}{ }^{5}}{\Phi}\right)
\end{aligned}
$$

where $\Phi_{s}$ represents the solute diameter. Eq. (19) [155] is normally used when the molecules have to pass through very tiny pores, while Eq. (20) [156] is more commonly used and gives accurate results when $D_{\text {eff }} / D_{0}<0.4$.

Finally, the water transport through nanoporous PS membranes was analyzed by Phillip et al. [151] by means of the Hagen-Poiseuille's law. These membranes possessed a porosity of $26 \%$, nanopores with a cylindrical pore morphology and an average pore diameter of $17 \mathrm{~nm}$, and a thickness of $0.3 \mu \mathrm{m}$. This system showed that the flow of water in the nanopores was consistent with the Hagen-Poiseuille's equation.

Therefore, theoretical models developed for both nanoporous polymeric materials and other nanoporous systems seem to describe the gas storage or fluid transport (both gas and liquid) of solutes through nanoporous membranes accurately. Furthermore, all of them seem to agree that a reduction in the pore size implies an increase either in the gas storage capacity or in molecular sieving. These expected improvements have been experimentally demonstrated both in polymeric materials and in other systems such as carbon, silicon, and alumina. The results concerning the latter will be described briefly below for comparison with the results obtained with polymeric materials.

Gas storage (in particular hydrogen storage) in porous materials such as zeolites, carbon materials, and metal-organic frameworks (MOFs) has been widely studied [157,158]. Morris and coworkers [157] compared the hydrogen adsorption capacity of different nanoporous systems such as zeolites, MOFs, and carbon materials using literature data (see Fig. 21), showing that the higher the BET surface area, the higher the amount of $\mathrm{H}_{2}$ adsorbed. The same result was obtained by Thomas [158], who found that the porosity and the BET surface area have the most influence on the maximum hydrogen

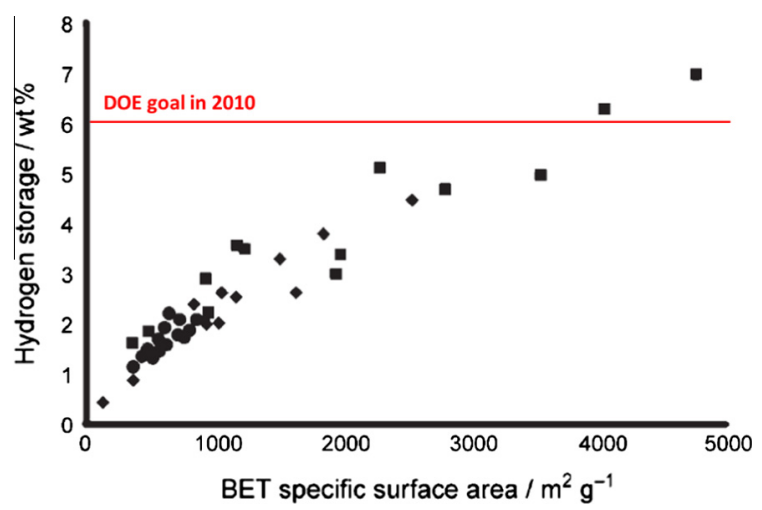

Fig. 21. Maximum $\mathrm{H}_{2}$ adsorption capacity at different pressures and temperatures as a function of the BET surface area for porous materials: zeolites $(\bullet)$, MOFs $(\boldsymbol{\square})$, and carbon materials $(\bullet)$. This figure has been adapted from Morris and Wheatley [157]. 
uptakes of all porous materials. Therefore, if one could obtain very high surface areas and high porosity simultaneously, a significantly increased adsorption would occur. Likewise, Fig. 21 illustrates that the only materials that are able to reach the requirements demanded by the DOE in 2010 are the MOFs.

Membrane-based gas separation currently involves innovative nanoporous membrane systems such as carbons [159-161], alloys [162], carbon/silica [163], zeolites [164,165], and crystalline aerogels [166]. For instance, Park and Lee [163] studied the permeability of several gases $\left(\mathrm{H}_{2}, \mathrm{He}, \mathrm{CO}_{2}\right.$, $\mathrm{O}_{2}, \mathrm{~N}_{2}$, etc.) through a nanoporous carbon/silica membrane (thickness: $25-30 \mu \mathrm{m}$; porosity and pore size: not specified), showing improved $\mathrm{O}_{2} / \mathrm{N}_{2}$ and $\mathrm{CO}_{2} / \mathrm{CH}_{4}$ selectivity (around $2.3 \%$ and $5 \%$, respectively) with respect to polymeric membranes and an improved $\mathrm{C}_{2} \mathrm{H}_{4} / \mathrm{C}_{2} \mathrm{H}_{6}$ selectivity around $0.7 \%$ for carbon membranes. In addition, the $\mathrm{O}_{2} / \mathrm{N}_{2}$ selectivity was also 3.3 times higher than that obtained byShiflett andFoley [159] in a nanoporous $C$ membrane (porosity: 20\%; thickness: $8-23 \mu \mathrm{m}$; pore size: $0.3-0.7 \mathrm{~nm}$ ). Differences in porosity, membrane thickness, and pore size could be the reasons underlying this phenomenon.

Nanoporous membranes for liquid transport or filtration have been also manufactured from a wide variety of materials [167]: alumina [168-171], silicon [172], SiC [173], silica [174], carbon [161], nanoporous crystalline aerogels [166], etc. Thormann et al. [171] observed that the flow rate of ethanol in nanoporous alumina membranes increased both with larger pore diameters and with thinner samples. However, the superior adsorptive behavior of bulky dyes (10 times higher in the best case) compared to commercial AC was found by Han and coworkers [161] in nanoporous carbon membranes. The high pore volumes and the high surface areas could be the reasons underlying this improvement.

Thus, gas storage and solute transport enhancement through non-polymeric nanoporous membranes are well established both theoretically and experimentally. Although the aforementioned porous materials present good properties for membranes in general, the ease of manufacturing, the superior flexibility, the good biocompatibility, and the tailored thermal, mechanical, and chemical properties with different synthetic approaches make nanoporous polymers excellent materials for filtration.

In the case of hydrogen adsorption, the major drawbacks of porous polymers are the relatively restricted number of synthetic strategies to achieve polymers with high surface areas $\left(>1000 \mathrm{~m}^{2} / \mathrm{g}\right.$ ) and the difficulty to achieve pores with sizes ideally lower than $2 \mathrm{~nm}$. However, new systems, such as polymers of intrinsic microporosity (PIMs) (rigid macromolecules that form nanoporous organic materials because of their inability to pack space efficiently [175]) [176-179], hypercrosslinked polymers [180-182], amorphous conjugated microporous polymers (CMPs) [183], and polymeric cocrystalline forms [184], have emerged to overcome these problems. For instance, McKeown et al. [176] and later Budd and coworkers [177] developed different PIMs systems with pore widths between 0.6 and $0.7 \mathrm{~nm}$ (the density and membrane thickness were not specified). These systems exhibited BET surface areas around $1050 \mathrm{~m}^{2} / \mathrm{g}$ (in the best case) and $\mathrm{H}_{2}$ uptakes up to $1.8 \mathrm{wt} . \%$ at $77 \mathrm{~K}$ and 1 bar, or up to $2.7 \mathrm{wt} . \%$ at $77 \mathrm{~K}$ and 10 bar. Similar values were achieved by Ghanem et al. [178], who prepared a triptycene-based PIM polymer membrane with pore widths around $0.6 \mathrm{~nm}$ (the porosity and membrane thickness were not specified). This material presented a BET value around $1065 \mathrm{~m}^{2} / \mathrm{g}$ and $\mathrm{H}_{2}$ uptakes up to $1.65 \mathrm{wt} . \%$ at $77 \mathrm{~K}$ and 1 bar or up to $2.7 \mathrm{wt} . \%$ at $77 \mathrm{~K}$ and 10 bar.

The $\mathrm{H}_{2}$ storage capacity of hypercrosslinked PS nanoporous membranes with pore widths around $4 \mathrm{~nm}$ were analyzed by Germain et al. [180] (the porosity and membrane thickness were not specified). In this case, BET surface areas up to $1200 \mathrm{~m}^{2} / \mathrm{g}$ and $\mathrm{H}_{2}$ uptakes up to $1.3 \mathrm{wt} . \%$ at $77 \mathrm{~K}$ and 1 bar were obtained. These results are consistent with those obtained by Lee et al. [181] in hypercrosslinked nanoporous PS (a broad pore size width distribution centered around $0.7 \mathrm{~nm}$ ), which showed BET surface areas around $1466 \mathrm{~m}^{2} / \mathrm{g}$ and $\mathrm{H}_{2}$ uptakes up to $1.3 \mathrm{wt} . \%$ at $77 \mathrm{~K}$ and 1 bar or up to $2.7 \mathrm{wt} . \%$ at $77 \mathrm{~K}$ and 10 bar. In both cases, the values reached were lower than in the case of nanoporous PIMs.

Although these results are promising, there are fewer studies on nanoporous membranes than on the best carbon-based materials (see Fig. 22). However, the $\mathrm{H}_{2}$ sorption capacity measured for these nanoporous polymers at 1 bar is comparable with that reported for AC and MOFs of equivalent surface areas and similar pore volumes. Thus, if the BET values could be increased, then the $\mathrm{H}_{2}$ capacities could be similar. 


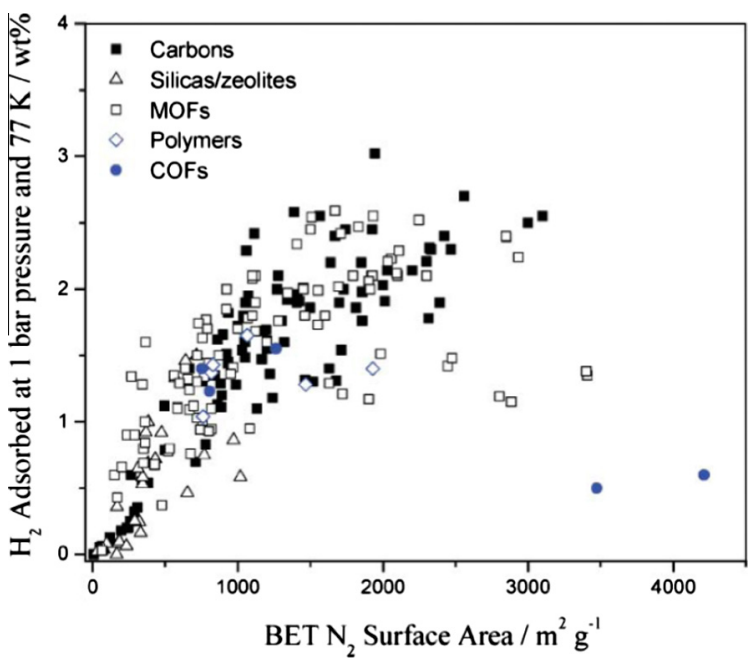

Fig. 22. Hydrogen adsorption at 1 bar and $77 \mathrm{~K}$ versus BET surface area for different nanoporous materials: carbon, silicas/ zeolites, polymers, COFs, and MOFs. This figure is included with permission from Thomas [158].

Polymeric membranes have traditionally had limited application to gas and liquid transport because of the wide distribution of pore sizes achieved, which leads to a broad molecular weight cut off. However, the ion track etching technique and, more recently, the block copolymer approach [185] have allowed the manufacture of nanoporous polymeric membranes with narrow pore size distributions and higher pore densities.

The gas and liquid transport of polydicyclopentadiene nanoporous membranes with a porosity of $40 \%$, a pore size around $14 \mathrm{~nm}$, and a membrane thickness of $100 \mu \mathrm{m}$ was studied by Phillip et al. [186]. The effective diffusion coefficients obtained varied according to the gas employed: for instance, it was $0.0184 \mathrm{~cm}^{2} / \mathrm{s}$ for $\mathrm{H}_{2}$ or $0.0047 \mathrm{~cm}^{2} / \mathrm{s}$ for Ar. These results were in good agreement with those predicted by Knudsen diffusion. These membranes presented a more precise molecular weight cut off (MWCO) for liquid transport of dextrans than phase inversion membranes. Nevertheless, the water flux values obtained at $30 \mathrm{kPa}\left(1 \cdot 10^{-6} \mathrm{~m}^{3} / \mathrm{m}^{2} \mathrm{~s}\right)$ were smaller than the typical flux values of commercial phase inversion membranes (between $3 \cdot 10^{-5}$ and $4 \cdot 10^{-4} \mathrm{~m}^{3} / \mathrm{m}^{2} \mathrm{~s}$ ). However, this water flux was greater than that achieved in the same conditions by the same author [187] using a nanoporous PS membrane (water flux $\approx 0.67 \cdot 10^{-7} \mathrm{~m}^{3} / \mathrm{m}^{2} \mathrm{~s}$ ) with a porosity of $27 \%$, a pore size around $24 \mathrm{~nm}$, and a thickness of $4 \mu \mathrm{m}$. The differences in porosity and pore size could be the reasons for this difference.

$\mathrm{CO}_{2}$ diffusivity through $50-\mu \mathrm{m}$-thick syndiotactic PS (s-PS) films (porosity $=7 \%$; pore size $\approx 1 \mathrm{~nm}$ ) was studied by Milano and Guerra [188], who obtained diffusivity values around $10^{-8} \mathrm{~cm}^{2} / \mathrm{s}$.

The liquid transport across nanoporous PS membranes has been widely analyzed in several works [187,189-191]. For instance, Yang and coworkers [189] created a PS nanoporous membrane with cylindrical pores (diameters around $15 \mathrm{~nm}$ ), a porosity around 20\%, and a membrane thickness of $100 \mathrm{~nm}$. This system, which was supported on a polysulfone (PSU) membrane, showed ultrahigh selectivity and flux for the separation of viruses $\left(\approx 12 \cdot 10^{-6} \mathrm{~m}^{3} / \mathrm{m}^{2} \mathrm{~s}\right.$, a value 10 times higher than that obtained with a PC membrane). Later, good dimensional stability under high pressures and excellent solvent resistance was also reported for the same type of nanoporous membranes for virus filtration [190].

A novel approach using flash freezing was developed by Samitsu et al. [192] to produce nanoporous polymer (PS, PC, polyvinyl chloride (PVC), etc.) nanofiber networks with pore diameters ranging from 12 to $21 \mathrm{~nm}$ (the porosity was only specified for the PS system and was equal to 56\%). These nanoporous polymers were able to separate toluene from aqueous solutions a few tens of ppm in concentration and could also adsorb a significant quantity of tetrahydrofuran from aqueous solution. However, 

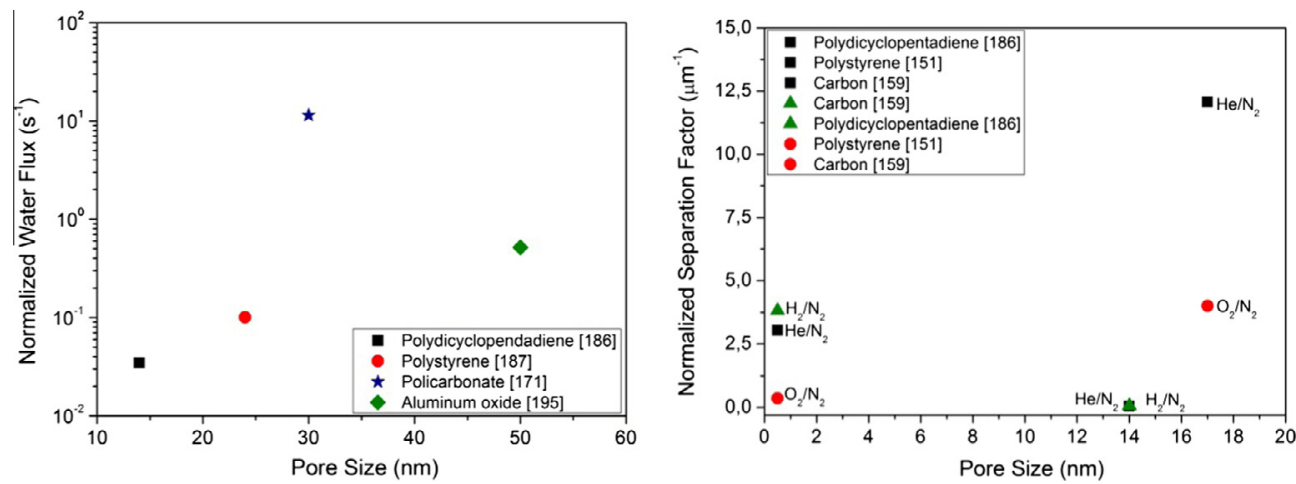

Fig. 23. Left: Normalized water flux measured at 1 bar for different polymeric and non-polymeric nanoporous membranes [171,186,187,195]. Right: Normalized separation factor for different polymeric and non-polymeric nanoporous membranes $[151,159,186]$.

the mechanical stability of these porous systems was poor compared to that of the solid $(n=3$ for the Young modulus of the PS system).

Other nanoporous polymeric systems such as polyimide [193], polyethylene [194], or polycarbonate (PC) [195] have also been investigated. Smuleac and coworkers [195] developed a nanoporous track-etched PC membrane (pore size: $30-100 \mathrm{~nm}$; porosity: $0.47 \%$; membrane thickness: $6-10 \mu \mathrm{m}$ ) which showed higher water fluxes (measured at 0.8 bar) as the pore size increased: $250 \cdot 10^{-2} \mathrm{~m}^{3}$ | $\mathrm{m}^{2} \mathrm{~s}$ for a pore size of $100 \mathrm{~nm}$ and $42 \cdot 10^{-2} \mathrm{~m}^{3} / \mathrm{m}^{2} \mathrm{~s}$ for a pore size of $30 \mathrm{~nm}$. Furthermore, they also demonstrated that the MWCO of $\mathrm{Na}_{2} \mathrm{SO}_{4}$ salt was higher in the membranes with lower pore sizes (a difference up to $800 \%$ for a feed concentration of $2 \mathrm{mM}$ ).

In conclusion, theoretical models for gas storage and solute transport (both gas and liquid) are well established both in polymeric and non-polymeric nanoporous membranes. All models agree that a reduction in pore size leads to enhanced storage and filtration capacities.

According to the results, the amount of gas stored, in particular of $\mathrm{H}_{2}$, in nanoporous polymers is far from values obtained with porous carbon-based systems. However, if it is possible to increase the BET specific surface area of polymeric materials by optimizing the current production processes or developing new ones, it will be possible to achieve higher values of hydrogen uptake. This opens a new line of research into the use of polymers as gas storage devices.

Fig. 23 illustrates a comparison of the normalized water flux and gas separation values obtained with polymeric and non-polymeric nanoporous membranes (not all results of the articles mentioned in this review are included, since many of them do not give a porosity value). In both cases, the values obtained have been divided by the membrane thickness and by the relative density in order to observe only the influence of the pore size on solute transport. With the exception of some cases, solute transport (both gas and liquid) increases as pore size increases, independent of the material used. Thus, the technical requirements of each application will determine what type of material (polymeric or not) is most appropriate. In this situation, the mechanical, thermal, and chemical resistances will play an important role.

Therefore, according to the theoretical and experimental results, nanoporous polymers could achieve filtration and gas storage performances similar to those of non-polymeric materials as long as they exhibit similar structural parameters: porosity, pore size, a narrow pore size distribution, a high BET specific surface area, etc. Even though they have not yet reached those yields, nanoporous polymers present other advantages (ease of manufacturing, superior flexibility, good biocompatibility, and tailored thermal, mechanical, and chemical properties). Furthermore, recently, nanoporous polymeric materials with acceptable structures (a Knudsen number around 1 for Knudsen diffusion) have begun to be developed by physical processes (the gas dissolution foaming process [60]). However, more work is needed to obtain finer porous structures and to carry out experimental measurements to confirm their applicability. 


\section{Other properties (sensors and optical and multifunctional materials)}

Apart from all the aforementioned features of nanoporous polymers, there other properties of emerging interest, such as sensing or optical properties, and uses of these materials as multifunctional materials.

There are two main sensor applications for which nanoporous materials have been studied: the stabilization of enzymes (biosensors) and humidity detection (humidity sensors).

In the field of biosensors, the stabilization of enzymes is crucial for the development of more reliable analytical devices. Several stabilization approaches (use of additives [196], covalent bonding on solid materials [197], or entrapment in different solid matrices [198]) have been developed for this purpose, and all of them are based on increasing the rigidity of the enzyme by reducing its tendency to open out. Recently, theoretical studies [199] have suggested that this tendency to unfold can also be avoided by introducing the enzyme within very small pores. In this case, the unfolded configurations of the enzyme are not thermodynamically favored. According to theoretical results, the maximum stabilization of enzymes occurs with pores with a spherical morphology whose size is 2-6 times the diameter of the original enzyme. Considering that the diameter of such a protein is about $10 \mathrm{~nm}$, it can be demonstrated that nanoporous materials are a perfect fit for this application.

This theoretical approach has been experimentally demonstrated in non-polymeric nanoporous materials (mainly carbon materials); however, because of the novelty of polymer-based materials, there is a lack of studies specifically on polymers (both theoretical and experimental). In any case, results concerning nanoporous carbons will be briefly summarized to give an idea of the initial results that have been obtained to date.

For instance, Sotiropoulou and coworkers [200] were able to decrease the leaching rate of the protein $m$-AChE (2.5 and 11.5 times lower than the free enzyme for AC and silica beads, respectively) and increase the operational stability of the resulting sensor by using two different nanoporous systems: activated carbons (pore size: $100-300 \mathrm{~nm}$; thickness: $0.1 \mathrm{~mm}$; porosity: not specified) and porous silica beads (pore diameter: $10 \mathrm{~nm}$ ). The lower pore diameter of the silica beads could justify the higher performance obtained. Other authors such as Gavalas and Chaniotakis [201,202] and Sotiropoulou et al. [203] studied the effect of introducing a mediator (fullerenes, diethylaminoethyl-dextran, and carbon nanotubes) into a nanoporous carbon matrix (porous structure parameters were not specified in detail) to improve the capacity to immobilize enzymes (glucose, lactate oxidase, and peroxide). In all cases, the use of a mediator led to an enhanced enzyme stabilization capacity.

Thus, experimental results on nanoporous carbon materials are in agreement with theoretical predictions, showing that the use of nanoporous materials may be very useful for the development of biosensors. However, further theoretical and experimental studies are needed, particularly for polymers, to show whether these nanoporous systems are suitable for the development of biosensors.

The use of humidity sensors for moisture detection is widespread in applications such as meteorological service, food processing, air conditioning, or electronics processing. Currently, most typical sensors have varying resistivity and capacity values with water adsorption. Nanoporous materials, characterized by a high surface-area-to-volume ratio, are a promising humidity sensor, since they can accurately detect resistance and/or capacitance changes owing to water adsorption inside the nanopores. Furthermore, nanoporous materials allow the optimization of the pore size according to the specific working conditions (temperature and relative humidity) in order to obtain the maximum performance of the sensor. For this purpose, the optimum pore size diameter can be calculated using Kelvin's relation [204]:

$$
\Phi=\frac{4 \gamma_{L} V}{R T \log \left(P / P_{S}\right)}
$$

where $P / P_{S}$ represents the relative humidity, $\gamma_{L}$ is the water surface tension, $R$ is the universal gas constant, $T$ is the temperature in $\mathrm{K}$, and $V$ is the volume of water.

For instance, Varghese and coworkers [205] studied the effect of pore size on the response of a nanoporous alumina sensor (pore size: $13-45 \mathrm{~nm}$; porosity and thickness: not specified) to humidity. They observed that, as the pore size increased, the humidity range over which the sensors had high 
sensitivity decreased (see Fig. 24). Fig. 24 shows that the humidity range for the porous material with a pore size of $13.6 \mathrm{~nm}$ ranged from $20 \%$ to $90 \% \mathrm{RH}$, whereas this range was reduced to $65-75 \% \mathrm{RH}$ for the nanoporous materials with pore sizes greater than $38.4 \mathrm{~nm}$.

Thus, the theoretical basis underlying the use of nanoporous materials as humidity sensors has been established, though the number of theoretical works is still low, especially for polymeric systems. Although the sensory characterization of nanoporous polymeric materials is a recent topic, there are other experimental works related to the use of different nanoporous systems based on ceramics, which will be discussed below briefly for comparison.

The use of nanoporous ceramics as humidity sensors has been studied extensively in recent years [206-209] because of their high thermal capacity to withstand thermal fluctuations as well as their high capacity to operate under harsh environments. Nitta and Hayakawa [206] developed a resistive nanoporous ceramic sensor (formula $\mathrm{MgCr}_{2} \mathrm{O}_{4}-\mathrm{TiO}_{2}$ ) with a porosity between $30 \%$ and $40 \%$, a pore size ranging from 10 to $30 \mathrm{~nm}$, and a thickness of $200 \mu \mathrm{m}$. These sensors exhibited a sensitivity around $0.22 \mathrm{M} \Omega / \%$ relative humidity ( $\mathrm{RH}$ ) with a high linear response for the $1-90 \% \mathrm{RH}$ range. In addition, two different nanoporous capacitive sensors, polysilicon and silicon carbide, were produced by Connolly et al. [207], with thicknesses of 0.4 and $0.5 \mu \mathrm{m}$, respectively (the porosity and pore size were not specified in the article). In this study, the normalized sensitivity capacity was higher for the nanoporous polysilicon system $(0.025 / \% \mathrm{RH})$ than for the SiC system $(0.01 / \% \mathrm{RH})$ in the $10-90 \% \mathrm{RH}$ range. Differences in the pore size and porosity could be the reasons underlying this effect.

In general, the experimental results in nanoporous systems (at least in ceramics) indicated good moisture sensing capacity with the reduction of the pore size to the nanometer scale. Although there are several works showing this effect in ceramic systems, to date there has been only one experimental work related to the sensing behavior of nanoporous polymers because of the novelty of the use of nanoporous materials, and particularly of nanoporous polymers, as sensors.

Yang et al. [210] designed various types of resistive nanoporous polymer humidity sensors such as polycarbonate (pore size: $200 \mathrm{~nm}$; thickness: $10 \mu \mathrm{m}$; porosity: not specified), cellulose acetate (pore size: $200 \mathrm{~nm}$; thickness: $125 \mu \mathrm{m}$; porosity: 66\%), and nylon (pore size: $100 \mathrm{~nm}$; thickness: $110 \mu \mathrm{m}$; porosity: 55\%). A highly linear response over a range of $40-100 \% \mathrm{RH}$ with a sensitivity around $20 \mathrm{G} \Omega / \%$ RH was obtained for nanoporous cellulose acetate and nylon systems. The response of PC was also linear for the same range of humidity, but the sensitivity value obtained was lower at around $4.5 \mathrm{G} \Omega / \% \mathrm{RH}$ (4.5 times lower than that obtained for the other porous polymers analyzed). Different porosities, thicknesses, and hydrophobicity values could be the reasons for this difference. However, even in the worst case, the sensitivity values obtained were better than those obtained by Nitta and
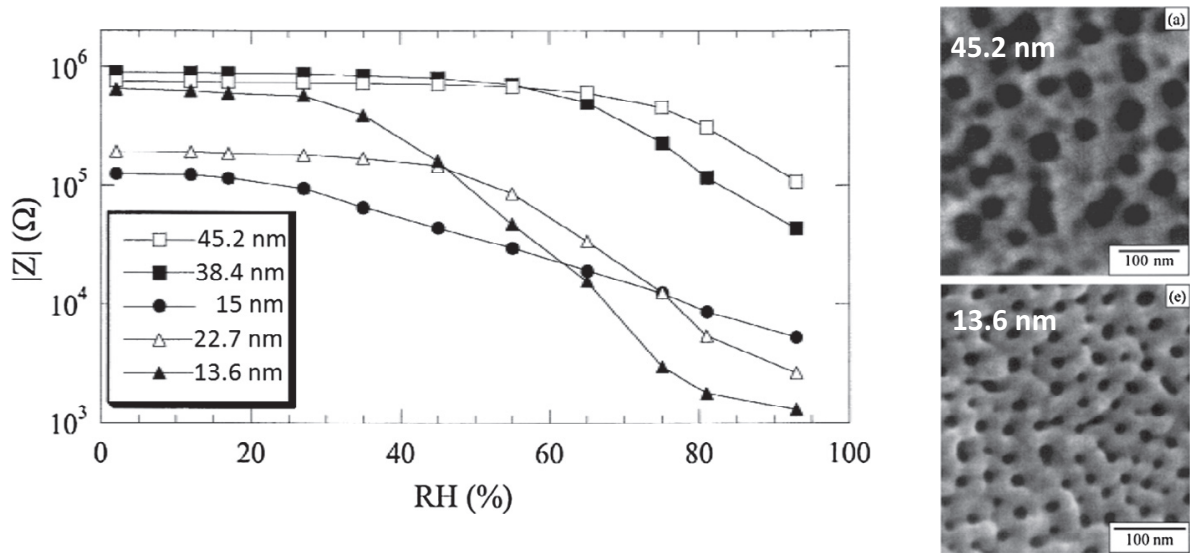

Fig. 24. Effect of pore size on the impedance of nanoporous alumina sensors measured at $5 \mathrm{kHz}$ over different humidity levels. This figure has been adapted from Varghese et al. [205]. 
Table 2

Different effective medium approximations developed for the calculation of the effective index of refraction $\left(n_{\text {eff }}\right)$, where $n_{s}$ is the refractive index of the solid, $n_{g}$ is the refractive index of the gas, and $V_{g}$ is the porosity.

\begin{tabular}{|c|c|c|c|}
\hline & Maxwell-Garnet Theory (MGT) [222] & Parallel model & Serial model \\
\hline \multirow[t]{2}{*}{$n_{\text {eff }}=$} & $n_{s}\left[1-\frac{3 V_{g}\left(n_{s}^{2}-n_{g}^{2}\right)}{2 n_{s}^{2}+n_{g}^{2}+V_{g}\left(n_{s}^{2}-n_{g}^{2}\right)}\right]^{1 / 2}$ & $\left(1-V_{g}\right) n_{s}+V_{g} n_{g}$ & {$\left[\frac{1-V_{g}}{n_{s}}+\frac{V_{g}}{n_{g}}\right]^{-1}$} \\
\hline & $\begin{array}{l}\text { Reciprocity model [223] } \\
n_{s} \frac{1+V_{g}\left(\sqrt{\frac{n_{s}}{n_{g}}}-1\right)}{1+V_{g}\left(\sqrt{\frac{n_{g}}{n_{s}}}-1\right)}\end{array}$ & \multicolumn{2}{|c|}{$\begin{array}{l}\text { Volume Averaging Theory (VAT) }[224,225] \\
{\left[\left(1-V_{g}\right) n_{s}^{2}+V_{g} n_{g}^{2}\right]^{1 / 2}}\end{array}$} \\
\hline
\end{tabular}

Hayakawa [206] using a nanoporous ceramic (three orders of magnitude more sensitive). The higher porosity of nanoporous polymers could be the explanation for this difference.

Therefore, nanoporous polymers seem to exhibit better humidity detection capacity than nanoporous ceramics. Nevertheless, the number of theoretical and experimental works on either polymeric or non-polymeric materials is still limited. Thus, further studies are needed in order to determine whether nanoporous systems are actually appropriate for moisture sensors.

Last, but not least important, are nanoporous cocrystalline polymers, which seem to be good candidates for sensing elements in gravimetric sensors. These materials can detect organic compounds or low-molecular-mass substances present in gaseous and liquid environments. For instance, Pilla et al. [211] showed how 1- $\mu \mathrm{m}$-thick s-PS films (porosity: 7\%; pore size: not specified) can work as gravimetric sensors for the detection of chloroform in both vapor and liquid phases.

In the field of optics, the demand for materials with a low refractive index ( $n$ ) has promoted great efforts to study the applicability of porous materials as waveguides [212,213], Fabry-Perot filters [214-216], Bragg reflectors [216,217], and antireflection coatings [218]. Porous materials can possess a very low value of $n$ because of the introduction of air, which has a refractive index of $n=1$. In this case, nanoporous materials are in demand because of the reduced dimensions of manufactured devices, where the pores must be much smaller than the thickness of the film. However, unlike dielectrics, in which the use of nanoporous materials is determined exclusively by the dimensions of the device, nanoporous materials for optics provide another advantage: if the pore size is much smaller than the wavelength of light, then light scattering from the pores is reduced [219]. Using this theoretical assumption, it has been speculated that nanoporous materials produced from amorphous polymers with a well-defined pore structure and pore sizes less than the wavelength of visible radiation could be transparent.

Therefore, understanding the effects of porosity, pore size and shape, and pore size distribution on the optical properties of nanoporous systems is crucial for better device performance. For this purpose, numerous effective medium theories have been developed. All of them treat heterogeneous media as homogeneous media with some effective properties. The most common models used to calculate the effective index of refraction are summarized in Table 2, although variations of them can also be found in the literature [220,221]. All the models mentioned consider only the porosity as a structural parameter of the foam, regardless of other important parameters such as pore size, shape, and pore distribution. Likewise, some of these models have been used to analyze the refractive index though they were not necessarily developed for this purpose (i.e., the MGT model was developed to calculate the electric permittivity). Thus, although the number of existing models is high, it is not clear which model is the most accurate in a given situation.

In order to clarify some of the aforementioned problems, Braun and Pilon [226] solved numerically the two-dimensional Maxwell's equations in non-absorbing nanoporous thin films with different morphologies for transverse electric (TE) absorbing electromagnetic waves. The effect of the film thickness $(L)$ (Fig. 25(a)), pore size ( $\Phi$ ) (Fig. 25(a)), pore shape (Fig. 25(b)), pore distribution (Fig. 25(c)), and porosity (Fig. 25(d)) on the effective index of refraction was studied in detail. It was found that, below a certain critical film thickness, the effective index of refraction depends on the pore size and shape, porosity, and pore distribution. However, beyond this critical thickness, effective medium approaches 


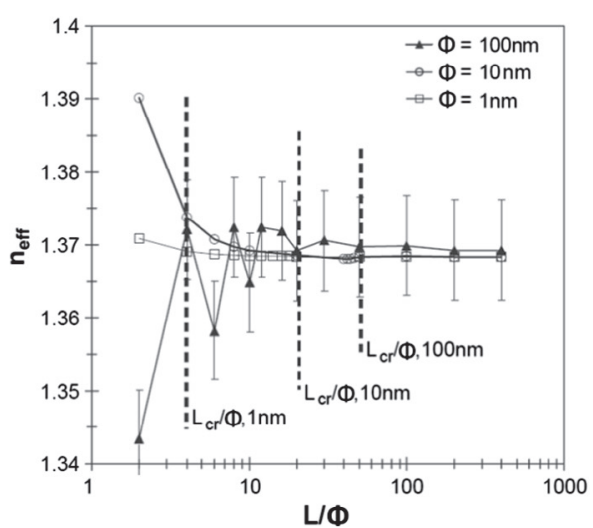

(a) Variation of $n_{\text {eff }}$ as a function of $L / \Phi$ for films with $19.63 \%$ porosity and different pore diameters.

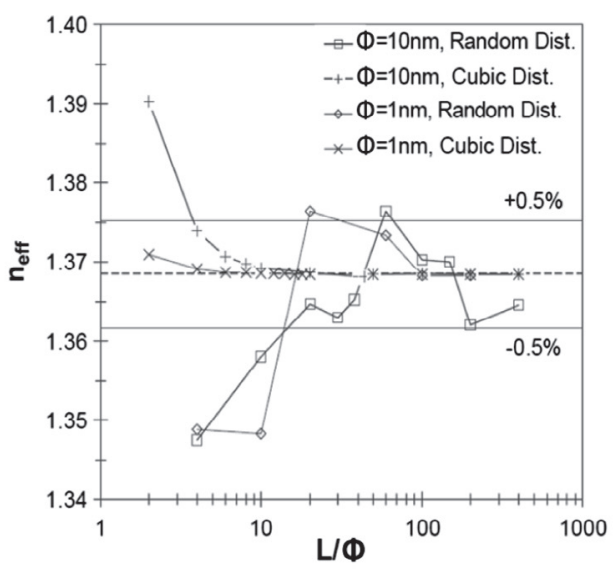

(c) Variation of $n_{\text {eff }}$ as a function of $L / \Phi$ for regular and random pore size distribution with a porosity of $19.63 \%$.

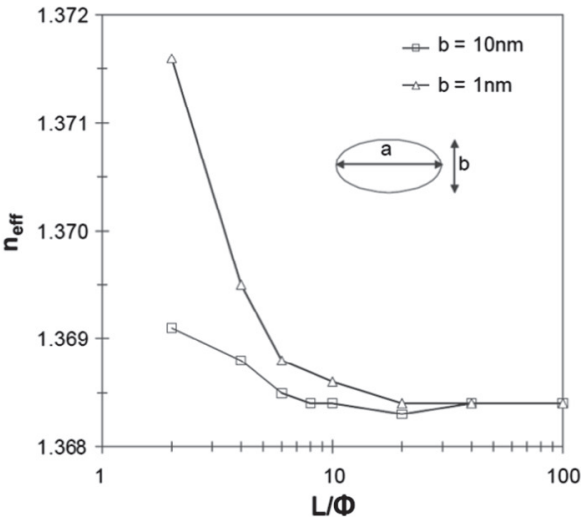

(b) Variation of $n_{\text {eff }}$ as a function of $L / \Phi$ for elliptical pores with an aspect ratio $a / b=2$, and a porosity of $19.63 \%$.

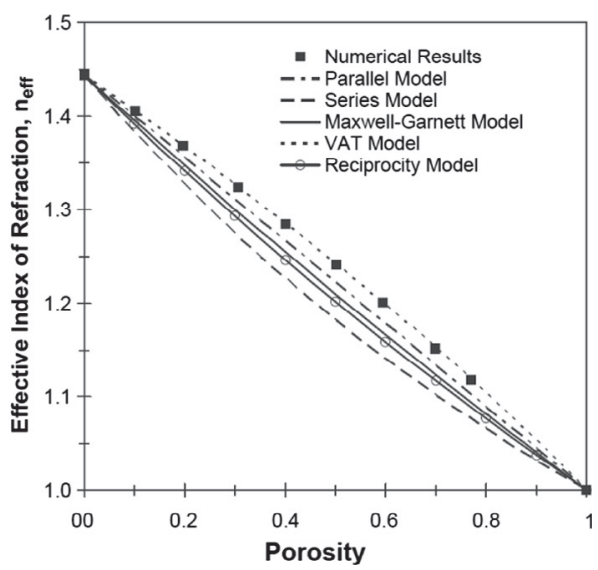

(d) Variation of $n_{\text {eff }}$ as a function of porosity for nanoporous $\mathrm{SiO}_{2}(\Phi=10 \mathrm{~nm})$ at $\lambda=1.55$ $\mu \mathrm{m}$.

Fig. 25. Variation of the effective index of refraction of a nanoporous film as a function of film thickness (a), pore shape (b), pore size distribution (c), and porosity (d). Images have been adapted from Braun and Pilon [226]. (a) Variation of $n_{\text {eff }}$ as a function of $L / \Phi$ for films with $19.63 \%$ porosity and different pore diameters. (b) Variation of $n_{\text {eff }}$ as a function of $L / \Phi$ for elliptical pores with an aspect ratio $a / b=2$, and a porosity of $19.63 \%$. (c) Variation of $n_{\text {eff }}$ as a function of $L / \Phi$ for regular and random pore size distribution with a porosity of $19.63 \%$. (d) Variation of $n_{\text {eff }}$ as a function of porosity for nanoporous $\operatorname{SiO}_{2}(\Phi=10 \mathrm{~nm})$ at $\lambda=1.55$ $\mu \mathrm{m}$.

are valid, and the effective index of refraction depends only on the porosity and the index of refraction of each of the constituent phases (solid and gas) (see Fig. 25 from (a) to (d)).

Similarly, Navid and Pilon [227] carried out another study to improve and better understand the theoretical models given in Table 2. The index of refraction of nanoporous films with different morphologies for normally incident transverse magnetic (TM) and transverse electric (TE) absorbing electromagnetic waves was determined by numerically solving the two-dimensional Maxwell's equations. They found that, for uniform pore distributions and spherical pores, the effective index of refraction for TE and TM waves is independent of both pore size and film thickness for $1<\Phi<10 \mathrm{~nm}$ and $L /$ 
$\Phi \geqslant 300$. This result is in good agreement with the work of Braun and Pilon [226], since the regime they considered is above the critical film thickness given above. In this situation, the TM numerical data agree well with the parallel model, whereas the TE numerical data are consistent with the VAT theory. In the case of a random pore distribution and different pore shapes, it was found that TE waves are independent of the porous morphology and can be appropriately described by the VAT model (this result is consistent with predictions from Braun and Pilon [226]). However, for TM waves, the index of refraction depends on the porosity, pore distribution, and pore shape.

Therefore, theoretical models developed for nanoporous materials in general (and thus valid for both polymeric and non-polymeric systems) are well established, although the application limits of each model have not yet been well defined. All of them agree that the enhancement of the effective optical properties (i.e., the achievement of a lower value of the effective index of refraction) of a nanoporous material is mainly determined by the porosity for film thicknesses above a certain critical value; however, for film thicknesses below this value, the improvement in the optical properties is also determined by the pore size and shape and pore distribution [226].

Although the modification of the index of refraction by varying the morphology of the porous system is a recent topic in the field of nanoporous polymers, there are other experimental works related to the use of different nanoporous systems, such as $\mathrm{TiO}_{2}$ [228], $\mathrm{GaN}$ [229], $\mathrm{SiO}_{2}$ [218], and silicon [213,215-217], which will be discussed below briefly for comparison.

Silicon-based multilayer porous systems have been widely used in the manufacture of antireflection coatings [218], waveguides [213], Bragg reflectors [215-217], and Fabry-Perot devices [215]. Depth variations in porosity are created to obtain regions with different refractive indices that allow tuning of the optical properties of the system. For instance, Zhang and coworkers [218] developed an antireflection coating by means of a two-layer refractive index gradient. For this purpose, they use a $\mathrm{SiO}_{2}$ aerogel nanoporous film (pore size: not specified; thickness: $220 \mathrm{~nm}$; porosity: not specified) as the low-refractive-index layer $(n=1.16)$ and a $\mathrm{TiO}_{2}$ film as the high-refractive-index layer $(n=1.40)$. This anti-reflective coating provided an average reflectance $<2 \%$ in the wavelength range from 1000 to $2000 \mathrm{~nm}$, which represents a reduction of 70\% with respect to the solid system.

Other applications of nanoporous films in optics can be found in the work of Lee and Kang [228]. These researchers were able to improve the efficiency (measured under $100 \mathrm{~mW} / \mathrm{cm}^{2}$ simulated light) of a dye-sensitized solar cell (DSSC) through the incorporation of a nanoporous $\mathrm{TiO}_{2}$ film (pore size: $10 \mathrm{~nm}$; thickness: $4 \mu \mathrm{m}$; porosity: not specified). The efficiency value obtained was two times higher than that of a commercial DSSC also based on $\mathrm{TiO}_{2}$. The cause of this improvement lies in the lower reflective Fresnel loss for incident light at its outer surface, which allowed more light to reach the active layer.

Another study was that carried out by Vajpeyi et al. [229], who obtained a considerable photoluminescence $(\mathrm{PL})$ intensity improvement at $77 \mathrm{~K}$ (2.3 times higher than as-grown GaN films) in a nanoporous GaN film with cylindrical pores (pore size: $\approx 85 \mathrm{~nm}$; thickness: $400 \mu \mathrm{m}$; porosity: not specified). They observed that the higher the pore length, the higher the PL intensity was. This system could be used as an intermediate layer for high-brightness light emitting devices.

Thus, experimental results obtained in non-polymeric nanoporous materials showed an improved optical response with respect to the solid or to the materials currently on the market. This improvement is in general governed by the porosity and not by the pore size. Although this apparent enhancement has been well demonstrated in non-polymeric systems, studies on nanoporous polymers are still scarce.

Cho et al. [230] introduced a novel method to produce highly antireflective coatings by means of nanoporous block copolymer (polystyrene-block-poly(4-vinylpyridine) (PS- $b$-P4VP) and polystyreneblock-poly(acrylic acid) (PS-b-PAA)) multilayer films. These films, with a pore size around $10 \mathrm{~nm}$ and a film thickness that varied from 25 to $104 \mathrm{~nm}$, presented an index of refraction that was strongly influenced by the porosity (refractive index: from 1.14 to 1.25 ; porosity: from $65.7 \%$ to $42.8 \%$, respectively). For the films with a thickness around $100 \mathrm{~nm}$, a high antireflective capacity with light transmissions around $99 \%$ at $540 \mathrm{~nm}$ was found.

Similarly, Hiller and coworkers [231] designed a new methodology (aqueous-based process) to produce poly(allylamine hydrochloride)/poly(acrylic acid) (PAH/PAA) anti-reflective nanoporous films with reversibly erasable porosity. These films, with a thickness ranging from 80 to $130 \mathrm{~nm}$, a pore size 
of $60 \mathrm{~nm}$, and a refractive index from 1.15 to 1.55 (although the article mentions that this factor varied with the porosity, the value was not specified), exhibited a light transmission $>98 \%$ at $540 \mathrm{~nm}$, a value 7.7\% higher than that of untreated glass.

Yokoyama et al. [54] and later Li and coworkers [232] calculated the porosity of several nanoporous polystyrene-b-poly(perfluorooctylethyl methacrylate) (PS-PFMA) films (thickness: $1 \mu \mathrm{m}[54] / 50 \mathrm{~nm}$ [232]; pore size: $15-30 \mathrm{~nm}$ ) from measurements of the index of refraction. Using the Lorentz-Lorentz equation [233], Yokoyama et al. [54] obtained porosities between $16 \%$ and $50 \%$ for indices of refraction ranging from 1.4 to 1.23 (lower values than that of the solid, $n_{s}=1.50$ ), respectively, whereas Li and coworkers [232] achieved porosities between 12 and 24\% and indices of refraction ranging from 1.42 to 1.37 (also lower values than that of the solid, $n_{s}=1.50$ ), respectively. Although the tendency observed in both studies was the same (the higher the porosity, the lower the index of refraction is), the maximum reduction obtained in the index of refraction in each case was different. The reason for this difference resides in the presence of a dense layer that covered the films developed by Yokoyama et al. [54].

Finally, Rizzo et al. [234] and Guerra and coworkers [184] found that s-PS films (thickness $\approx 20 \mu \mathrm{m}$; pore size $\approx 1 \mathrm{~nm}$; porosity: $7 \%$ ) exhibited chiral optical responses both in the infrared and in the UV-visible regions, opening the opportunity to achieve s-PS-based films with tunable chiral optical properties.

Thus, nanoporous polymers seem to present enhanced optical behavior compared to the solid, which is mainly governed by the porosity of the system and not by the pore size. However, the number of studies is still too limited to obtain definitive conclusions.

The use of a polymeric system or not will depend on the technical specifications of each application. However, further studies on the mechanical, thermal, or chemical resistances of both polymeric and non-polymeric materials are needed to verify whether these systems are potential candidates for use in optics.

According to experimental and theoretical results, the pore size has no influence on the optics of nanoporous materials for film thicknesses above a critical value in principle; the porosity is primarily responsible for the improvement of this property in this situation. Only for film thicknesses below this critical value does the pore size play an important role. It is possible that, in this situation, light scattering from pores will have more influence, and, consequently, the transparency of amorphous nanoporous polymers could be reached.

Finally, although it is very useful to have materials with specific improved properties (mechanical, thermal, dielectric, optical, etc.), the current trend in designed materials implies the achievement of a material that combines a set of well-defined and enhanced properties. For instance, Harbuzaru and coworkers [235] proposed lanthanide-based nanoporous metal-organic frameworks (Ln-MOFs) as a material with interesting multifunctional properties such as luminescence, magnetism, hydrophobicity, and high thermal stability (no specific data are provided for the cellular structure or for the properties mentioned). However, nanoporous silica aerogels films (thicknesses between 3 and $110 \mathrm{~nm}$ ) with porosities higher than $75 \%$ (pore size not specified) have also been proposed by Hrubesh and Poco [236] as multifunctional materials because of the excellent optical, acoustical, thermal, and electronic properties exhibited by this system and demonstrated elsewhere [237,238]. Recently, Notario and coworkers [14,67] have demonstrated that PMMA-based nanoporous materials (pore size: $<300 \mathrm{~nm}$; porosity: $\approx 60 \%$ ) exhibit improved thermal and mechanical properties as well as promising dielectric (unpublished work) and filtration [60] properties.

Therefore, nanoporous materials are promising candidates for use in multifunctional systems. Although studies in both polymeric and non-polymeric systems are still scarce, the first results obtained have created high expectations.

\section{Conclusions}

In this review, the influence of the reduction in pore size to the nanometer range on the key physical properties of porous polymeric materials (mechanical properties, thermal properties, etc.) are described and analyzed in detail. 
It was expected that the reduction in the pore size to the nanoscale together with the modification of the porous architecture would produce a series of improvements in several physical properties of these novel materials (mechanical, thermal, dielectric, optical, sensing, filtration, etc.). However, it has been found that the confinement of the constituent phases (gas and solid) in the nanometer range also leads to unexpected modifications or effects.

It has been demonstrated that nanoporous polymeric materials exhibit superior mechanical behavior at high strain rates and superior shore hardness compared with both microporous and solid materials. However, the studies on the mechanical response at low strain rates were inconclusive.

A possible alteration of the fundamental properties of the base polymer due to the confinement of the polymer chains within the pore walls, or due to the stretching of the polymer chains induced during the manufacturing process, could be the reason for the different tensile behaviors obtained in different papers. Nevertheless, further studies with different polymeric matrices are needed to understand, confirm or discard the contradictory tensile results obtained.

Thermal conductivity measurements in nanoporous polymers have shown a reduction of the thermal conductivity when the pore size was below one micron. The confinement of both the gaseous phase (the Knudsen effect) and the solid phase (different phonon scattering mechanisms and increased tortuosity) are the phenomena underlying this effect. To date, studies on nanoporous polymers are still scarce; nevertheless, the Knudsen effect depends only on the morphology of the porous structure and is independent of the solid matrix. Thus, it can be stated that there is sufficient evidence to confirm its presence and potential advantages in nanoporous polymeric materials.

New low- $k$ nanoporous polymers, with a lower dielectric constant than the solid, have been achieved by the introduction of air into the polymer matrix.

Moreover, it was demonstrated that the pore size does not provide an additional advantage to low$k$ nanoporous systems; this was only a requirement imposed by the dimensions of the devices to be developed. Nevertheless, the existence or future appearance of side effects due to the reduction of pore size to the nanoscale cannot be completely discarded.

Filtration and membrane studies showed that a reduction in pore size leads to enhanced storage and filtration capacities. It was demonstrated that nanoporous polymers could reach filtration and gas storage performances similar to those of non-polymeric materials as long as they exhibit similar structural parameters: porosity, pore size, narrow pore size distribution, high BET specific surface area, etc. Although nanoporous polymeric materials were not the most conventional materials in this field, they presented other advantages (ease of manufacturing, superior flexibility, good biocompatibility, and tailored thermal, mechanical, and chemical properties) that make them materials of significant interest.

Nanoporous polymers also have a promising future in emerging fields such as sensing and optics. Nanoporous materials have proven very useful for the development of biosensors, since they prevent the tendency of enzymes to unfold. Although there are no articles related to nanoporous polymers, the good results obtained with nanoporous carbon-based materials suggest that polymer systems may also be used in this application. Furthermore, nanoporous polymers can also be employed as humidity sensors, because they can accurately detect resistance and/or capacitance variations due to water adsorption inside the nanopores. Initial results demonstrated that nanoporous polymeric materials exhibited a better humidity detection capacity than nanoporous ceramics. Nevertheless, the number of articles is still limited, and thus further studies are required in order to determine whether nanoporous polymers are appropriate as sensors.

Nanoporous polymers present enhanced optical behavior (i.e., a reduced index of refraction) compared to the solid, which is mainly governed by the porosity of the system. It was demonstrated that the pore size has, in principle, no influence on the optics of nanoporous materials for film thicknesses above a critical value, and the porosity is primarily responsible for the improvement in this property in this situation. Only for film thicknesses below this critical value does the pore size play an important role. It is possible that, in this situation, the light scattering from the pores will play a key role in the light transmission through the films, and consequently transparent nanoporous polymer films could be produced from amorphous polymers.

Furthermore, nanoporous polymers are promising candidates for use in multifunctional systems. Although the number of studies is still low, the initial results obtained have led to high expectations. 
The aforementioned results obtained with nanoporous polymers are consistent with those obtained in other non-polymeric nanoporous systems and with the theoretical predictions developed up to now. However, the different matrices employed (polymer against metal) make that the results found for mechanical properties not comparable. Likewise, most of the theoretical models developed to study the mechanical behavior of nanoporous materials have been tested on non-polymeric systems, and the development of more specific models for polymers is necessary.

Therefore, according to these results, significant progress has been made in last years in the development of nanoporous polymeric materials. Their improved thermal, mechanical, dielectric, optical, filtration, and sensing properties, among others, make these materials promising candidates for applications such as thermal insulation, cushioning, packaging, electronics, and filtration. However, significant technical challenges remain in the production of nanoporous polymers with adequate densities, pore sizes, and external dimensions that allow for characterization of their properties and their production as a scalable industrial process. In addition, a better understanding of the structure-property relationships for these materials is needed. Fortunately, nanoporous material production is becoming an area of increased interest for both academia and industry, leading to further progress towards this target.

\section{Acknowledgments}

Financial support from FPI Grant BES-2013-062852 (B. Notario) from the Spanish Ministry of Education is gratefully acknowledged. Financial assistance from the MINECO and FEDER Program (MAT 2012-34901) and the Junta of Castile and Leon (VA035U13) is gratefully acknowledged.

\section{References}

[1] Gibson LJ, Ashby MF. Cellular solids: structure and properties. 2nd ed. Cambridge: Cambridge University Press; 1997.

[2] Weaire D, Hutzler S. The physics of foams. Oxford, UK: Oxford University Press; 1999.

[3] Klempner D, Sendijarevi'c V, Aseeva RM. Handbook of polymeric foams and foam technology. Munich: Hanser Publishers; 2004.

[4] Eaves D. Handbook of polymer foams. Rapra Technology; 2004.

[5] Business Communications Company Inc. RP-120X polymeric foams. USA: Updated Edition; 2004.

[6] Martini-Vvedensky JE, Suh NP, Waldman FA. Microcellular closed cell foams and their method of manufacture. Massachusetts Institute of Technology; 1984.

[7] Kumar V. Process synthesis for manufacturing microcellular thermoplastic parts. Massachusetts Institute of Technology; 1988.

[8] Kumar V, Suh NP. A process for making microcellular thermoplastic parts. Polym Eng Sci 1990;30:1323-9.

[9] Shimbo M, Higashitani I, Miyano Y. Mechanism of strength improvement of foamed plastics having fine cell. J Cell Plast 2007;43:157-67.

[10] Nadella K, Kumar V. Tensile and flexural properties of solid-state microcellular Abs panels. In: Gdoutos EE, editor. Experimental analysis of nano and engineering materials and structures. Netherlands: Springer; 2007. p. 765-6.

[11] Kumar V, Seeler KA, Vander Wel M, Weller J. Experimental characterization of the tensile behavior of microcellular polycarbonate foams. J Eng Mater Technol 1994;116:439-45.

[12] Kumar V, Weller JE, Ma M, Montecillo R, Kwapisz RR. The effect of additives on microcellular PVC foams: Part II. Tensile behaviour. Cell Polym 1998;17:350-61.

[13] Miller D, Kumar V. Microcellular and nanocellular solid-state polyetherimide (PEI) foams using sub-critical carbon dioxide II. Tensile and impact properties. Polymer 2011;52:2910-9.

[14] Notario B, Pinto J, Solorzano E, Saja JAd, Dumon M, Rodriguez-Perez MA. Experimental validation of the Knudsen effect in nanocellular polymeric foams. Polymer 2015;56:57-67.

[15] Hentze HP, Antonietti M. Porous polymers and resins for biotechnological and biomedical applications. Rev Mol Biotechnol 2002;90:27-53.

[16] Li L, Shen X, Hong SW, Hayward RC, Russell TP. Fabrication of co-continuous nanostructured and porous polymer membranes: spinodal decomposition of homopolymer and random copolymer blends. Angew Chem Int Ed Engl 2012;51:4089-94.

[17] Park SH, Xia YN. Macroporous membranes with highly ordered and three-dimensionally interconnected spherical pores. Adv Mater 1998;10:1045-8.

[18] du Fresne von Hohenesche C, Schmidt DF, Schädler V. Nanoporous melamine-formaldehyde gels by microemulsion templating. Chem Mater 2008;20:6124-9.

[19] Hedrick JL, Miller RD, Hawker CJ, Carter KR, Volksen W, Yoon DY, et al. Templating nanoporosity in thin-film dielectric insulators. Adv Mater 1998;10:1049-53.

[20] Costeux S, Zhu L. Low density thermoplastic nanofoams nucleated by nanoparticles. Polymer 2013;54:2785-95.

[21] Miller D, Chatchaisucha P, Kumar V. Microcellular and nanocellular solid-state polyetherimide (PEI) foams using subcritical carbon dioxide I. Processing and structure. Polymer 2009;50:5576-84. 
[22] Cheng LP, Dwan AH, Gryte CC. Membrane formation by isothermal precipitation in polyamide-formic acid-water systems I. Description of membrane morphology. J Polym Sci Part B Polym Phys 1995;33:211-22.

[23] Cheng LP, Dwan AH, Gryte CC. Membrane formation by isothermal precipitation in polyamide-formic acid-water systems II. Precipitation dynamics.. J Polym Sci Part B Polym Phys 1995;33:223-35.

[24] Kiefer J, Hilborn JG, Hedrick JL. Chemically induced phase separation: a new technique for the synthesis of macroporous epoxy networks. Polymer 1996;37:5715-25.

[25] Nam YS, Park TG. Biodegradable polymeric microcellular foams by modified thermally induced phase separation method. Biomaterials 1999;20:1783-90.

[26] Schugens C, Maquet V, Grandfils C, Jerome R, Teyssie P. Biodegradable and macroporous polylactide implants for cell transplantation. 1. Preparation of macroporous polylactide supports by solid-liquid phase separation. Polymer 1996;37:1027-38.

[27] Walheim S, Schäffer E, Mlynek J, Steiner U. Nanophase-separated polymer films as high-performance antireflection coatings. Science 1999;283:520-2.

[28] Hentze HP, Antonietti M. Template synthesis of porous organic polymers. Curr Opin Solid State Mater Sci 2001;5:343-53.

[29] Lazzari M, López-Quintela MA. Block copolymers as a tool for nanomaterial fabrication. Adv Mater 2003;15:1583-94.

[30] Lin JM, Uchiyama K, Hobo T. Enantiomeric resolution of dansyl amino acids by capillary electrochromatography based on molecular imprinting method. Chromatographia 1998;47:625-9.

[31] Mayes AG, Andersson LI, Mosbach K. Sugar binding polymer showing high anomeric and empimeric discrimination obtained by non-covalent molecular imprinting. Anal Biochem 1994;222:483-8.

[32] Cheong SH, Rachkov AE, Park JK, Yano K, Karube I. Synthesis and binding properties of a noncovalent molecularly imprinted testosterone-specific polymer. J Polym Sci Part A Polym Chem 1998;36:1725-32.

[33] Park SH, Xia Y. Fabrication of three-dimensional macroporous membranes with assemblies of microspheres as templates. Chem Mater 1998;10:1745-7.

[34] Olson DA, Chen L, Hillmyer MA. Templating nanoporous polymers with ordered block copolymers $\dagger$. Chem Mater 2007;20:869-90.

[35] Zalusky AS, Olayo-Valles R, Wolf JH, Hillmyer MA. Ordered nanoporous polymers from polystyrene-polylactide block copolymers. J Am Chem Soc 2002;124:12761-73.

[36] Hedrick JL, Russell TP, Labadie J, Lucas M, Swanson S. High temperature nanofoams derived from rigid and semi-rigid polyimides. Polymer 1995;36:2685-97.

[37] Kazarian SG. Polymer processing with supercritical fluids. Polym Sci Series C 2000;42:78-101.

[38] Tsivintzelis I, Angelopoulou AG, Panayiotou C. Foaming of polymers with supercritical $\mathrm{CO}_{2}$ : an experimental and theoretical study. Polymer 2007;48:5928-39.

[39] Reverchon E, Cardea J. Production of controlled polymeric foams by supercritical $\mathrm{CO}_{2}$. J Supercrit Fluids 2007;40:144-52.

[40] Jacobs LJM, Kemmere MF, Keurentjes JTF. Sustainable polymer foaming using high pressure carbon dioxide: a review on fundamentals, processes and applications. Green Chem 2008;10:731-8.

[41] Wells SL, DeSimone J. $\mathrm{CO}_{2}$ technology platform: an important tool for environmental problem solving. Angew Chem Int Ed 2001;40:518-27.

[42] Kumar V, Weller J. Production of microcellular polycarbonate using carbon dioxide for bubble nucleation. J Eng Ind 1994;116:413-20.

[43] Reglero Ruiz JA, Viot P, Dumon M. Microcellular foaming of polymethylmethacrylate in a batch supercritical $\mathrm{CO}_{2}$ process: effect of microstructure on compression behavior. J Appl Polym Sci 2010;118:320-31.

[44] Goel SK, Beckman EJ. Generation of microcellular polymeric foams using supercritical carbon dioxide. I: effect of pressure and temperature on nucleation. Polym Eng Sci 1994;34:1137-47.

[45] Guo Q, Wang J, Park CB. A microcellular foaming simulation system with a high pressure-drop rate. Ind Eng Chem Res 2006;45:6153-61.

[46] Krause B, Sijbesma HJP, Münüklü P, Van der Vegt NFA, Wessling M. Bicontinuous nanoporous polymers by carbon dioxide foaming. Macromolecules 2001;34:8792-801.

[47] Pinto J, Dumon M, Pedros M, Reglero JA, Rodriguez-Perez MA. Nanocellular $\mathrm{CO}_{2}$ foaming of PMMA assisted by block copolymer nanostructuration. Chem Eng J 2014;243C:428-35.

[48] Janani H, Famili MHN. Investigation of a strategy for well controlled inducement of microcellular and nanocellular morphologies in polymers. Polym Eng Sci 2010;50:1558-70.

[49] Siripurapu S, DeSimone JM, Khan SA, Spontak RJ. Controlled foaming of polymer films through restricted surface diffusion and the addition of nanosilica particles or $\mathrm{CO}_{2}$-philic surfactants. Macromolecules 2005;38:2271-80.

[50] Fujimoto Y, Ray SS, Okamoto M, Ogami A, Yamada K, Ueda K. Well-controlled biodegradable nanocomposite foams: from microcellular to nanocellular. Macromol Rapid Commun 2003;24:457-61.

[51] Ema Y, Ikeya M, Okamoto M. Foam processing and cellular structure of polylactide-based nanocomposites. Polymer 2006;47:5350-9.

[52] Urbanczyk L, Calberg C, Detrembleur C, Jérôme C, Alexandre M. Batch foaming of SAN/clay nanocomposites with $\mathrm{scCO}_{2}$ : a very tunable way of controlling the cellular morphology. Polymer 2010;51:3520-31.

[53] Ruckdäschel H, Gutmann P, Altstädt V, Schmalz H, Müller AHE. Foaming of microstructured and nanostructured polymer blends. In: John A, editor. Complex macromolecular systems I. Springer; 2010. p. 199-252.

[54] Yokoyama BH, Li L, Nemoto T, Sugiyama K. Tunable nanocellular polymeric monoliths using fluorinated block copolymer templates and supercritical carbon dioxide. Adv Mater 2004;16:1542-6.

[55] Spitael P, Macosko CW, McClurg RB. Block copolymer micelles for nucleation of microcellular thermoplastic foams. Macromolecules 2004;37:6874-82.

[56] Nemoto T, Takagi J, Ohshima M. Nanoscale cellular foams from a poly(propylene)-rubber blend. Macromol Mater Eng 2008;293:991-8.

[57] Otsuka T, Taki K, Ohshima M. Nanocellular foams of PS/PMMA polymer blends. Macromol Mater Eng 2008;293:78-82.

[58] Costeux S, Khan I, Bunker SP, Jeon HK. Experimental study and modeling of nanofoams formation from single phase acrylic copolymers. J Cell Plast 2014. 
[59] Costeux S, Bunker SP, Jeon HK. Homogeneous nanocellular foams from styrenic-acrylic polymer blends. J Mater Res 2013;28:2351-65.

[60] Pinto J, Dumon M, Rodriguez-Perez MA, Garcia R, Dietz C. Block copolymers self-assembly allows obtaining tunable micro or nanoporous membranes or depth filters based on PMMA; fabrication method and nanostructures. J Phys Chem C 2014; 118:4656-63.

[61] Handa YP, Zhang Z. A new technique for measuring retrograde vitrification in polymer-gas systems and for making ultramicrocellular foams from the retrograde phase. J Polym Sci Part B Polym Phys 2000;38:716-25.

[62] Costeux S. CO -blown nanocellular foams. J Appl Polym Sci 2014.

[63] Lu X, Caps R, Fricke J, Alviso CT, Pekala RW. Correlation between structure and thermal conductivity of organic aerogels. J Non-Cryst Solids 1995;188:226-34.

[64] Schmidt D, Raman VI, Egger C, du Fresne C, Schädler V. Templated cross-linking reactions for designing nanoporous materials. Mater Sci Eng C 2007;27:1487-90.

[65] Pinto J, Notario B, Verdejo R, Dumon M, Costeux S, Rodriguez-Perez MA. Molecular confinement of solid and gaseous phases of self-standing nanoporous polymers inducing enhanced and unexpected physical properties. Adv Mater 2015 [submitted for publication].

[66] Reglero Ruiz JA, Dumon M, Pinto J, Rodriguez-Pérez MA. Low-density nanocellular foams produced by high-pressure carbon dioxide. Macromol Mater Eng 2011;296:752-9.

[67] Notario B, Pinto J, Rodriguez-Perez MA. Towards a new generation of polymeric foams: PMMA nanocellular foams with enhanced physical properties. Polymer 2015;63:116-26.

[68] Mandelbrot B. How long is the coast of Britain? Statistical self-similarity and fractional dimension. Science 1967;156:636-8.

[69] Ma X, Peyton AJ, Zhao YY. Eddy current measurements of electrical conductivity and magnetic permeability of porous metals. NDT \& E Int 2006;39:562-8.

[70] Collias DI, Baird DG. Impact toughening of polycarbonate by microcellular foaming. Polymer 1994;35:3978-83.

[71] Sun H, Sur GS, Mark JE. Microcellular foams from polyethersulfone and polyphenylsulfone. Preparation and mechanical properties. Eur Polym J 2002;38:2373-81.

[72] Juntunen RP, Kumar V, Weller JE. Impact strength of high density of microcellular of poly(vinyl chloride) foams. J Vinyl Add Tech 2000;6:93-9.

[73] Hodge AM, Biener J, Hayes JR, Bythrow PM, Volkert CA, Hamza AV. Scaling equation for yield strength of nanoporous open-cell foams. Acta Mater 2007;55:1343-9.

[74] Fan HL, Fang DN. Modeling and limits of strength of nanoporous foams. Mater Des 2009;30:1441-4.

[75] Xia R, Li X, Qin Q, Liu J, Feng XQ. Surface effects on the mechanical properties of nanoporous materials. Nanotechnology 2011;22:265714.

[76] Zhang WX, Wang TJ. Effect of surface energy on the yield strength of nanoporous materials. Appl Phys Lett 2007;90.

[77] Duan HL, Wang J, Karihaloo BL, Huang ZP. Nanoporous materials can be made stiffer than non-porous counterparts by surface modification. Acta Mater 2006;54:2983-90.

[78] Pande CS, Masumura RA, Armstrong RW. Pile-up based Hall-Petch relation for nanoscale materials. Nanostruct Mater 1993;2:323-31.

[79] Biener J, Hodge AM, Hayes JR, Volkert CA, Zepeda-Ruiz LA, Hamza AV, et al. Size effects on the mechanical behavior of nanoporous Au. Nano Lett 2006;6:2379-82.

[80] Hodge AM, Hayes JR, Caro JA, Biener J, Hamza AV. Characterization and mechanical behavior of nanoporous gold. Adv Eng Mater 2006;8:853-7.

[81] Weissmuller J, Newman RC, Jin HJ, Hodge AM, Kysar JW. Nanoporous metals by alloy corrosion: formation and mechanical properties. MRS Bull 2009;34:577-86.

[82] Xia R, Xu C, Wu W, Li X, Feng X-Q, Ding Y. Microtensile tests of mechanical properties of nanoporous Au thin films. J Mater Sci 2009;44:4728-33.

[83] Seker E, Gaskins JT, Bart-Smith H, Zhu J, Reed ML, Zangari G, et al. The effects of post-fabrication annealing on the mechanical properties of freestanding nanoporous gold structures. Acta Mater 2007;55:4593-602.

[84] Xia Z, Riester L, Sheldon BW, Curtin WA, Liang J, Yin A, et al. Mechanical properties of highly ordered nanoporous anodic alumina membranes. Rev Adv Mater Sci 2004;6:131-9.

[85] Sharudin RWB, Ohshima M. $\mathrm{CO}_{2}$-induced mechanical reinforcement of polyolefin-based nanocellular foams. Macromol Mater Eng 2011;296:1046-54.

[86] Sue HJ, Yee AF. Micromechanical modeling of crack-tip rubber particle cavitational process in polymer toughening. Polym Eng Sci 1996;36:2320-6.

[87] Sue HJ, Huang J, Yee AF. Interfacial adhesion and toughening mechanisms in an alloy of polycarbonate/polyethylene. Polymer 1992;33:4868-71.

[88] Borggreve RJM, Gaymans RJ, Eichenwald HM. Impact behaviour of nylon-rubber blends: 6. Influence of structure on voiding processes; toughening mechanism. Polymer 1989;30:78-83.

[89] Barlow C, Kumar V, Flinn B, Bordia RK, Weller J. Impact strength of high density solid-state microcellular polycarbonate foams. J Eng Mater Technol 2001;123:229-33.

[90] Ikeda-Fukazawa T, Kita D, Nagashima K. Raman spectroscopic study of $\mathrm{CO}_{2}$ sorption process in poly methyl methacrylate. J Polym Sci Part B Polym Phys 2008;46:831-42.

[91] Solorzano E, Rodriguez-Perez MA, Lázaro J, de Saja JA. Influence of solid phase conductivity and cellular structure on the heat transfer mechanisms of cellular materials: diverse case Studies. Adv Eng Mater 2009;11:818-24.

[92] Russell HW. Principles of heat flow in porous insulators*. J Am Ceram Soc 1935;18:1-5.

[93] Bedeaux D, Kapral R. The effective reaction rate and diffusion coefficients for a two-phase medium. J Chem Phys $1983 ; 79$.

[94] Collishaw PG, Evans JRG. An assessment of expressions for the apparent thermal conductivity of cellular materials. J Mater Sci 1994;29:2261-73.

[95] Holman JP. Heat transfer. New York: McGraw-Hill; 1981. 
[96] Alvarez-Lainez M, Rodriguez-Perez MA, De Saja JA. Thermal conductivity of open-cell polyolefin foams. J Polym Sci Part B Polym Phys 2008;46:212-21.

[97] Glicksman LR. Heat-transfer and aging of cellular foam insulation. Cell Polym 1991;10:276-93.

[98] Ferkl P, Pokorný R, Bobák M, Kosek J. Heat transfer in one-dimensional micro- and nano-cellular foams. Chem Eng Sci 2013;97:50-8.

[99] Hrubesh LW, Pekala RW. Thermal properties of organic and inorganic aerogels. J Mater Res 1994;9:731-8.

[100] Forest C, Chaumont P, Cassagnau P, Swoboda B, Sonntag P. Polymer nano-foams for insulating applications prepared from $\mathrm{CO}_{2}$ foaming. Prog Polym Sci 2014.

[101] Sundarram SS, Li W. On thermal conductivity of micro-and nanocellular polymer foams. Polym Eng Sci 2013;53:1901-9.

[102] Lee JH, Grossman JC, Reed J, Galli G. Lattice thermal conductivity of nanoporous Si: molecular dynamics study. Appl Phys Lett 2007;91.

[103] Bera C, Mingo N, Volz S. Marked effects of alloying on the thermal conductivity of nanoporous materials. Phys Rev Lett 2010;104.

[104] Tsui BY, Yang CC, Fang KL. Anisotropic thermal conductivity of nanoporous silica film. IEEE Trans Electron Devices 2004;51:20-7.

[105] Solórzano E, Reglero JA, Rodríguez-Pérez MA, Lehmhus D, Wichmann M, de Saja JA. An experimental study on the thermal conductivity of aluminium foams by using the transient plane source method. Int J Heat Mass Transfer 2008;51:6259-67.

[106] Lee OJ, Lee KH, Yim TJ, Kim SY, Yoo KP. Determination of mesopore size of aerogels from thermal conductivity measurements. Non-Cryst Solids 2002;298:287-92.

[107] Reichenauer G, Heinemann U, Ebert HP. Relationship between pore size and the gas pressure dependence of the gaseous thermal conductivity. Colloids Surf A 2007;300:204-10.

[108] Cuce E, Cuce PM, Wood CJ, Riffat SB. Toward aerogel based thermal superinsulation in buildings: a comprehensive review. Renew Sustain Energy Rev 2014;34:273-99.

[109] Song DW, Shen WN, Dunn B, Moore CD, Goorsky MS, Radetic T, et al. Thermal conductivity of nanoporous bismuth thin films. Appl Phys Lett 2004;84.

[110] Nait-Ali B, Haberko K, Vesteghem H, Absi J, Smith DS. Thermal conductivity of highly porous zirconia. J Eur Ceram Soc 2006;26:3567-74.

[111] (ATEPA) ATdPA. Libro Blanco del Poliuretano Proyectado. Madrid; 2010.

[112] Glassbrenner C, Slack G. Thermal conductivity of silicon and germanium from $3^{\circ} \mathrm{K}$ to the melting point. Phys Rev 1964;134:A1058-69.

[113] Costeux S, Zhu L, Jeon H, Bunker S, Kalantar T. Nanoporous polymeric foam having high cell density without nanofiller. Dow Global Technologies LLC; 2011.

[114] Costeux S, Bunker SP, Jeon HK, Jog PK. Polymeric nanofoam. Dow Global Technologies LLC; 2013.

[115] Liu S, Duvigneau J, Vancso GJ. Nanocellular polymer foams as promising high performance thermal insulation materials. Eur Polymer J 2015;65:33-45.

[116] Association SI. National technology roadmap for semiconductors. San Jose, California; 1997.

[117] Miller RD. In search of low-K dielectrics. Science 1999;286:421-3.

[118] Ro HW, Kim KJ, Theato P, Gidley DW, Yoon DY. Novel inorganic-organic hybrid block copolymers as pore generators for nanoporous ultralow-dielectric-constant films. Macromolecules 2005;38:1031-4.

[119] Wu Y, Zhao X, Li F, Fan Z. Evaluation of mixing rules for dielectric constants of composite dielectrics by MC-FEM calculation on 3D cubic lattice. J Electroceram 2003;11:227-39.

[120] Krause B, Koops G-H, van der Vegt NFA, Wessling M, Wübbenhorst M, van Turnhout J. Ultralow-k dielectrics made by supercritical foaming of thin polymer films. Adv Mater 2002;14:1041-6.

[121] Jin C, Luttmer JD, Smith DM, Ramos TA. Nanoporous silica as an ultralow-k dielectric. MRS Bull 1997;22:39-42.

[122] Baskaran S, Liu J, Domansky K, Kohler N, Li X, Coyle C, et al. Low dielectric constant mesoporous silica films through molecularly template synthesis. Adv Mater 2000;12:291-4.

[123] Ramos T, Wallace S, Smith DM. Nanoporous silica for low k dielectrics. MRS Proc 1997;495.

[124] Yang S, Mirau PA, Pai CS, Nalamasu O, Rechmanis E, Pai JC, et al. Nanoporous ultralow dielectric constant organosilicates template by triblock copolymers. Chem Mater 2002;14:369-74.

[125] Yang S, Mirau PA, Pai CS, Nalamasu O, Rechmanis E, Lin EK, et al. Molecular templating of nanoporous ultralow dielectric constant (1.5) organosilicates by tailoring the microphase separation of triblock copolymers. Chem Mater $2001 ; 13: 2762-4$.

[126] Nguyen CY, Carter KR, Hawker CJ, Hedrick JL, Jaffe RL, Miller RD, et al. Low-dielectric, nanoporous organosilicate films prepared via inorganic/organic polymer hybrid templates. Chem Mater 1999;11:3080-5.

[127] Lee B, Park YH, Hwang YT, Oh W, Yoon J, Ree M. Ultralow-k nanoporous organosilicate dielectric films imprinted with dendritic spheres. Nat Mater 2005;4:147-50.

[128] Flannery CM, Wittkowski T, Jung K, Hillebrands B, Baklanov MR. Critical properties of nanoporous low dielectric constant films revealed by Brillouin light scattering and surface acoustic wave spectroscopy. Appl Phys Lett 2002;80:4594-6.

[129] Hawker CJ, Hedrick JL, Miller RD, Volksen W. Supramolecular approaches to nanoscale dielectric foams for advanced microelectronic devices. MRS Bull 2000;25:54-8.

[130] Lee Y-J, Huang J-M, Kuo S-W, Chang F-C. Low-dielectric, nanoporous polyimide films prepared from PEO-POSS nanoparticles. Polymer 2005;46:10056-65.

[131] Hedrick JL, Carter KR, Cha HJ, Hawker CJ, DiPietro RA, Labadie JW, et al. High-temperature polyimide nanofoams for microelectronic applications. React Funct Polym 1996;30:43-53.

[132] Carter KR, DiPietro RA, Sanchez MI, Swanson SA. Nanoporous polyimides derived from highly fluorinated polyimide/poly (propylene oxide) copolymers. Chem Mater 2001;13:213-21.

[133] Zhang Y, Ke S, Huang H, Zhao L, Yu L, Chan HLW. Dielectric relaxation in polyimide nanofoamed films with low dielectric constant. Appl Phys Lett 2008;92:052910.

[134] Fu GD, Zong BY, Kang ET, Neoh KG, Lin CC, Liaw DJ. Nanoporous low-dielectric constant polyimide films via poly(amic acid)s with RAFT-Graft copolymerized methyl methacrylate side chains. Ind Eng Chem Res 2004;43:6723-30. 
[135] Mehdipour-Ataei S, Aram E. New polyimide and nanoporous structures with low dielectric constant. Adv Polym Technol 2014;33.

[136] Li X, Zou H, Liu P. Structure and dielectric properties of polyimide/silica nanocomposite nanofoam prepared by solid-state foaming. J Appl Polym Sci 2015;132:42355.

[137] Fu GD, Yuan Z, Kang ET, Neoh KG, Lai DM, Huan ACH. Nanoporous ultra-low dielectric constant fluoropolymer films via selective UV decomposition of poly(pentafluorostyrene)-block-poly(methyl methacrylate) copolymers prepared using atom transfer radical polymerization. Adv Funct Mater 2005;15:315-22.

[138] Fu GD, Shang Z, Hong L, Kang ET, Neoh KG. Nanoporous, ultralow-dielectric- constant fluoropolymer films from agglomerated and crosslinked hollow nanospheres of poly(pentafluorostyrene)-block-poly(divinylbenzene). Adv Mater 2005; 17:2622-6.

[139] Xu Y, Tsai YP, Tu KN, Zhao B, Liu QZ, Brogo M, et al. Dielectric property and microstructure of a porous polymer material with ultralow dielectric constant. Appl Phys Lett 1999;75:853.

[140] Su Y-C, Chen W-C, Ou K-l, Chang F-C. Study of the morphologies and dielectric constants of nanoporous materials derived from benzoxazine-terminated poly( $\varepsilon$-caprolactone)/polybenzoxazine co-polymers. Polymer 2005;46:3758-66.

[141] Energy Do. DOE hydrogen program 2006 annual program report; 2006. p. 273.

[142] Cabria I, López MJ, Alonso JA. The optimum average nanopore size for hydrogen storage in carbon nanoporous materials. Carbon 2007;45:2649-58.

[143] Bénard P, Chahine R, Chandonia PA, Cossement D, Dorval-Douville G, Lafi L, et al. Comparison of hydrogen adsorption on nanoporous materials. J Alloys Compd 2007;446-447:380-4.

[144] Bénard P, Chahine R. Determination of the adsorption isotherms of hydrogen on activated carbons above the critical temperature of the adsorbate over wide temperature and pressure ranges. Langmuir 2001;17:1950-5.

[145] Li L. Nanoporous polymers for membrane applications. Technical University of Denmark; 2012.

[146] Mulder M. Basic principles of membrane technology. 2nd ed. USA: Kluwer Academic Publishers; 1996.

[147] Baker RW. Membrane technology and applications. 2nd ed. Chichester, UK; 2004.

[148] Bhatia SK. Modeling pure gas permeation in nanoporous materials and membranes. Langmuir 2010;26:8373-85.

[149] Derouane EG, Andre JM, Lucas AA. Surface curvature effects in physisorption and catalysis by microporous solids and molecular sieves. J Catal 1988;110:58-73.

[150] Yashonath S, Santikary P. Diffusion of sorbates in zeolites Y and A: novel dependence on sorbate size and strength of sorbate-zeolite interaction. J Phys Chem 1994;98:6368-76.

[151] Phillip WA, Rzayev J, Hillmyer MA, Cussler EL. Gas and water liquid transport through nanoporous block copolymer membranes. J Membr Sci 2006;286:144-52.

[152] Epstein N. On tortuosity and the tortuosity factor in flow and diffusion through porous media. Chem Eng Sci 1989;44:777-9.

[153] Li L, Schulte L, Clausen LD, Hansen KM, Jonsson GE, Ndoni S. Gyroid nanoporous membranes with tunable permeability. ACS Nano 2011;5:7754-66.

[154] Adiga SP, Curtiss LA, Elam JW, Pellin MJ, Shih CC, Shih CM, et al. Nanoporous materials for biomedical devices. Biol Mater Sci 2008:26-32.

[155] Pappenheimer JR. Passage of molecules through capillary walls. Physiol Rev 1953;33:387-423.

[156] Renkin EM. Filtration, diffusion, and molecular sieving through porous cellulose membranes. J General Physiol 1954;38:225-43.

[157] Morris RE, Wheatley PS. Gas storage in nanoporous materials. Angew Chem Int Ed Engl 2008;47:4966-81.

[158] Thomas KM. Adsorption and desorption of hydrogen on metal-organic framework materials for storage applications: comparison with other nanoporous materials. Dalton Trans 2009:1487-505.

[159] Shiflett MB, Foley HC. Ultrasonic deposition of high-selectivity nanoporous carbon membranes. Science 1999;285:1902-5.

[160] Shiflett MB, Pedrick JF, McLean SR, Subramoney S, Foley HC. Characterization of supported nanoporous carbon membranes. Adv Mater 2000;12:21-5.

[161] Han S, Sohn K, Hyeon T. Fabrication of new nanoporous carbons through silica templates and their application to the adsorption of bulky dyes. Chem Mater 2000;12:3337-41.

[162] Rösler J, Mukherji D. Design of nanoporous superalloy membranes for functional applications. Adv Eng Mater 2003;5:916-8.

[163] Park HB, Lee YM. Fabrication and characterization of nanoporous carbon/silica membranes. Adv Mater 2005;17:477-83.

[164] Newsam JM. The zeolite cage structure. Science 1986;231:1093-9.

[165] Bein T. Synthesis and applications of molecular sieve layers and membranes. Chem Mater 1996;8:1636-53.

[166] Daniel C, Longo S, Ricciardi R, Reverchon E, Guerra G. Monolithic nanoporous crystalline aerogels. Macromol Rapid Commun 2013;34:1194-207.

[167] Adiga SP, Jin C, Curtiss LA, Monteiro-Riviere NA, Narayan RJ. Nanoporous membranes for medical and biological applications. Nanomed Nanobiotechnol 2009;1:568-81.

[168] Gultepe E, Nagesha D, Sridhar S, Amiji M. Nanoporous inorganic membranes or coatings for sustained drug delivery in implantable devices. Adv Drug Delivery Rev 2010;62:305-15.

[169] Swan EE, Popat KC, Desai TA. Peptide-immobilized nanoporous alumina membranes for enhanced osteoblast adhesion. Biomaterials 2005;26:1969-76.

[170] La Flamme KE, Popat KC, Leoni L, Markiewicz E, La Tempa TJ, Roman BB, et al. Biocompatibility of nanoporous alumina membranes for immunoisolation. Biomaterials 2007;28:2638-45.

[171] Thormann A, Teuscher N, Pfannmoller M, Rothe U, Heilmann A. Nanoporous aluminum oxide membranes for filtration and biofunctionalization. Small 2007;3:1032-40.

[172] Desai TA, Hansford DJ, Leoni L, Essepreis M, Ferrari M. Nanoporous anti-fouling silicon membranes for biosensor applications. Biosens Bioelectron 2000;15:453-62.

[173] Rosenbloom AJ, Sipe DM, Shishkin Y, Ke Y, Devaty RP, Choyke WJ. Nanoporous SiC: a candidate semi-permeable material for biomedical applications. Biomed Microdevices 2004;6:261-7. 
[174] Ng E-P, Mintova S. Nanoporous materials with enhanced hydrophilicity and high water sorption capacity. Microporous Mesoporous Mater 2008;114:1-26.

[175] Budd PM, McKeown NB, Fritsch D. Free volume and intrinsic microporosity in polymers. J Mater Chem 2005;15:1977-86.

[176] McKeown NB, Gahnem B, Msayib KJ, Budd PM, Tattershall CE, Mahmood K, et al. Towards polymer-based hydrogen storage materials: engineering ultramicroporous cavities within polymers of intrinsic microporosity. Angew Chem Int Ed Engl 2006;45:1804-7.

[177] Budd PM, Butler A, Selbie J, Mahmood K, McKeown NB, Ghanem B, et al. The potential of organic polymer-based hydrogen storage materials. Phys Chem Chem Phys 2007;9:1802-8.

[178] Ghanem BS, Msayib KJ, McKeown NB, Harris KD, Pan Z, Budd PM, et al. A triptycene-based polymer of intrinsic microposity that displays enhanced surface area and hydrogen adsorption. Chem Commun (Camb) 2007:67-9.

[179] Mckeown NB, Budd PM. Polymers of intrinsic microporosity (PIMs): organic materials for membrane separations, heterogeneous catalysis and hydrogen storage. Chem Soc Rev 2006;35:675-83.

[180] Germain J, Hradil J, Fréchet JMJ, Svec F. High surface area nanoporous polymers for reversible hydrogen storage. Chem Mater 2006;18:4430-5.

[181] Lee JY, Wood CD, Bradshaw D, Rosseinsky MJ, Cooper AI. Hydrogen adsorption in microporous hypercrosslinked polymers. Chem Commun 2006;25:2670-2.

[182] Germain J, Fréchet JMJ, Svec F. Hypercrosslinked polyanilines with nanoporous structure and high surface area: potential adsorbents for hydrogen storage. J Mater Chem 2007;17:4989-97.

[183] Jiang JX, Su F, Trewin A, Wood CD, Niu H, Jones JTA, et al. Synthetic control of the pore dimension and surface area in conjugated microporous polymer and copolymer networks. J Am Chem Soc 2008;130:7710-20.

[184] Guerra G, Daniel C, Rizzo P, Tarallo O. Advanced materials based on polymer cocrystalline forms. J Polym Sci Part B Polym Phys 2012;50:305-22.

[185] Schulte L, Grydgaard A, Jakobsen MR, Szewczykowski PP, Guo F, Vigild ME, et al. Nanoporous materials from stable and metastable structures of 1,2-PB-b-PDMS block copolymers. Polymer 2011;52:422-9.

[186] Phillip WA, Amendt M, O'Neill B, Chen L, Hillmyer MA, Cussler EL. Diffusion and flow across nanoporous polydicyclopentadiene-based membranes. ACS Appl Mater Interfaces 2009;1:472-80.

[187] Phillip WA, O'Neill B, Rodwogin M, Hillmyer MA, Cussler EL. Self-assembled block copolymer thin films as water filtration membranes. ACS Appl Mater Interfaces 2010;2:847-53.

[188] Milano G, Guerra G. Understanding at molecular level of nanoporous and co-crystalline materials based on syndiotactic polystyrene. Prog Mater Sci 2009;54:68-88.

[189] Yang SY, Ryu I, Kim HY, Kim JK, Jang SK, Russell TP. Nanoporous membranes with ultrahigh selectivity and flux for the filtration of viruses. Adv Mater 2006;18:709-12.

[190] Yang SY, Park J, Yoon J, Ree M, Jang SK, Kim JK. Virus filtration membranes prepared from nanoporous block copolymers with good dimensional stability under high pressures and excellent solvent resistance. Adv Funct Mater 2008;18:1371-7.

[191] Jackson EA, Hillmyer MA. Nanoporous membranes derived from block copolymers: from drug delivery to water filtration. ACS Nano 2010;4:3548-53.

[192] Samitsu S, Zhang R, Peng X, Krishnan MR, Fujii Y, Ichinose I. Flash freezing route to mesoporous polymer nanofibre networks. Nat Commun 2013;4:2653.

[193] Metz S, Trautmann C, Bertsch A, Renaud P. Flexible microchannels with integrated nanoporous membranes for filtration and separation of molecules and particles. Micro Electro Mech Syst 2002:81-4.

[194] Uehara H, Kakiage M, Sekiya M, Sakuma D, Yamonobe T, Takano N, et al. Size selective diffusion in nanoporous but flexible membranes for glucose sensors. ACS Nano 2009;3:924-32.

[195] Smuleac V, Butterfield DA, Bhattacharyya D. Permeability and separation characteristics of polypeptide-functionalized polycarbonate track-etched membranes. Chem Mater 2004;16:2762-71.

[196] Chaniotakis NA. Enzyme stabilization strategies based on electrolytes and polyelectrolytes for biosensor applications. Anal Bioanal Chem 2004;378:89-95.

[197] Abad JM, Velez M, Santamaria C, Guisan JM, Matheus PR, Vazquez L, et al. Immobilization of peroxidase glycoprotein on gold electrodes modified with mixed epoxy-boronic acid monolayers. J Am Chem Soc 2002;124:12845-53.

[198] Besanger TR, Chen Y, Deisingh AK, Hodgson R, Jin W, Mayer S, et al. Screening of inhibitors using enzymes entrapped in sol-gel-derived materials. Anal Chem 2003;75:2382-91.

[199] Zhou HX, Dill KA. Stabilization of proteins in confined spaces. Biochemistry 2001;40:11289-93.

[200] Sotiropoulou S, Vamvakaki V, Chaniotakis NA. Stabilization of enzymes in nanoporous materials for biosensor applications. Biosens Bioelectron 2005;20:1674-9.

[201] Gavalas VG, Chaniotakis NA. [60]Fullerene-mediated amperometric biosensors. Anal Chim Acta 2000;409:131-5.

[202] Gavalas VG, Chaniotakis NA. Polyelectrolyte stabilized oxidase based biosensors: effect of diethylaminoethyl-dextran on the stabilization of glucose and lactate oxidases into porous conductive carbon. Anal Chim Acta 2000;404:67-73.

[203] Sotiropoulou S, Gavalas V, Vamvakaki V, Chaniotakis NA. Novel carbon materials in biosensor systems. Biosens Bioelectron 2003;18:211-5.

[204] Dickey EC, Varghese OK, Ong KG, Gong D, Paulose M, Grimes CA. Room temperature ammonia and humidity sensing using highly ordered nanoporous alumina films. Sensors 2002;2:91-110.

[205] Varghese OK, Gong D, Paulose M, Ong KG, Grimes CA, Dickey EC. Highly ordered nanoporous alumina films: effect of pore size and uniformity on sensing performance. J Mater Res 2002;17:1162-71.

[206] Nitta T, Hayakawa S. Ceramic humidity sensors. IEEE Trans Compon Hybrids Manuf Technol 1980;3:237-43.

[207] Connolly EJ, French PJ, Pham HTM, Sarro PM. Relative humidity sensors based on porous polysilicon and porous silicon carbide. In: Sensors, 2002 proceedings of IEEE, vol. 1; 2002. p. 499-502.

[208] An DK, Mai LH. Surface effect humidity sensor based on alumina and porous silicon materials some electrical parameters, sensitivity and internal noises in comparison. In: Sensors, 2002 proceedings of IEEE, vol. 1; 2002. p. 633-40.

[209] Kim SJ, Park JY, Lee SH, Yi SH. Humidity sensors using porous silicon layer with mesa structure. J Phys D Appl Phys 2000;33:1781-4. 
[210] Yang B, Aksak B, Lin Q Sitti M. Compliant and low-cost humidity nanosensors using nanoporous polymer membranes. Sens Actuators B Chem 2006;114:254-62.

[211] Pilla P, Cusano A, Cutolo A, Giordano M, Mensitieri G, Rizzo P, et al. Molecular sensing by nanoporous crystalline polymers. Sensors 2009;9:9816-57.

[212] Arrand HF, Benson TM, Loni A, Krueger MG, Thoenissen M, Lueth H. Self-aligned porous silicon optical waveguides. Electron Lett 1997;33:1724-5.

[213] Loni A, Canham LT, Berger MG, Arens-Fischer R, Munder H, Luth H, et al. Porous silicon multilayer optical waveguides. Thin Solid Films 1996;276:143-6.

[214] Zangooie S, Jansson R, Arwin H. Ellipsometric characterization of anisotropic porous silicon Fabry-Pérot filters and investigation of temperature effects on capillary condensation efficiency. J Appl Phys 1999;86:850.

[215] Berger MG, Thönissen M, Arens-Fischer R, Münder H, Lüth H, Arntzen M, et al. Investigation and design of optical properties of porosity superlattices. Thin Solid Films 1995;255:313-6.

[216] Kordás K, Beke S, Pap AE, Uusimäki A, Leppävuori S. Optical properties of porous silicon. Opt Mater 2004;25:257-60.

[217] Zangooie S, Schubert M, Trimble C, Thompson DW, Woollam JA. Infrared ellipsometry characterization of porous silicon Bragg reflectors. Appl Opt 2001;40:906-12.

[218] Zhang Q, Wang J, Wu G, Shen J, Buddhudu S. Interference coating by hydrophobic aerogel-like $\mathrm{SiO}_{2}$ thin films. Mater Chem Phys 2001;72:56-9.

[219] Macleod HA. Thin-film optical filters. New York; 1969.

[220] Bruggeman DAG. Dielectric constant and conductivity of mixtures of isotropic materials. Ann Phys (Leipzig) 1935;24:636-79.

[221] Garahan A, Pilon L, Yin J, Saxena I. Effective optical properties of absorbing nanoporous and nanocomposite thin films. J Appl Phys 2007;101:014320.

[222] Garnett JCM. Colours in metal glasses and in metallic films. Phil Trans R Soc London A 1904;203:385-420.

[223] Choy TC. Effective medium theory: principles and applications. Oxford: Oxford University Press; 1999.

[224] Río JAd, Whitaker S. Maxwell's equations in two-phase systems I: local electrodynamic equilibrium. Transp Porous Media 2000;39:159-86.

[225] Rio JAd, Whitaker S. Maxwell's equation in two-phase systems II: two-equation model. Transp Porous Media 2000;39:259-87.

[226] Braun MM, Pilon L. Effective optical properties of non-absorbing nanoporous thin films. Thin Solid Films 2006;496:505-14.

[227] Navid A, Pilon L. Effect of polarization and morphology on the optical properties of absorbing nanoporous thin films. Thin Solid Films 2008;516:4159-67.

[228] Lee Y, Kang M. The optical properties of nanoporous structured titanium dioxide and the photovoltaic efficiency on DSSC. Mater Chem Phys 2010;122:284-9.

[229] Vajpeyi AP, Tripathy S, Chua SJ, Fitzgerald EA. Investigation of optical properties of nanoporous GaN films. Physica E 2005;28:141-9.

[230] Cho J, Hong J, Char K, Caruso F. Nanoporous block copolymer micelle/micelle multilayer films with dual optical properties. J Am Chem Soc 2006;128:9935-42.

[231] Hiller JA, Mendelsohn JD, Rubner MF. Reversible erasable nanoporous anti-reflection coatings from polyelectrolyte multilayers. Nat Mater 2002;1:59-63.

[232] Li L, Nemoto T, Sugiyama K, Yokoyama $\mathrm{H} . \mathrm{CO}_{2}$ foaming in thin films of block copolymer containing fluorinated blocks. Macromolecules 2006;39:4746-55.

[233] Born M, Wolf E. Principles of optics: electromagnetic theory of propagation, interference and diffraction of light. Cambridge, United Kingdom: Cambridge University Press; 1999.

[234] Rizzo P, Montefusco T, Guerra G. Chiral optical films based on achiral chromophore guests. J Am Chem Soc 2011;133:9872-7.

[235] Harbuzaru BV, Corma A, Rey F, Atienzar P, Jorda JL, Garcia H, et al. Metal-organic nanoporous structures with anisotropic photoluminescence and magnetic properties and their use as sensors. Angew Chem Int Ed Engl 2008;47:1080-3.

[236] Hrubesh LW, Poco JF. Thin aerogel films for optical, thermal, acoustic and electronic applications. J Non-Cryst Solids 1995; $188: 46-53$.

[237] Fricke J. In: Aerogels, editor. Springer proceedings in physics; 1986.

[238] Vacher R, Phalippou J, Pelous J, Woignier T. 2nd International symposia on aerogels. Rev Phys Appl; 1989. 